\title{
Amarillo National Resource Center for Plutonium
}

A Higher Education Consortium of The Texas A\&M University System, Texas Tech University, and The University of Texas System

\section{Process Modeling of Plutonium Conversion and MOX Fabrication for Plutonium Disposition}

\author{
Kenneth L. Schwartz \\ Department of Nuclear Engineering \\ The University of Texas
}

RECEIVED

NOV 89998

OSTI

This report was prepared with the support of the U.S. Department of Energy (DOE), Cooperative Agreement No. DE-FCO4-95AL85832. However, any opinions, findings, conclusions, or recommendations expressed herein are those of the author(s) and do not necessarily reflect the views of DOE. This work was conducted through the Amarillo National Resource Center for Plutonium.

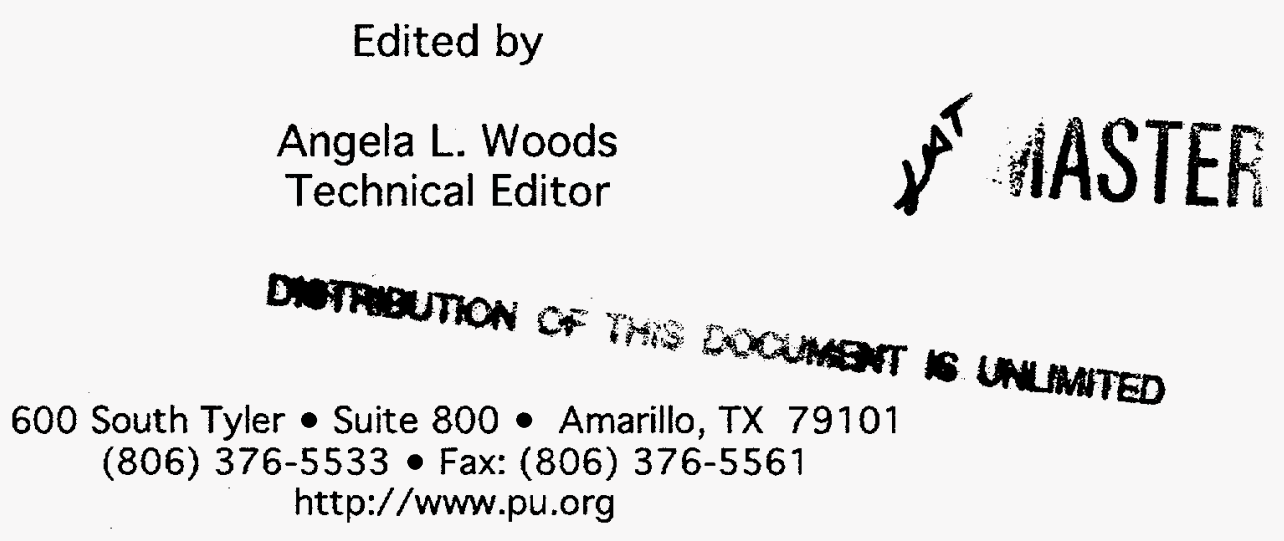

Edited by

Angela L. Woods

Technical Editor

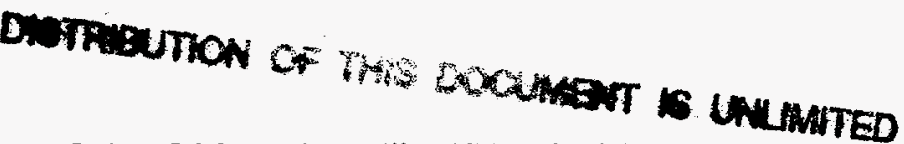

http://www.pu.org 


\section{DISCLAIMER}

This report was prepared as an account of work sponsored by an agency of the United States Government. Neither the United States Government nor any agency thereof, nor any of their employees, makes any warranty, express or implied, or assumes any legal liability or responsibility for the accuracy, completeness, or usefulness of any information, apparatus, product, or process disclosed, or represents that its use would not infringe privately owned rights. Reference herein to any specific commercial product, process, or service by trade name, trademark, manufacturer, or otherwise does not necessarily constitute or imply its endorsement, recommendation, or favoring by the United States Government or any agency thereof. The views and opinions of authors expressed herein do not necessarily state or reflect those of the United States Government or any agency thereof. 


\section{DISCLAIMER}

Portions of this document may be illegible in electronic image products. Images are produced from the best available original document. 


\title{
AMARILLO NATIONAL RESOURCE CENTER FOR PLUTONIUM/ A HIGHER EDUCATION CONSORTIUM
}

\author{
A Report on \\ Process Modeling of Plutonium Conversion and \\ MOX Fabrication for Plutonium Disposition
}

\author{
Kenneth L. Schwartz \\ Department of Nuclear Engineering \\ The University of Texas \\ Austin, Texas 78712
}

Submitted for publication to

\section{Amarillo National Resource Center for Plutonium}

October 1998 


\section{DEDICATION}

This work is dedicated to my family for their continuing support. It is also dedicated to my Mom, who taught me that learning can be fun, and that the impact I have on peoples' lives can come in all sizes; always try to make them good ones. 


\section{ACKNOWLEDGEMENTS}

First and foremost I would like to thank Dr. Sheldon Landsberger who has been a continuing source of drive and strength for many years. He has been my teacher, mentor, the father I never wanted, and a good friend.

I want to thank Sinan Goktepeli for showing me easier ways of accomplishing much of the data analysis.
I would also like to thank Carl Beard for his direction and guidance on this and related works, and Xiaoyun Yang for his help with researching some of the data.

Lastly, I want to thank the ANRCP for their support in funding and education of this and related research.

This thesis was completed on July 20 , 1998. 


\title{
Process Modeling of Plutonium Conversion and MOX Fabrication for Plutonium Disposition
}

\author{
Kenneth Lawrence Schwartz, M.S.E. \\ The University of Texas at Austin \\ SUPERVISOR: Sheldon Landsberger
}

Two processes are currently under consideration for the disposition of $35 \mathrm{MT}$ of surplus plutonium through its conversion into fuel for power production. These processes are the ARIES process, by which plutonium metal is converted into a powdered oxide form, and MOX fuel fabrication, where the oxide powder is combined with uranium oxide powder to form ceramic fuel. This study was undertaken to determine the optimal size for both facilities, whereby the $35 \mathrm{MT}$ of plutonium metal will be converted into fuel and burned for power.

The bounding conditions used were a plutonium concentration of 3-7\%, a burnup of
20,000-40,000 MWd/MTHM, a core fraction of 0.1 to 0.4 , and the number of reactors ranging from 2-6. Using these boundary conditions, the optimal cost was found with a plutonium concentration of $7 \%$. This resulted in an optimal throughput ranging from 2,000 to $5,000 \mathrm{~kg} \mathrm{Pu} /$ year. The data showed minimal costs, resulting from throughputs in this range, at $3,840,2,779$, and $3,497 \mathrm{~kg}$ $\mathrm{Pu} /$ year, which results in a facility lifetime of $9.1,12.6$, and 10.0 years, respectively. 


\section{TABLE OF CONTENTS}

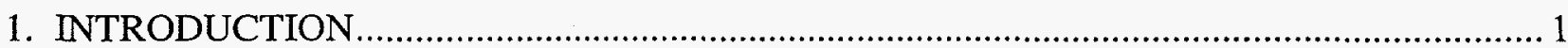

2. BACKGROUND

2.1 Description of the ARIES Process ................................................................................... 3

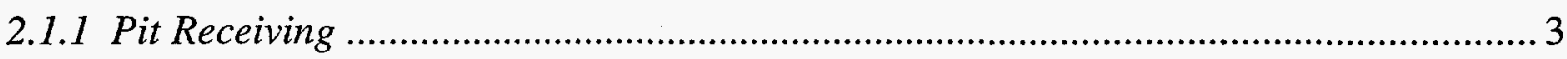

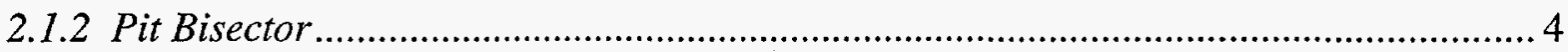

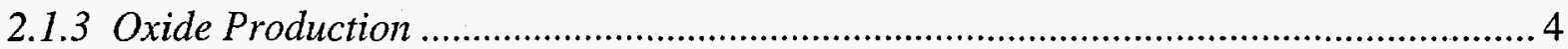

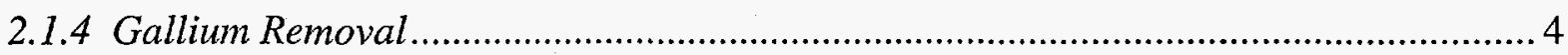

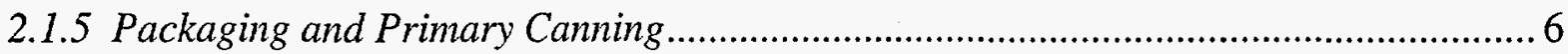

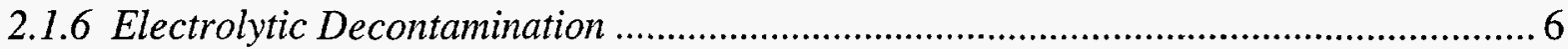

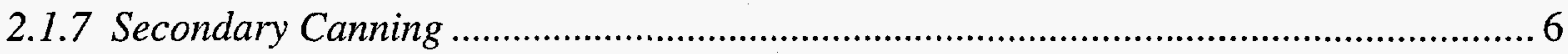

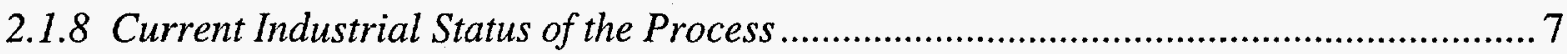

2.1.9 Potential Process Variations ................................................................................... 7

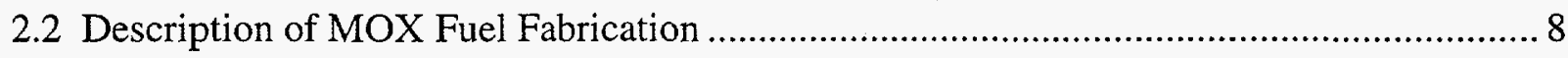

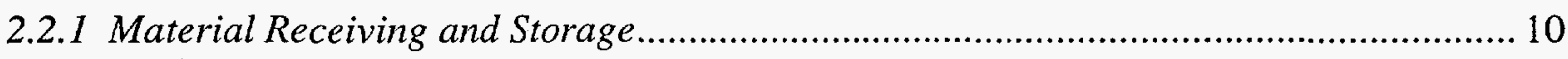

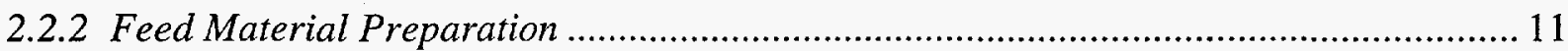

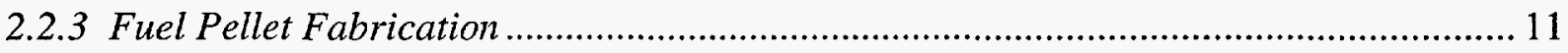

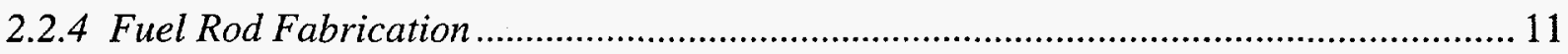

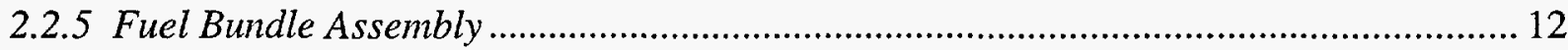

2.2.6 Process Materials Recycling ………………….................................................. 12

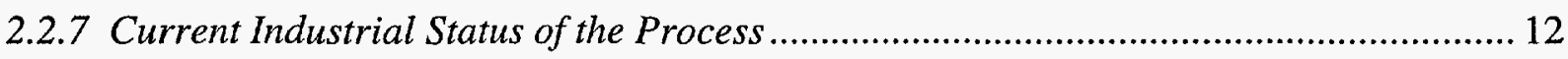

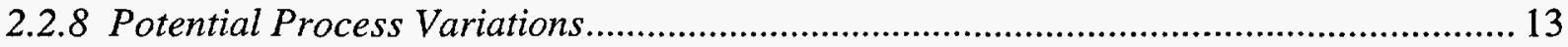

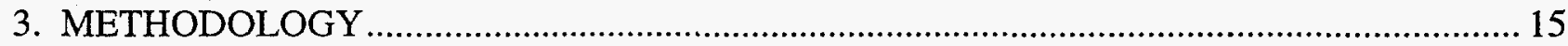

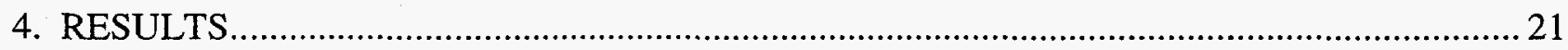

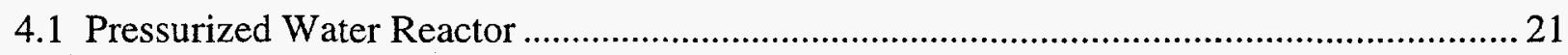

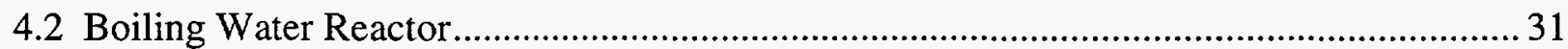

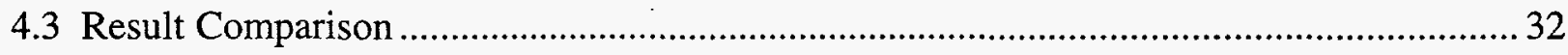

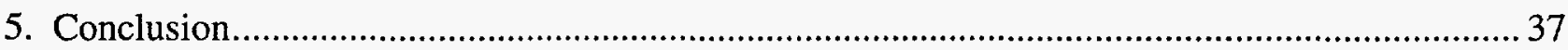

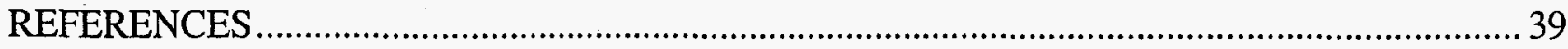

APPENDIX A: FORTRAN Program Example with Partial Results .............................................. A-1 


\section{LIST OF TABLES}

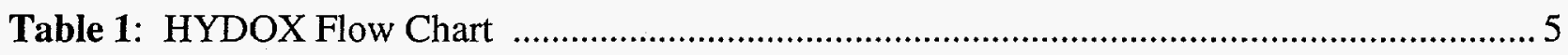

Table 2: Variable Definitions to Calculate Required Plutonium................................................. 15

Table 3: Variables to Calculate the Number of Bundles Needed per Year........................................ 17

Table 4: Percentages and Production Rates for Back-Calculating Plutonium Flow ........................ 19

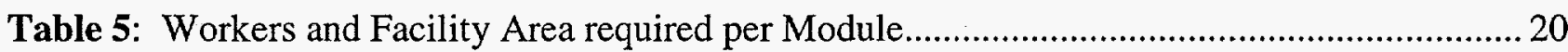

Table 6: Comparison of Minimum Values Calculated for each Facility and the Combined Total. 27

Table 7: Comparison of Minimum Values Calculated for Each Facility and the Combined Total for BWR Fuel

Table 8: Optimal Values of Combined Pu Throughput for the MOX FFF and ARIES Facility for

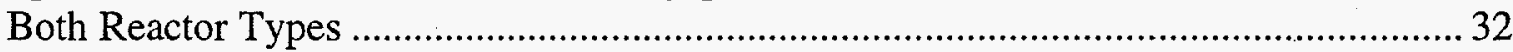

Table 9: Number of Workers and Land Area at Minimums for PWR Fuel .....................................32 


\section{LIST OF FIGURES}

Figure 1: Flow Diagram for the ARIES Pit Conversion Facility ............................................

Figure 2a: Flow Diagram for the MOX Fuel Fabrication Facility ............................................... 9

Figure 2b: Flow Diagram for the MOX Fuel Fabrication Facility ............................................... 9

Figure 2c: Flow Diagram for the MOX Fuel Fabrication Facility ................................................ 10

Figure 3: Simplified MOX Reverse Material Flowchart............................................................. 16

Figure 4: Number of Man-Hours Required over the Lifetime of the MOX FFF Facility vs. the Yearly Throughput of the Facility to Produce MOX Fuel for a PWR at 3\%, 5\%, and 7\% $\mathrm{Pu}$ Concentration

Figure 5: Number of Square-Feet of the Facility Multiplied by the Number of Hours of Operation Required over the Lifetime of the MOX FFF Facility vs. the Yearly Throughput of the Facility to Produce MOX Fuel for a PWR at 3\%, 5\%, and 7\% Pu Concentration

Figure 6: Number of Man-Hours Required over the Lifetime of the ARIES Facility vs. the Yearly Throughput of the Facility to Produce MOX Fuel for a PWR at 3\% and 5\% Pu Concentration

Figure 7: Number of Man-Hours Required over the Lifetime of the MOX FFF Facility vs. the Yearly Throughput of the Facility to Produce MOX Fuel for a PWR at 7\% Pu Concentration for Throughputs between 1800 and $5300 \mathrm{~kg}$ Pu per Year.

Figure 8: Number of Man-Hours over the Lifetime of the ARIES Facility vs. the Yearly Throughput of the Facility to Produce $\mathrm{PuO}_{2}$ for MOX Fuel Production for a PWR at 7\% $\mathrm{Pu}$ Concentration for Throughputs between 1800 and $5300 \mathrm{~kg}$ Pu per Year.

Figure 9: Number of Man-Hours over the Lifetime of the Combined MOX FFF and ARIES Facility vs. the Yearly Throughput of the Facility to Produce MOX Fuel for a PWR at 7\% Pu Concentration for Throughputs between 1800 and $5300 \mathrm{~kg}$ Pu per Year.....

Figure 10: Number of Square Feet of the Facility Multiplied by the Number of Hours of Operation Required over the Lifetime of the Combined MOX FFF and ARIES Facility vs. the Yearly Throughput of the Facility to Produce MOX Fuel for a PWR at 7\% Concentration Plotted between 1800 and $5300 \mathrm{~kg}$ Pu per Year

Figure 11: Number of Man-Hours Required over the Lifetime of the MOX FFF Facility vs. the Yearly Throughput of the Facility to Produce MOX Fuel for a BWR at 3\%, 5\% and 7\% $\mathrm{Pu}$ Concentration 
Figure 12: Number of Man-Hours Required over the Lifetime of the MOX FFF Facility vs. the Yearly Throughput of the Facility to Produce MOX Fuel for a BWR at 7\% Pu Concentration for Throughputs between 1800 and $5300 \mathrm{~kg}$ Pu per Year

Figure 13: Number of Man-Hours Required over the Lifetime of the ARIES Facility vs. the Yearly Throughput of the Facility to Produce PuO2 for MOX Fuel for a BWR at $7 \% \mathrm{Pu}$ Concentration for Throughputs between 1800 and $5300 \mathrm{~kg}$ Pu per Year 30

Figure 14: Number of Man-Hours Required over the Lifetime of the Combined MOX FFF and ARIES Facility vs. the Yearly Throughput of the Facility to Produce MOX Fuel for a BWR at 7\% Pu Concentration for Throughputs between 1800 and $5300 \mathrm{~kg}$ Pu per Year 31

Figure 15: Burnup of the MOX Fuel When Used for Power Production vs. the Corefraction of the Reactor that is MOX Fuel for Various Number of Reactors (3-6) Used to Produce Power from the MOX Fuel 33

Figure 16: Burnup of the MOX Fuel When Used for Power Production vs. the Corefraction of the Reactor that is MOX Fuel for Various Number of Reactors (2-6) Used to Produce Power from the MOX Fuel for a Throughput of $2779 \mathrm{~kg}$ Pu per Year 34

Figure 17: Burnup of the MOX Fuel When Used for Power Production vs. the Corefraction of the Reactor that is MOX Fuel for Various Numbers of Reactors (3-6) Used to Produce Power from the MOX Fuel for a Throughput of $3840 \mathrm{~kg}$ Pu Per Year. 35 


\section{INTRODUCTION}

In an effort to reduce the global stockpile of nuclear explosive devices, over 50 metric tons of weapons-grade plutonium has been declared surplus by the United States. This surplus must now be rendered unattractive for use in nuclear weapons. The goal is that this drive will be concurrent with similar activities in Russia. One method currently under investigation is the conversion of the plutonium metal into mixed-oxide reactor fuel. This fuel would be used in currently operational reactors for power production. The final product would be rendered non-weapons-usable and be compliant with the spent fuel standard.

In order to accomplish this task, two separate plants would be built. The first would convert the plutonium metal into a powdered-oxide form. The second plant would combine the plutonium oxide powder with uranium oxide powder and fabricate mixed-oxide fuel pellets. These pellets would be used to make fuel bundles for power production. At each defined step through the production process, modules, that require defined area and manpower for operation, will be used to process the material(s). Each module can process a certain quantity over a period of time. The number of modules required at each step will depend upon the quantity of material needed in the following module. By varying the properties of the desired mixed-oxide fuel, and the number of reactors that will be used, the number of modules, and therefore the total area and manpower required, can be determined. By examining the results, the optimal desired properties and number of reactors can be determined to keep the manpower and needed facility area to a minimum. This would result in minimizing the cost of the processing facilities. The goal of this thesis is to determine what throughputs would result in the minimum cost of lifetime operation of the two facilities. 



\section{BACKGROUND}

The procedure currently proposed for the conversion, from a metal into an oxide form, is the Advanced Recovery and Integrated Extraction System (ARIES) (LAUR-97-2909, 8). The plutonium will enter this process in the form of plutonium weapons components, known as pits. A pit is a spherical shell of plutonium, surrounded by a beryllium or stainless-steel cladding, and, depending on the weapon type that it came out of, may have a variety of other attached components. These other components will be removed and sent to other parts of the plant for handling. The remaining pit will be bisected; the plutonium will be removed from the cladding and converted into an oxide. This oxide will undergo gallium removal, then be canned, tagged, decontaminated, and assayed for record (LA-13178). The ARIES facility is intended to put out 35 metric tons of plutonium, in a dioxide powder form.

The second step in the conversion process is the production of MOX fuel rods. This entails combining the plutonium dioxide with depleted or natural uranium dioxide, and using this mixture to fabricate ceramic fuel pellets. A column of pellets is loaded into Zircaloy cladding to form fuel rods. These fuel rods will then be used to form fuel bundles. The fuel bundles will be used as reactor fuel in either boiling water reactors (BWR) or pressurized water reactors (PWR), which could use enrichments ranging from 3 $\mathrm{wt} \%$ to $7 \mathrm{wt} \%$. The fabrication capacity of the MOX fabrication facility will vary depending upon the final fuel design, the number of reactors employed, the loading pattern, and the cycle length. The nominal facility envisioned by DOE at this time has a fabrication capacity of $100 \mathrm{MT}$ of MOX fuel ${ }^{1}$. The $100 \mathrm{MT}$ facility will combine approximately $96.5 \mathrm{MT}$ of $\mathrm{UO}_{2}$ with the 3.5

\footnotetext{
${ }^{1} 100 \mathrm{MT}$ is the combined weight of plutonium and uranium metal. This number does not include oxygen.
}

MT of $\mathrm{PuO}_{2}$ obtained each year from the ARIES process.

Both facilities will be designed to meet federal, state, and local environmental, health, and safety requirements and considerations. Occupational radiological exposures will adhere to federal guidelines, and the plants will be designed around the ALARA principle (As Low As Reasonably Achievable). The current outlook is the start of operations for the ARIES plant and MOX fabrication facility to begin in 2005 and 2006, respectively.

\subsection{DESCRIPTION OF THE ARIES PROCESS}

ARIES is a modular, low-waste method of disassembling pits and converting the plutonium into a stable, unclassified form. ARIES is made up of a series of interconnected glove-box modules with a non-destructive assay (NDA) module attached. Due to its modular nature, the ARIES line can be adjusted to a variety of throughputs, changes in the process requirements, and new technologies, without having to retrofit the entire line. The ARIES process consists of a number of steps, including pit receiving, pit bisecting, oxide production, primary canning, electrolytic decontamination, secondary canning, and NDA.

\subsubsection{Pit Receiving}

Upon arrival at the ARIES facility, the explosives, electronics, highly enriched uranium (HEU) and tritium (if applicable) will be removed from the pit and declassified. The plutonium pit will then undergo a nondestructive assay to ascertain the amount and isotopic concentration of plutonium being introduced into the processing system. This assay involves the use of a number of survey instruments, (e.g., calorimeters, spectroscopy systems, mass scales, etc.), and is able to determine the quantity of plutonium present. 
Once the assay is completed, the plutonium is introduced into the glovebox system. This introduction will consist of passing the pit through an airlock system, into the inert lower pressure argon atmosphere of the glovebox.

Each pit contains approximately $4 \mathrm{~kg}$ of plutonium. By the time the storage container arrives at the facility, the pit will have been separated from its tritium components. When it arrives, it will be checked for tritium contamination. If the pit contains tritium, it will be sent to the Special Recovery Line (SRL) to have the tritium removed first. If the pit does not contain tritium, it will then be removed from the container and checked for surface contamination. If contaminated, it is cleaned. Each pit will be assayed for accountability of plutonium. During the process, assaying will consist of weighing and cataloging to ensure accountability of the plutonium at each step of the conversion process. The pits are then sent on to the bisector module. The containers are checked for contamination, cleaned, and packed for reuse.

\subsubsection{Pit Bisector}

The ARIES process requires that all pits introduced into the system be bisected into hemispherical halves. In order to accomplish this task, a device similar to a pipe cutter is used. Following the removal of any external equipment, the pit is placed into the bisector. A blade that rotates with respect to the pit is used to cut into the pit. The pit is bisected into two $\sim 2 \mathrm{~kg}$ hemispheres, and all plutonium-bearing components are now ready for plutonium removal. Items that do not contain plutonium can be decontaminated, transferred out of the glovebox, and declassified as necessary. Declassification entails converting the item into a different form and weight in order that the original item is not able to be reproduced. This is accomplished by cutting the item and melting the pieces into pucks for disposal.

\subsubsection{Oxide Production}

The plutonium-bearing hemisphere is placed into the HYDOX unit. HYDOX is the generic term for the module in which the conversion of plutonium metal to plutonium oxide takes place. The plutonium must be separated from the subassemblies. Hydrogen gas is used to form plutonium hydride, which flakes off and falls to the bottom of the unit, where it is collected in a mesh-frit. Nitrogen gas is passed upward through the plutonium hydride, driving off the hydrogen, and leaving behind plutonium nitride. Once the reaction has gone to completion, oxygen is passed through the plutonium nitride, driving off the nitrogen and forming plutonium oxide. The oxide powder is assayed upon removal from the reactor for accountability. A HYDOX module contains two reactors, each capable of handling a pit hemisphere. The $2 \mathrm{~kg}$ of plutonium hemisphere will be loaded into a module and weighed. Once put in the HYDOX reactor, the atmosphere will be evacuated to less than 200 millitorr. The steps of transformation from metal to oxide are shown in Table 1, along with associated times of completion. All HEU remaining is sent to HEU processing, and non-special nuclear materials are sent for declassification.

\subsubsection{Gallium Removal}

The oxide powder is then passed to another glovebox for gallium oxide $\left(\mathrm{Ga}_{2} \mathrm{O}_{3}\right)$ removal. Since the eventual intended use of the plutonium oxide is in the formation of nuclear fuel rods, it is desirable that any gallium that is present be removed. This is due to the effect of gallium on the fuel fabrication process and the potential of a corrosive reaction between gallium and the Zircaloy cladding normally used in nuclear fuel construction. A second reason comes from the fact that in order to create MOX fuel, the plutonium oxide must be made into a 
Table 1: HYDOX Flow Chart (LA-UR-97-2208)

\begin{tabular}{|l|l|l|l|}
\hline Step Procedure & $\begin{array}{l}\text { Time } \\
\text { Required } \\
(\mathrm{min})\end{array}$ & $\begin{array}{l}\text { Mater. Present at } \\
\text { Start/Form of Mater. }\end{array}$ & $\begin{array}{l}\text { Ideal Density of } \\
\text { Mater. Present } \\
\left(\mathrm{g} / \mathrm{cm}^{3}\right)\end{array}$ \\
\hline Add Hydrogen & 120 & $\mathrm{Pu} /$ metal & 19.86 \\
\hline $\begin{array}{l}\text { Purge with Argon and } \\
\text { Evacuate }\end{array}$ & 20 & $\mathrm{PuH}_{2}, \mathrm{PuH}_{3} /$ powder & $10.40,9.61$ \\
\hline Heat to $250-500^{\circ} \mathrm{C}$ & 60 & $\mathrm{PuH}_{2}, \mathrm{PuH}_{3} /$ powder & $10.40,9.61$ \\
\hline Add Nitrogen & 240 & $\mathrm{PuH}_{2}, \mathrm{PuH}_{3} /$ powder & $10.40,9.61$ \\
\hline Evacuate $\mathrm{N}_{2}$ and $\mathrm{H}_{2}$ & 20 & $\mathrm{PuN} /$ powder $^{\circ}$ & 14.25 \\
\hline Heat to $650^{\circ} \mathrm{C}$ & 60 & $\mathrm{PuN} /$ powder & 14.25 \\
\hline Add Oxygen & 120 & $\mathrm{PuN} /$ powder $_{2}$ & 14.25 \\
\hline Heat to $850-1000^{\circ} \mathrm{C}$ & 60 & $\mathrm{PuO}_{2} /$ powder & 11.46 \\
\hline Cool Down & 480 & $\mathrm{PuO}_{2} /$ powder & 11.46 \\
\hline
\end{tabular}

ceramic. It was determined that as little as $2000 \mathrm{ppm}$ of gallium in the plutonium will hinder the sintering process during ceramic production (LA-UR-97-4423, 11). Therefore, the gallium must be removed while the plutonium oxide is still in a powdered form. The goal is to get the gallium concentration as low as reasonably achievable. A concentration of less than 100 ppm is desirable in the plutonium dioxide used for MOX fuel, with the lower the better.

To remove the gallium, the plutonium oxide is heated to a temperature at which gallium oxide sublimes into a gaseous form, $\mathrm{Ga}_{2} \mathrm{O}_{3}$. The gallium oxide is driven off via a negative pressure and condensed for disposal. The current dry removal system being developed is the Thermally Induced Gallium Removal (TIGR) system. In this method, the $\mathrm{PuO}_{2}$ powder will be raised to $1000-1100^{\circ} \mathrm{C}$. Argon, containing 5-6\% $\mathrm{H}_{2}$, will be drawn over the powder. The hydrogen will thermodynamically reduce the $\mathrm{Ga}_{2} \mathrm{O}_{3}$ to $\mathrm{GaO}_{2}$. Since the sublimation pressure of $\mathrm{GaO}_{2}$ is much greater than $\mathrm{Ga}_{2} \mathrm{O}_{3}$ and $\mathrm{PuO}_{2}$, the $\mathrm{GaO}_{2}$ will be driven off selectively from the powder. The gallium will exit the module, along with the argon and $\mathrm{H}_{2} \mathrm{O}$ formed from the reduction. The gallium will be recondensed after exit. This process takes approximately half of the time of one cycle of the HYDOX reactor ( 1 cycle $\approx 20$ hours). Therefore, it is currently recommended that there be one gallium removal module per HYDOX module (2 reactors). This will process 5 to $6 \mathrm{~kg}$ of $\mathrm{PuO}_{2}$ powder per cycle. After the gallium removal, the powder should be ball-milled to ensure particle size will meet fuel specifications. The quantity of gallium per pit can vary from $<200 \mathrm{ppm}$, up to approximately $1 \%$, or $10,000 \mathrm{ppm}$. We will therefore assume a conservative estimate of $1 \%$, which will result in the removal of approximately $40 \mathrm{~g}$ of gallium per pit, or about $70 \mathrm{~kg}$ of gallium per year. The gaseous gallium collection process is still under study.

A second process that is being reviewed as a backup baseline procedure is the removal of gallium using ion exchange. The first step of this process is to dissolve a quantity of $\mathrm{PuO}_{2}$ powder by a solution of nitric acid, with a small amount of $\mathrm{HF}$, to

\footnotetext{
${ }^{2}$ LA-UR-97-2208, Appendix B

${ }^{3}$ Taube, 48
} 
form plutonium nitrate. This feed solution, which contains gallium and americium, is then loaded onto an anion exchange resin. The plutonium will bind with the resin, leaving the gallium and americium in the feed solution. The resin is washed down with nitric acid, and the gallium and americium is carried with it. To remove the plutonium, the plutonium-bearing resin is washed down with a weak solution of nitric acid to disassociate the plutonium nitrate anion. The resultant solution is mixed with oxalic acid, which will precipitate out plutonium oxalate. This oxalate is calcified to water and carbon dioxide, leaving $\mathrm{PuO}_{2}$. A single process line has the capacity to remove the gallium from .75 metric tons of plutonium per year (LAUR-97-3769).

The plutonium oxide that remains after the gallium is withdrawn, is removed from the unit and combined with oxide from previous HYDOX processing. This is done to homogenize the gallium content between batches. The plutonium oxide is now ready for packaging, and shipment or storage.

\subsubsection{Packaging and Primary Canning}

A dual packaging system is used in order to ensure containment integrity. The primary packaging is done while the plutonium is still in the glove box. The plutonium is placed in the primary can, and the container is purged with helium gas. The lid is welded onto the primary container, and when completed, the can is leaked checked by measuring for the presence of helium. If necessary, the welding process can be repeated. Periodically, an empty can will be laser marked, outside of containment, and sent along for tracking purposes.

\subsubsection{Electrolytic Decontamination}

The primary container is now ready for electrolytic decontamination. The decontamination glovebox is comprised of a contaminated side and a clean side. The cans enter in the contaminated side, are wiped clean, and sent into the electrolytic decontamination chamber. This involves setting up the can as an electrode in a low voltage circuit, and applying an electrolyte fluid to remove any external contamination. The container is rinsed and dried inside that chamber, the door to the clean side is opened, and the can is checked for contamination. If the can is still contaminated, the process is repeated. If the can is clean, the can is removed and sent to the next chamber for secondary canning. In addition to the primary containers, all materials removed from the glovebox will be decontaminated using this method.

All fluids used are recycled, and any contaminants removed from the containers will be filtered from the solution. This, along with the rinse water, will be periodically removed from the chamber. As the waste will be homogeneous, and probably contain sufficient transuranic isotopes, it will be classified as TRU waste, and sent to waste management for disposal.

\subsubsection{Secondary Canning}

Once the primary containers are removed from the glovebox, they are laser marked to identify the contents, placed into secondary containers, and purged with helium as before. The secondary container lid is then welded on, and the container checked for weld integrity. This can is also laser marked for identification of can contents. The final step that a container undergoes is a nondestructive assay, in order to maintain plutonium accountability. The containers are ready for either storage or shipment; they are ready for inspection and are in an unclassified form appropriate for the application of traditional international safeguards. 


\subsubsection{Current Industrial Status of the Process}

At this time, the ARIES process has not been used as an industrial-scale process. Each component of the process has different levels of experience associated with it. Pit receiving and bisecting are currently in use regularly at Los Alamos National Laboratory and are therefore well-known. The laser marking and canning are also processes that are in industrial use. There are two methods for gallium removal, each with different levels of experience associated. The wet chemical separation process is a demonstrated process and has been used at industrial-scale. The dry process is still in the final developmental stage and has not been tested in production quantities. The hydridedehydride process, which produces a metal product, is a demonstrated process and has been used on large quantities of plutonium. The hydride-nitride-oxide process has been used on small quantities, but is not a well tested procedure.

\subsubsection{Potential Process Variations}

In certain parts of the ARIES process, more than one method is being analyzed to accomplish the task required. The baseline procedure is as described above. For the gallium removal step, an aqueous procedure is also being investigated. Since the goal of ARIES is to be a dry process, the thermal removal is favored. For the removal of the plutonium from the cladding, the hydridenitride-oxide method is favored. The other method under observation is the hydrideoxide method. This method converts the plutonium hydride directly into an oxide by adding oxygen, which will react with the powdered hydride. If the plutonium is to be converted back into a metal for storage purposes, the hydride-dehydride process will

\section{Pit Conversion Facility-Material Balance and Yearly Throughput}

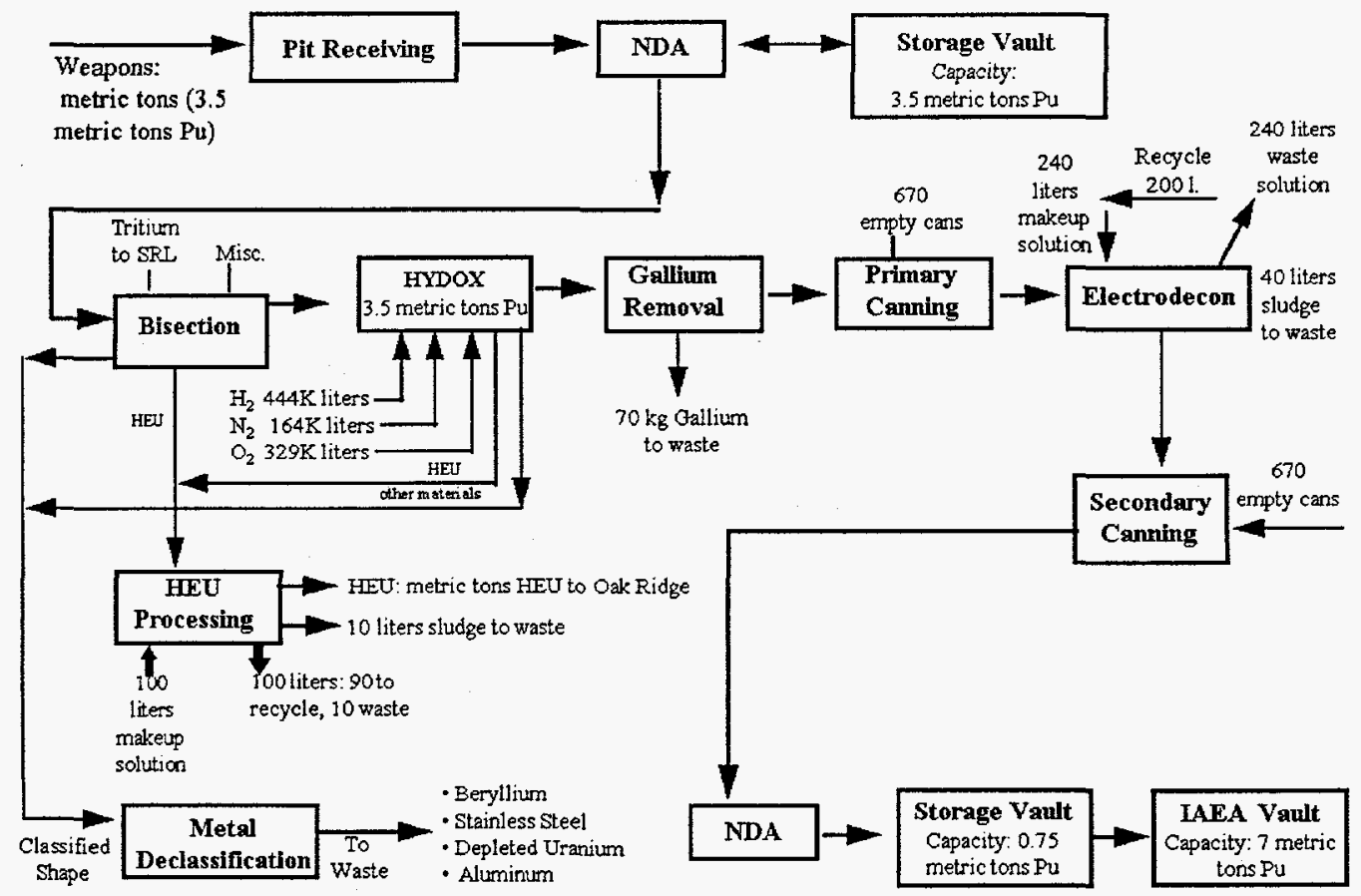

Figure 1: Flow Diagram for the ARIES Pit Conversion Facility (LA-UR-97-2909, 33) 
be used. This will heat up the hydride and drive off the hydrogen gas, leaving plutonium metal, which can then be melted into a metal disk, or puck, recast into a nominal mass, and canned using the same procedures. If a metal is to be formed, no gallium removal is to be done as the metal will not be used for MOX fuel directly in the metal form.

\subsection{DESCRIPTION OF MOX FUEL FABRICATION}

The purpose of the MOX fuel fabrication facility is to combine plutonium dioxide $\left(\mathrm{PuO}_{2}\right)$ powder with uranium dioxide $\left(\mathrm{UO}_{2}\right)$ powder to form mixed-oxide fuel rods. The fuel rods may then be used to generate power in a variety of power plants.

Upon arrival at the MOX fabrication facility, the $\mathrm{PuO}_{2}, \mathrm{UO}_{2}$, and other materials for the process are received and stored. The $\mathrm{UO}_{2}$ is received onsite in a ready-to-use condition. Both powders are weighed and blended together and milled to form a uniform mixture. A further portion of $\mathrm{UO}_{2}$ is blended to reduce the plutonium concentration. This mixture is blended again to uniformity. A portion of the mixture is removed to add to the next batch.

The mixture is then sent to pellet fabrication. The MOX powder is mixed with lubricant and binding agents, and pressed into pellets. These pellets are loaded into sintering boats, which are then transferred to a sintering furnace and sintered in an argon and 6\% hydrogen atmosphere to ensure the oxygento-metal ratio. After sintering, the pellets are checked to ensure that they have the proper properties, such as size, density, and homogeneity. Rejected pellets are sent to be recycled. Pellets that are accepted are ground to proper dimensions and inspected. Rejected pellets are sent back to be recycled.
To prepare the fuel rods, the pellets and other components, depending on the type of rod, are loaded into the Zircaloy casing. The end is decontaminated, the casing is backfilled with helium, and the endcap is welded on (the rod arrives with one endcap welded into place). The rod is then inspected for flaws and leak-tested. Accepted rods are stored for their use in fuel bundles. Rejected rods are sent back to be recycled.

To prepare a fuel bundle, the rods are removed from storage and the bundle is compiled. A completed bundle may include depletable neutron absorbers and/or enriched uranium fuel rods depending on the type of reactor the bundle is intended for. The assembled bundle is cleaned and inspected. Accepted bundles are sent to storage for shipping to a reactor site. Rejected bundles are sent back for recycling.

As some of the materials along the process may have been rejected, these materials will be recycled for reuse. If a bundle is rejected, the fuel rods are removed and inspected. If they are acceptable, they will be reused to form a new bundle. The other components of the bundle are inspected, and if not usable, they will be decontaminated and thrown away as scrap. If a fuel rod is rejected, the pellets will be removed and checked. If the pellets are acceptable, they will be used to make another fuel rod. If the rod components are not acceptable, they will be decontaminated and thrown away as scrap. If fuel pellets are found to be unacceptable, but are still uncontaminated, they will be crushed back into a powder. This powder will be heated in a moist environment to convert to $\mathrm{UO}_{2}$ into $\mathrm{U}_{3} \mathrm{O}_{8}$, and heated again in an argon-hydrogen atmosphere to revert $\mathrm{U}_{3} \mathrm{O}_{8}$ back into $\mathrm{UO}_{2}$. This powder will then be sent to storage to be mixed with fresh powder (LA-UR-97-2067, 69). 


\section{Mixed Oxide Fuel - Material Balance and Throughput}

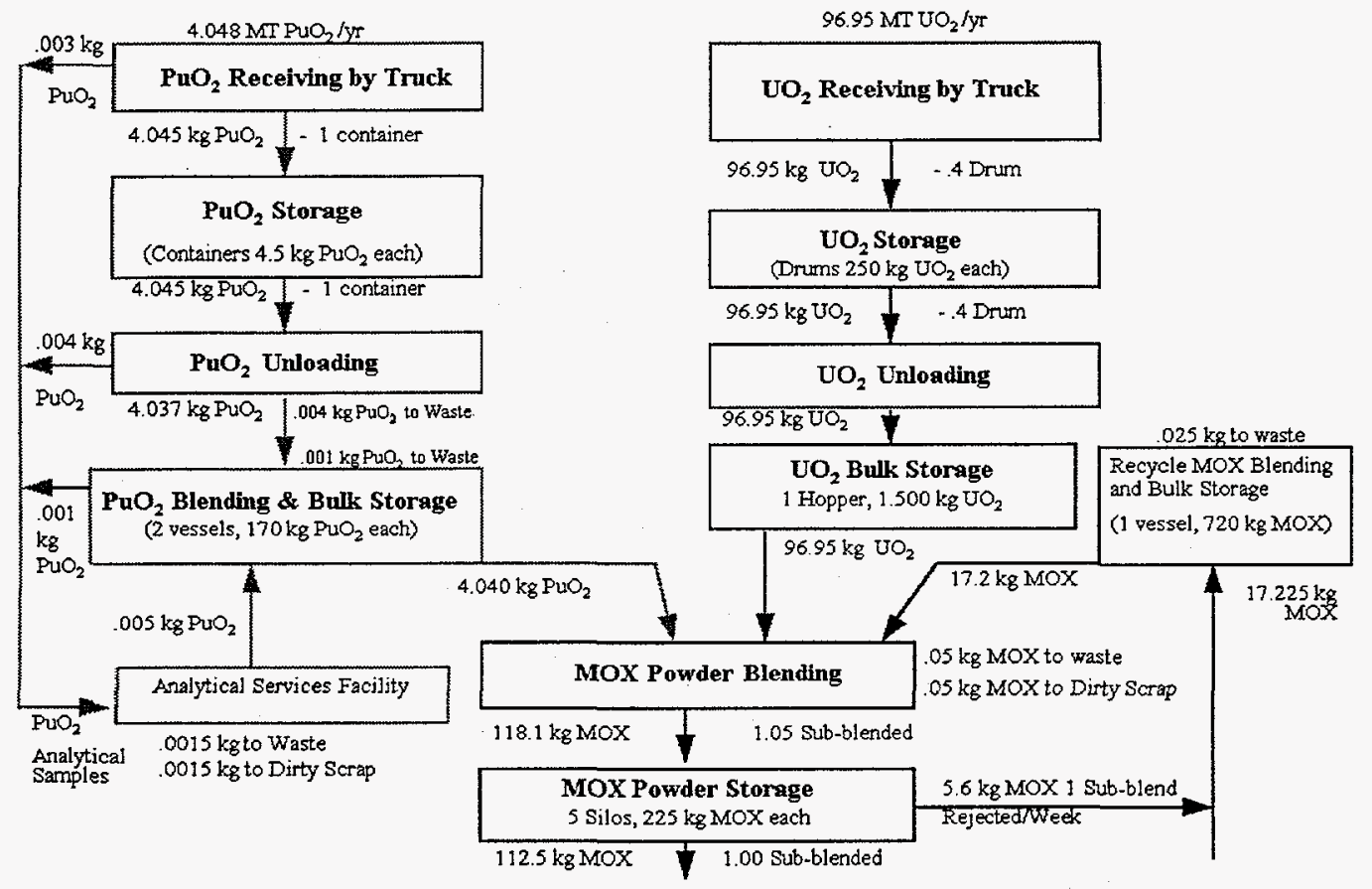

Figure 2a: Flow Diagram for the MOX Fuel Fabrication Facility (LA-UR-97-2067, 141)

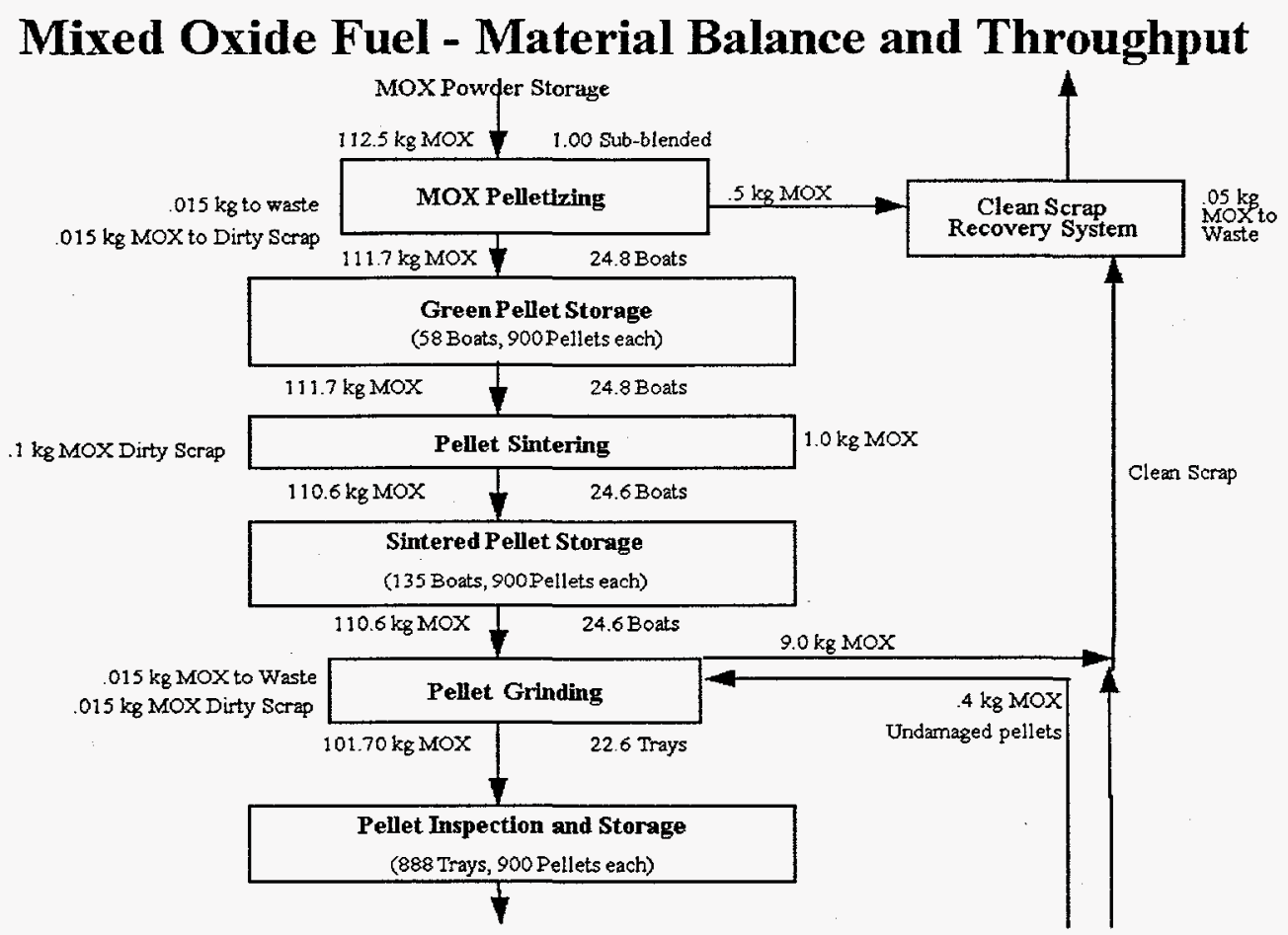

Figure 2b: Flow Diagram for the MOX Fuel Fabrication Facility (LA-UR-97-2067, 141) 


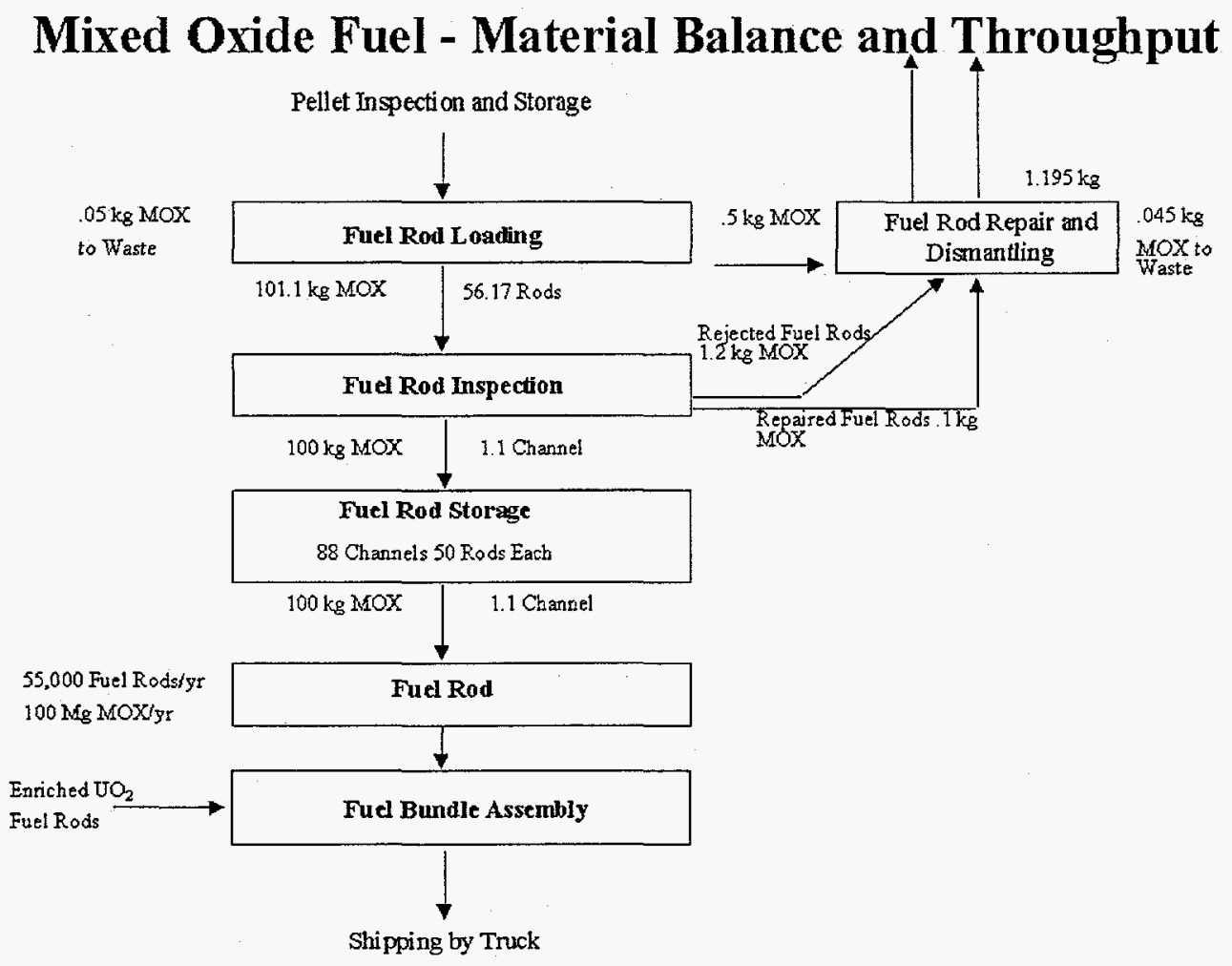

Figure 2c: Flow Diagram for the MOX Fuel Fabrication Facility (LA-UR-97-2067, 141)

In order to fully describe each subprocess in the fuel assembly facility, certain assumptions must be made. It is assumed that the facility will be shut down for scheduled maintenance and repairs for a total of one week every six months. During this time, no MOX fuel will be constructed. This leaves 50 weeks of operational time. At 20 shifts per week, there are 1000 shifts per year. With 8 hours per shift, this yields 8000 hours per year.

\subsubsection{Materials Receiving and Storage}

In materials receiving and storage, all materials required to convert the plutonium and uranium powders into fuel bundles are received, inspected, sampled, and stored. The materials for the pellet fabrication are $\mathrm{PuO}_{2}$ from the ARIES facility and $\mathrm{UO}_{2}$ from natural or depleted uranium. The $\mathrm{PuO}_{2}$ will arrive in double-canned containers. Each double-can has the capacity of $4.5 \mathrm{~kg} \mathrm{PuO}_{2}$. (Each mass given is the mass of the metal in the powder, i.e., $4.5 \mathrm{~kg}$ Pu metal in a powder dioxide form.) If the ARIES and MOX facilities are not at the same site, each shipment will contain 38 cans for a total of $171 \mathrm{~kg}$ of $\mathrm{PuO}_{2}$ per shipment. The $\mathrm{UO}_{2}$ will arrive in 55 gallon drums, each with a capacity of $250 \mathrm{~kg}$ of $\mathrm{UO}_{2}$. Each shipment will contain 70 drums, for a total of $17,500 \mathrm{~kg}$ of $\mathrm{UO}_{2}$ per shipment. About 5 grams of $\mathrm{PuO}_{2}$ will be sampled from each can, and sent to be analyzed for accountability. Unused quantities will be returned to the process, and used amounts will be sent to waste handling. All $\mathrm{PuO}_{2}$ will be sent to a designated storage vault. Uranium dioxide drums will be sent to facility storage.

Other radioactive materials received could potentially include enriched uranium fuel rods used for the final assembly of a fuel bundle. The number of rods and enrichment of the uranium will vary depending on the type of reactor for which the fuel bundles are being used. The facility will also receive 
depletable neutron absorbers and neutron absorber rods, fuel bundle and fuel pin hardware, process gases, and other materials required in the process, such as lubricants and binders. All materials received are inspected and analyzed to ensure that they meet required specifications. These materials will be sent to facility storage after leaving receiving. Appropriate measures will be taken to ensure the security of the $\mathrm{PuO}_{2}$, as well as to comply with criticality requirements.

\subsubsection{Feed Material Preparation}

The $\mathrm{PuO}_{2}$ is taken from the vault and entered into a glovebox. The $\mathrm{PuO}_{2}$ is milled and screened to obtain an optimal particle size distribution. This powder is then mixed with powder from a previous batch that has also been milled and screened, and the new powder is placed into storage. This is done to ensure homogeneity and consistency between the batches to obtain MOX pellets that have uniform properties. When required, a quantity is weighed out and set aside. The $\mathrm{UO}_{2}$ is removed from storage and two quantities are weighed out. The first is to give the batch a $30 \mathrm{w} / \mathrm{PuO}$. The second will be blended after the primary blending to obtain the final desired weight percent $(5 \mathrm{w} / \mathrm{o}$ $\left.\mathrm{PuO}_{2}\right)($ See Section 2.2.8). If required, a quantity of depletable neutron absorber will also be weighed out. A lubricant, zinc stearate, will be used to aid in the ceramic pellet production, and is also weighed out. All feed materials are then combined, and a portion from a previous batch is added to maintain consistency. A portion of the final blended batch is then removed to combine with the following batch. A larger batch size is preferred to be able to remove a larger portion for consistency. However, batch size will be limited to comply with criticality safety limits.

\subsubsection{Fuel Pellet Fabrication}

The feed mixture is to be put into a press, and pressed into pellets approximately $1 \mathrm{~cm}$ in length. Each pellet contains $5 \mathrm{~g}$ of MOX. These pellets are loaded into boats, each with a capacity of 900 pellets. The pellets are sent into a furnace to be sintered. The sintering process will take place in an argon- $6 \%$ hydrogen atmosphere to maintain metal-oxygen ratio. The temperature in the sintering oven is to be slowly ramped up to $1600{ }^{\circ} \mathrm{C}$. It remains there for $2 \frac{1}{2}$ hours, and then is ramped down to ambient temperature $\left(\sim 20^{\circ} \mathrm{C}\right)$. The entire sintering process takes approximately 24 hours. When complete, the sintered pellets are inspected for flaws resulting during the heating process. They are also to be analyzed to check for consistency in density and homogeneity requirements. Any pellet not meeting specifications will be sent back to materials preparation to be crushed back into a powder, milled, and reblended. The accepted pellets are to be ground to a uniform cylindrical shape and size and stored until needed.

The equipment used in this procedure will generate a large amount of heat, and a cooling tower will be required to lower the temperature of the feed water used to cool the machinery. The additional materials that are required at this step are hydrogen and argon gases, and zinc stearate for use as a lubricant in the pressing process. There will be a small amount of MOX powder resulting from grinding that will be sent to waste handling.

\subsubsection{Fuel Rod Fabrication}

Fuel rod hardware will be removed from storage, cleaned, and inspected for any flaws. One end of the fuel rod is already sealed by a welded-on cap. Sintered fuel pellets are removed from storage, inspected, and then loaded into the fuel rod, 360 pellets per rod (1.8 $\mathrm{kg} \mathrm{MOX).} \mathrm{This} \mathrm{quantity} \mathrm{is} \mathrm{used}$ for both PWR and BWR fuel rods (LA-UR97-2067). The rod is back-filled with helium 
gas, and the second cap is welded. The rod is leak tested and again inspected for flaws. Accepted rods are cleaned and stored. Defective rods are recycled by removing the fuel pellets, and determining if the rod usable. If not, the rod is decontaminated and sent away as waste. The fuel pellets are again checked, and if usable, they are reloaded into another fuel rod.

\subsubsection{Fuel Bundle Assembly}

The fuel bundle components are removed from storage, cleaned, and checked for flaws. Flawed components will either be recycled or disposed. MOX, enriched uranium fuel, and guide rods will be removed from storage and inspected. The number of MOX and enriched uranium fuel rods will depend upon the type of reactor for which the bundle is intended. The assembly will then be welded together.

The two primary types of reactor cores being considered are the pressurized water reactor (PWR) and the boiling water reactor (BWR). The PWR fuel bundle consists of a $17 \times 17$ grid ( 289 positions) of which 264 are loaded with fuel rods. The remaining 25 positions are for guide and instrumentation thimbles. The BWR bundle consists of a $9 \times 9$ rod assembly. For initial start-up in a BWR, a configuration, based on the GE-11 design, will consist of approximately $36 \%$ of the fuel rods consisting of MOX fuel rods, and the remaining will consist of low-enriched uranium fuel. The second design, to be implemented at a later stage, will consist entirely of MOX fuel rods and no enricheduranium rods. The construction may also include depletable neutron absorbing rods as required. After construction of the bundle, it will be inspected for flaws. If flawed, it will be disassembled and reused. Accepted bundles will be sent to storage for shipment to power plants.

\subsubsection{Process Material Recycling \\ Material that may be recycled during}

the process include bundle and rod components that were found to be flawed and fuel pellets that were rejected for not meeting specifications, such as density, homogeneity, and dimensional constraints. When a bundle is found to be flawed, usable fuel rods are removed and sent back to storage. Flawed bundle component are decontaminated and sent for scrap. Flawed fuel rods are disassembled, and the fuel pellets are removed. Acceptable fuel pellets are sent back to storage for reuse. Fuel rod components are decontaminated and sent for scrap.

Due to natural imperfections and uncontrollable inconsistencies in the pellet production process, a certain number of the fuel pellets will fail to meet specifications. There is also the possibility that a quantity of unirradiated fuel rods may be shipped to the plant from storage at other DOE sites for disassembly, and flawed MOX pellets will be removed. These pellets and other clean scrap will be crushed and refined as previously described. The wastes generated by this process will be similar to those described in previous processes.

\subsubsection{Current Industrial Status of the Process}

The fabrication of $\mathrm{UO}_{2}$ ceramic fuel bundles has been in use for over 40 years. As such, most of the processes in this procedure have many years of industrial practice and use behind them. The combination of $\mathrm{PuO}_{2}$ and $\mathrm{UO}_{2}$ powders in the production of fuel rods has been in practice in Belgium and France for over 10 years and is also currently in practice by BNFL in England.

In the production of the feed materials for ceramic production, blending is the common practice to combine various powders to ensure a homogeneous mixture. Milling is the standard method for grinding powders to a 
specific particle size distribution. The sintering, grinding, rod construction, and bundle formation are all standard practices to produce nuclear reactor fuel, both in the United States and Europe.

\subsubsection{Potential Process Variations}

In Europe, there are two methods of producing MOX fuel practiced today. The first is the MIMAS process, used by France's Cogema facilities. The procedure proposed in this report is a slightly more automated version of the process, known as the AMIMAS, or Advanced MIMAS, process. The MIMAS process itself is only slightly different than the second process, used by BNFL known as the Short Binderless Route (SBR). The difference between the two is that during the feed materials preparation, the SBR process mixes the $\mathrm{PuO}_{2}$ and $\mathrm{UO}_{2}$ in one step to obtain the final desired composition. The MIMAS and AMIMAS process first combines the powders to obtain approximately a $30 \mathrm{w} / \mathrm{PuO}_{2}$, and then adds an additional quantity of $\mathrm{UO}_{2}$ for a second mixing to get the desired $\mathrm{PuO}_{2}$ weight percent. 



\section{METHODOLOGY}

In order to minimize the cost of the facilities, and optimize the output, the evaluation is broken into three steps. The first step is to determine the quantity of plutonium that would be required to run the reactors each year. The second step is to determine the fixed variables in the MOX Fuel Fabrication Facility (MOX FFF) to determine how the square-foot area and number of workers change relative to the amount of plutonium required. The third step is to perform the same analysis on the ARIES plant. The evaluation is performed in the reverse-order of the fabrication of the fuel. This is done because the nuclear reactors used to burn MOX fuel are ones that are already in operation. Because of this, it is easy to identify which variables can be changed due to the properties of the nuclear reactors. This minimizes the uncertainty of the results.

In order to calculate the quantity of plutonium required by the nuclear reactors, the variables must be defined. It is easiest to define the governing equation to calculate the quantity of plutonium required per year. Equation 1 is the defining equation, with the definition of the variables given in table 2 . The output of this equation will be used as the input for the MOX fuel fabrication calculations. Initially, the values of the required mass of plutonium throughput per year will be calculated using the bounding conditions to determine the minimum and maximum possible values. The input values for the steps that follow will come from varying the mass of plutonium as a function of the plutonium concentration between the two extremes to obtain output values for the number of workers and facility size. The previous equation (1) will then be used again by feeding in the local minimums of the plotted values to find what values for the previous variables would be optimal.

The first process that needs to be evaluated is the MOX fuel fabrication.

$$
P u_{\text {required }}=\frac{\text { PowerLevel }}{\text { Burnup }} * P u_{\text {conc }} * \text { Corefraction } * \operatorname{Re} \text { actors } * \text { days } *(k g / M T)
$$

Table 2: Variable Definitions to Calculate Required Plutonium

\begin{tabular}{|c|c|c|}
\hline Variable & Definition & Default Value or Range \\
\hline $\mathrm{Pu}_{\text {required }}$ & $\begin{array}{c}\text { Amount of plutonium required for } \\
\text { power production }\end{array}$ & $\begin{array}{c}\text { Defining Variable }(\mathrm{kg} \text { of } \\
\text { plutonium/yr) }\end{array}$ \\
\hline Power Level & Power level of reactors being used & 3000 Megawatts (MW) \\
\hline Burnup & Burnup of reactor fuel & $\begin{array}{c}20000-40000 \text { Megawatt- } \\
\text { days/Metric tons of heavy } \\
\text { metal (MWd/MTHM) }\end{array}$ \\
\hline $\mathrm{Pu}_{\text {conc }}$ & $\begin{array}{c}\text { Plutonium concentration of MOX } \\
\text { fuel pellets }\end{array}$ & $3-7(\%)$ \\
\hline Corefraction & $\begin{array}{c}\text { Fraction of reactor core that will } \\
\text { contain MOX fuel }\end{array}$ & $10-40(\%)$ \\
\hline Reactors & $\begin{array}{c}\text { Number of Reactors used to burn } \\
\text { MOX fuel }\end{array}$ & $2-6$ reactors \\
\hline Days & Number of days per year & 365 days \\
\hline $\mathrm{Kg} /$ metricton & Number of kilograms per metric ton & $1000 \mathrm{~kg} /$ metric ton \\
\hline
\end{tabular}


For this, the initial step analyzed was the shipment of the finished MOX fuel bundles, working in the reverse order of the process, to the arrival of the plutonium dioxide $\left(\mathrm{PuO}_{2}\right)$ powder at the MOX FFF. An assumption was made that the bundles are shipped to the nuclear reactors as they are needed; therefore calculations will not include the shipping module from the MOX FFF. As the number of shipments to be made per year will be relatively low, the number of workers and square-foot area required by the shipping module will be ignored. The steps in the optimization study of the MOX FFF will closely resemble analyzing the flow modules in the reverse order of Figure 2. A simplified version is given in Figure 3. In order to determine how many fuel bundles the Fuel
Bundle Assembly needs to produce per year, the number of $\mathrm{kg}$ of plutonium in each bundle needs to be known. To calculate the mass of plutonium per bundle, the number of MOX fuel rods and the mass of plutonium per rod needs to be known. The mass of plutonium per fuel rod was calculated from the number of fuel pellets per rod and the quantity of plutonium per pellet. To define the governing variable in this equation, the type of reactors to be used must be known. The types of reactors have been identified to be Boiling Water Reactors (BWR) and Pressurized Water Reactors (PWR). The BWRs used for this study are based upon studies from General Electric (GE-11 design), and the PWRs, are based upon studies from Westinghouse (Westinghouse ER).

Fuel to Reactors

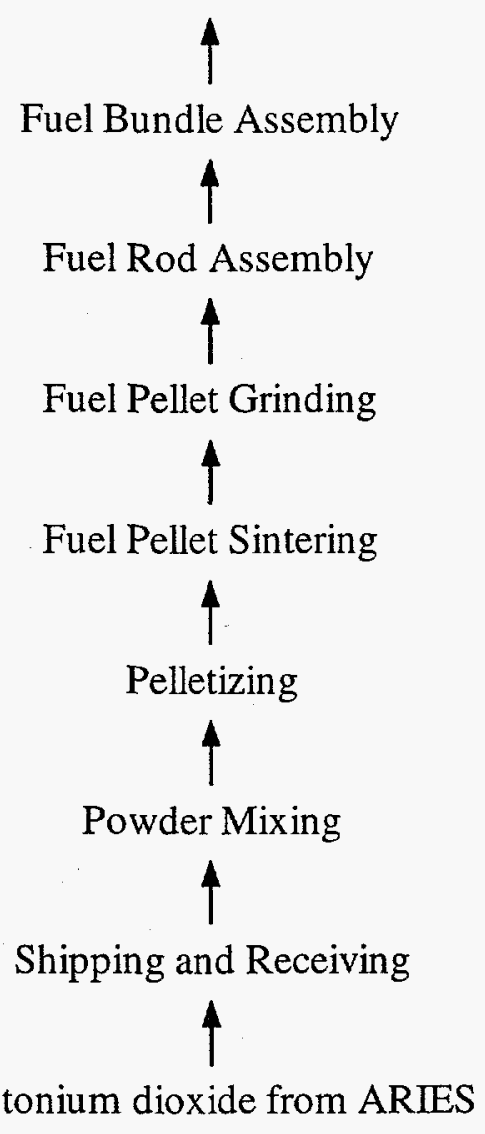

Figure 3: Simplified MOX Reverse Material Flowchart 
These two types were selected for this study because they would allow MOX fuel to be fabricated and used in existing powerproducing reactors, without requiring new reactors to be built. It was also identified that CANDU heavy-water reactors (HWR) could be used, but these are not included in this study.
The calculation steps are shown in the following equations:

$$
\begin{aligned}
& \text { Bundles } \operatorname{Re} \text { quired }_{\text {year }}=\frac{P u_{\text {required }}}{P u_{\text {bundle }}} \\
& P u_{\text {bundle }}=\text { Rods }_{\text {bundle }} * P e l l e t s_{\text {rod }} * \text { Mass }_{\text {pellet }} * P u_{\text {conc }}
\end{aligned}
$$

Table 3: Variables to Calculate the Number of Bundles Needed per Year (LA-UR-97-2067, 140)

\begin{tabular}{|l|l|l|}
\hline \multicolumn{1}{|c|}{ Variable } & \multicolumn{1}{|c|}{ Definition } & \multicolumn{1}{c|}{ Default quantity or range } \\
\hline Bundles Required & $\begin{array}{l}\text { Number of bundles required per } \\
\text { year from the MOX FFF }\end{array}$ & Defining variable \\
\hline Punde $_{\text {bunde }}$ & Mass of plutonium per bundle & Embedded variable $(\mathrm{kg})$ \\
\hline Rods $_{\text {bundle }}$ & Number of fuel rods per bundle & $\begin{array}{l}\text { BWR }-54 \\
\text { PWR }-264\end{array}$ \\
\hline Pellets $_{\text {rod }}$ & $\begin{array}{l}\text { Number of MOX fuel pellets per } \\
\text { fuel rod }\end{array}$ & 360 pellets/rod \\
\hline Mass $_{\text {pellet }}$ & Mass of MOX fuel pellet & $0.005 \mathrm{~kg}$ \\
\hline
\end{tabular}

The number of bundles per year will vary greatly depending upon what type of reactor for which the bundles are intended. As the assumption is made that there are 360 pellets per rod, regardless of the reactor type (LAUR-97-2067, 140), the number of rods per bundle is the only variable that is dependant upon the reactor type. The numbers given in Table 2 are determined from the following assumptions given in Section 2.2.5.

A PWR fuel bundle assembly consists of a $17 \times 17$ rod array, where 264 of the rod bays are filled with MOX fuel rods. The remaining rod bays will be occupied by guide thimbles and instrumentation thimbles.

A BWR fuel bundle assembly will consist of a $9 \times 9$ array, where 54 of the rod positions will be occupied by MOX fuel. Of the remaining positions, 20 will be filled by gadolinium rods, and 2 will be filled by water rods.

To determine the number of workers and the area that is needed to produce the required number of bundles, the rate at which a specific number of workers can produce the bundles is required. The rates for most of the following production steps for the MOX FFF were determined using a flowchart showing $100 \mathrm{~kg}$ MOX fuel production during a single 8-hour shift (LA-UR-97-2067). The flowchart shows a production of 56.17 fuel rods per shift, which results in $\sim 7$ rods/hour. It is planned that the facility will run three 8hour shifts per day, 20 shifts per week, and 50 weeks per year. This results in an operating time of 8000 hours per year. To calculate the number of bundles produced per year:

Bundles $_{\text {year }}=\frac{7\left[\frac{\text { rods }}{\text { hour }}\right] * 8000\left[\frac{\text { hours }}{\text { year }}\right]}{\text { Rods }_{\text {bundle }}}$

where Rods $s_{\text {bundle }}$ is the number of rods per bundle (determined by reactor type). The number of workers per module for bundle construction was assumed to be three, two for 
bundle assembly, and one to check for contamination. The area of one module for the bundle assembly is estimated based on a prospective site diagram to be $-3,000 \mathrm{ft}^{2}$ (LAUR-97-2067). To calculate the number of modules required, the number of bundles required per year is divided by the number of bundles that can be produced per year by one module, and rounded to the next integer:

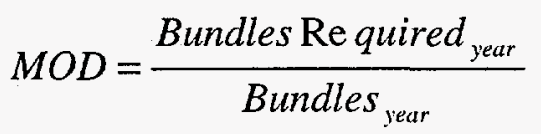

If MOD is not an integer, then MOD = MOD +1 , i.e., if the number of bundles required divided by the number of bundles a module can produce is not a whole number, then the number of modules needed must be rounded up to the next whole number to allow enough production to meet demand. The total number of workers or area needed for bundle production is then the number of workers or area multiplied by the number of modules (MOD). It is assumed that there is no waste of plutonium from bundle production since all components containing plutonium have been checked for flaws in other steps of the process. If a bundle is not constructed properly, then it will be disassembled and reconstructed. Therefore, the quantity of components that are recycled are assumed to be $100 \%$.

Since no plutonium is wasted or added in the bundle production, the input variable for fuel rod assembly is the same as that for fuel bundle assembly. The required number of pins is calculated by multiplying the number of bundles required by the number of pins per bundle (determined by reactor type).

$$
\text { Pins }_{\text {year }}=\text { Bundles Re quired }_{\text {year }} * \text { Pins }_{\text {bundle }}
$$

Fuel rods are constructed by loading hollow tubes, made from zircaloy, with MOX fuel pellets. During this procedure, some of the fuel pellets may be found to be defective, or some of the rods may be flawed. This would result in some of the MOX either being recycled, or disposed of as waste. The recycled material may return to processing either directly as repaired fuel rods; it may be reintroduced during the pellet grinding stage; or, it may end up being re-blended with fresh MOX powder. Because of waste and recycling, more fuel rods must be produced than will be sent to fuel bundle production. The number of fuel rods to be produced, compared with the number that are sent on, are calculated as:

Pin:Required $\}_{\text {ear }}=$ Pins: $_{\text {year }} *\left(1+\right.$ Re jected $d_{\text {pins }}+$ Waste $_{\text {pins }}-$ Recycled pin.s $)$

where Rejected ${ }_{\text {pins }}$, Waste ${ }_{\text {pins }}$, and Recycled $d_{\text {pins }}$ are percentages based on PinsRequired $d_{\text {year }}$ from the flowchart. A list of the modifying percentages used is shown in Table 4.

The last step before the pellets are loaded into the fuel rods is to grind the pellets into the exact size needed. Pellets are cylindrical in shape, with an outer diameter of 0.3088 in. They have dimples at each end to capture fission escape gases. In order to calculate the number of pellets needed from pellet grinding, the first step is to multiply the number of pins required by the number of pellets per pin (360).

$$
\text { Pellets }_{\text {yeur }}=\text { Pins Re quired } \text { year }^{*} \text { Pellets / Pin }
$$

In order to obtain the total pellets needed before grinding, repeat the process described by Equation 7, using applicable percentages. This equation is used in all of the following steps of the MOX FFF, with the exception of shipping and receiving, to determine the input amount needed. Before 
pellets are sent to grinding, they have been sintered to form a hard ceramic from a green pressed-powder pellet. The pellets are formed by pressing a mixture of $\mathrm{PuO}_{2}, \mathrm{UO}_{2}$, and a binder, into a long thin rod, which is cut into pellets. To quantify the amount of

Table 4. Percentages and production rates for back-calculating plutonium flow

(Calculations based on LA-UR-97-2067 and LA-UR-97-2909) powder required, the number of pellets required is multiplied by the mass of a pellet:

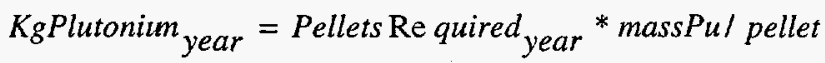

(9)
The $\mathrm{PuO}_{2}$ used in blending the powders is received at the MOX FFF in cans. Each can will contain approximately $4.5 \mathrm{~kg}$ of plutonium powder. The number of cans that will be required by the facility per year is determined by dividing the amount of $\mathrm{Pu}$ required for blending by the amount of $\mathrm{Pu}$ in each can. It is assumed that there will be no plutonium waste, recycled, or rejected from shipping and receiving at the plant.

The plutonium dioxide is shipped in cans from the ARIES facility to the MOX FFF. The total number of cans remains unchanged, and is used for the calculations of the shipping and receiving, secondary

Table 4: Percentages and Production Rates for Back-Calculating Plutonium Flow (Calculations Based on LA-UR-97-2067 and LA-UR-97-2909)

\begin{tabular}{|c|c|c|c|}
\hline \multicolumn{4}{|l|}{ Percentages } \\
\hline Module & Waste & Rejection & Recycling \\
\hline \multicolumn{4}{|l|}{ MOX } \\
\hline Fuel Rod Assembly & $4.92 \mathrm{e}-4$ & $1.57 \mathrm{e}-2$ & $9.81 \mathrm{e}-4$ \\
\hline Pellet Grinding & $2.71 \mathrm{e}-4$ & $7.78 \mathrm{e}-2$ & $3.62 \mathrm{e}-3$ \\
\hline Sintering & $8.95 \mathrm{e}-4$ & $8.95 \mathrm{e}-3$ & 0 \\
\hline Pelletizing & $2.67 e-4$ & $4.44 \mathrm{e}-3$ & $8.89 \mathrm{e}-3$ \\
\hline Blending & $9.9 \mathrm{e}-4$ & $5.55 \mathrm{e}-2$ & $1.81 \mathrm{e}-1$ \\
\hline \multicolumn{4}{|l|}{ Production Rates } \\
\hline MOX & & ARIES & \\
\hline Module & Rate/module/year & Module & Rate/module/year \\
\hline $\begin{array}{l}\text { Fuel Bundle } \\
\text { Assembly }\end{array}$ & $\begin{array}{l}24,000 \text { pins / \# of } \\
\text { pins per bundle }\end{array}$ & $\begin{array}{l}\text { Shipping and } \\
\text { Receiving }\end{array}$ & 912 containers/year \\
\hline Fuel Rod Assembly & 3,200 pins/year & Secondary Canning & 1,920 cans/year \\
\hline Pellet Grinding & 460,800 pellets/year & $\begin{array}{l}\text { Electro- } \\
\text { decontamination }\end{array}$ & 1,280 cans/year \\
\hline Sintering & $\begin{array}{l}3,197,135 \\
\text { pellets/year }\end{array}$ & Primary Canning & $1,920 \mathrm{cans} / \mathrm{year}$ \\
\hline Pelletizing & $\begin{array}{l}1,826,934 \\
\text { pellets/year }\end{array}$ & Gallium Removal & $1,536 \mathrm{~kg} \mathrm{Pu} /$ year \\
\hline Blending & $3,360 \mathrm{~kg} \mathrm{Pu} /$ year & HYDOX & $384 \mathrm{~kg} \mathrm{Pu} /$ year \\
\hline \multirow[t]{3}{*}{$\begin{array}{l}\text { Shipping and } \\
\text { Receiving }\end{array}$} & 912 containers/year & Pit Bisection & $1,540 \mathrm{~kg} \mathrm{Pu} /$ year \\
\hline & & NDA & $2,160 \mathrm{~kg} \mathrm{Pu} /$ year \\
\hline & & Pit Receiving & As many as possible \\
\hline
\end{tabular}


canning, electrolytic decontamination, and primary canning steps. To perform the calculations of the gallium removal stage (dry removal), the mass of plutonium is used. This is the same mass that was used to determine the total number of cans (KgPlutonium $\mathrm{Kear}_{\text {y }}$ ). For the HYDOX conversion step, waste and recycled material must also be taken into account.
The data used for the previous calculations are given in Table 4. It shows the percentages that are used for waste, recycling, and rejection (where applicable). It also shows the calculated production rates per module. Table 5 gives the workers and area per module used.

Table 5: Workers and Facility Area Required per Module (Calculations based on LA-UR-97-2067 and LA-UR-97-2909)

\begin{tabular}{|c|c|c|}
\hline Module & Workers/module/shift & Land Area per module (square feet) \\
\hline MOX & & 3000 \\
\hline Fuel Bundle Assembly & 3 & 3000 \\
\hline Fuel Rod Assembly & 3 & 400 \\
\hline Pellet Grinding & 2 & 1000 \\
\hline Sintering & 2 & 1000 \\
\hline Pelletizing & 2 & 700 \\
\hline Blending & 2 & 4000 \\
\hline Shipping and Receiving & 3 & \\
\hline ARIES & & 4000 \\
\hline Shipping and Receiving & 3 & 1000 \\
\hline Secondary Canning & 2 & 600 \\
\hline Electro-decontamination & 2 & 600 \\
\hline Primary Canning & 2 & 500 \\
\hline Gallium Removal & 2 & 500 \\
\hline HYDOX & 2 & 1300 \\
\hline Pit Bisection & 2 & 1300 \\
\hline NDA & 2 & 2000 \\
\hline Pit Receiving & 2 & \\
\hline
\end{tabular}




\section{RESULTS}

\subsection{PRESSURIZED WATER REACTOR (PWR)}

Results were obtained first by using the input values for a PWR. A FORTRAN program was used to calculate and tabulate the worker and square-foot land area totals for both facilities. This was done by increasing the amount of plutonium required per year from the minimum amount to the maximum amounts based upon the plutonium concentration in the fuel. This number was varied between $3 \%$ and $7 \%$ plutonium, increasing by $0.5 \%$ each step. The calculated minimums and maximums were used as the second variable, increasing by $5 \mathrm{~kg}$ Pu per year for each step. The results were saved in a text file along with the number of years it would take to convert $35 \mathrm{MT}$ into MOX fuel based upon the yearly throughput. The resulting text file was formatted in a spreadsheet to allow analysis of data. The number of workers and land area were multiplied by 8000 (the number of working hours per year) and the number of years to complete conversion. Selected results for the varying plutonium concentration were plotted against each other to show a comparison. The results are shown in Figure 4 and Figure 5. These figures show that the minimum cost plot is at $7 \%$ enrichment.

The units of the graphs are either in man-hours lifetime, or square-foot- hours lifetime. The square-foot-hours can be multiplied by the cost of operating 1 square foot of production per hour to find the lifetime cost of the facility.

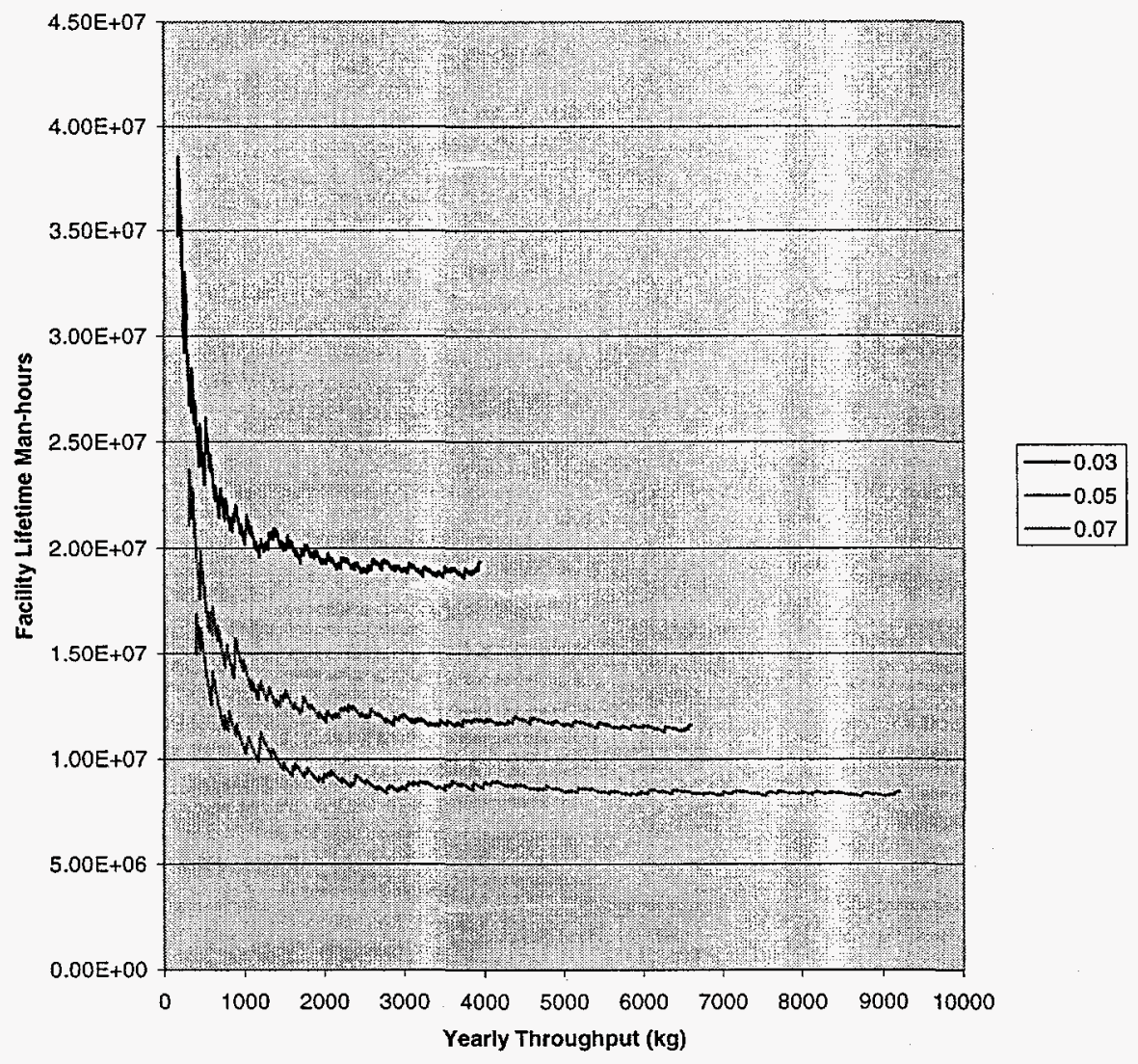

Figure 4: Number of Man-Hours Required Over the Lifetime of the MOX FFF Facility Versus the Yearly Throughput of the Facility to Produce MOX Fuel for a PWR at 3\%, 5\%, and 7\% Pu Concentration 


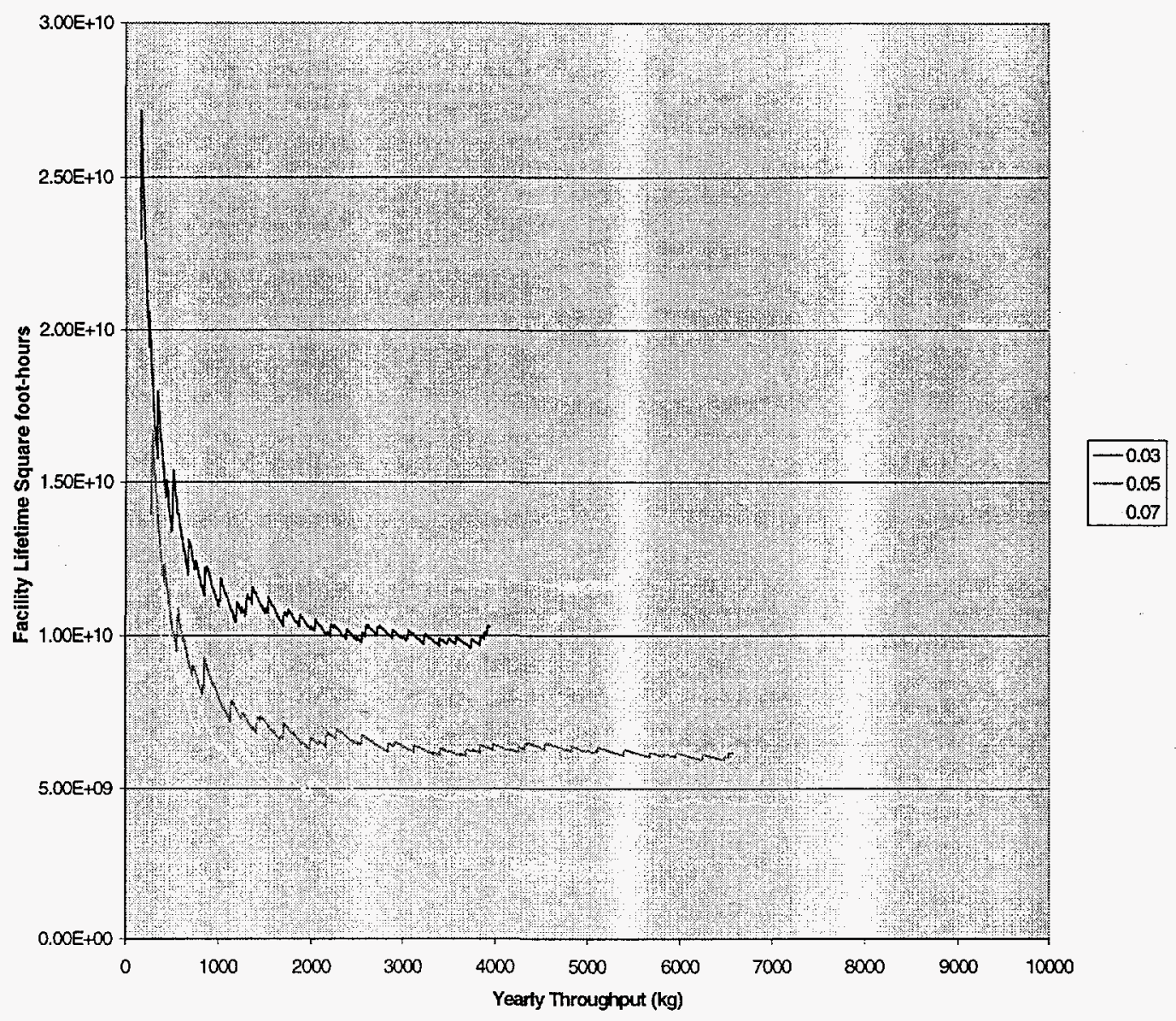

Figure 5: Number of Square-Feet of the Facility Multiplied by the Number of Hours of Operation Required over the Lifetime of the MOX FFF Facility versus the Yearly Throughput of the Facility to Produce MOX Fuel for a PWR at 3\%, 5\%, and 7\% Pu Concentration

From Figures 4 and 5, it can be observed that less land area and fewer number of workers are required for higher concentrations of plutonium. This is primarily due to the reduced number of pellets that need to be manufactured in the MOX facility. The smaller the number of pellets, the fewer the number of rods and bundles required.
Figure 6 shows the comparison between the number of lifetime man-hours for the ARIES facility for a plutonium concentration of $3 \%$ and $5 \%$. This figure demonstrates that the number of worker hours is not dependent upon the plutonium concentration. It is only dependent upon the flow rate of plutonium required per year. 


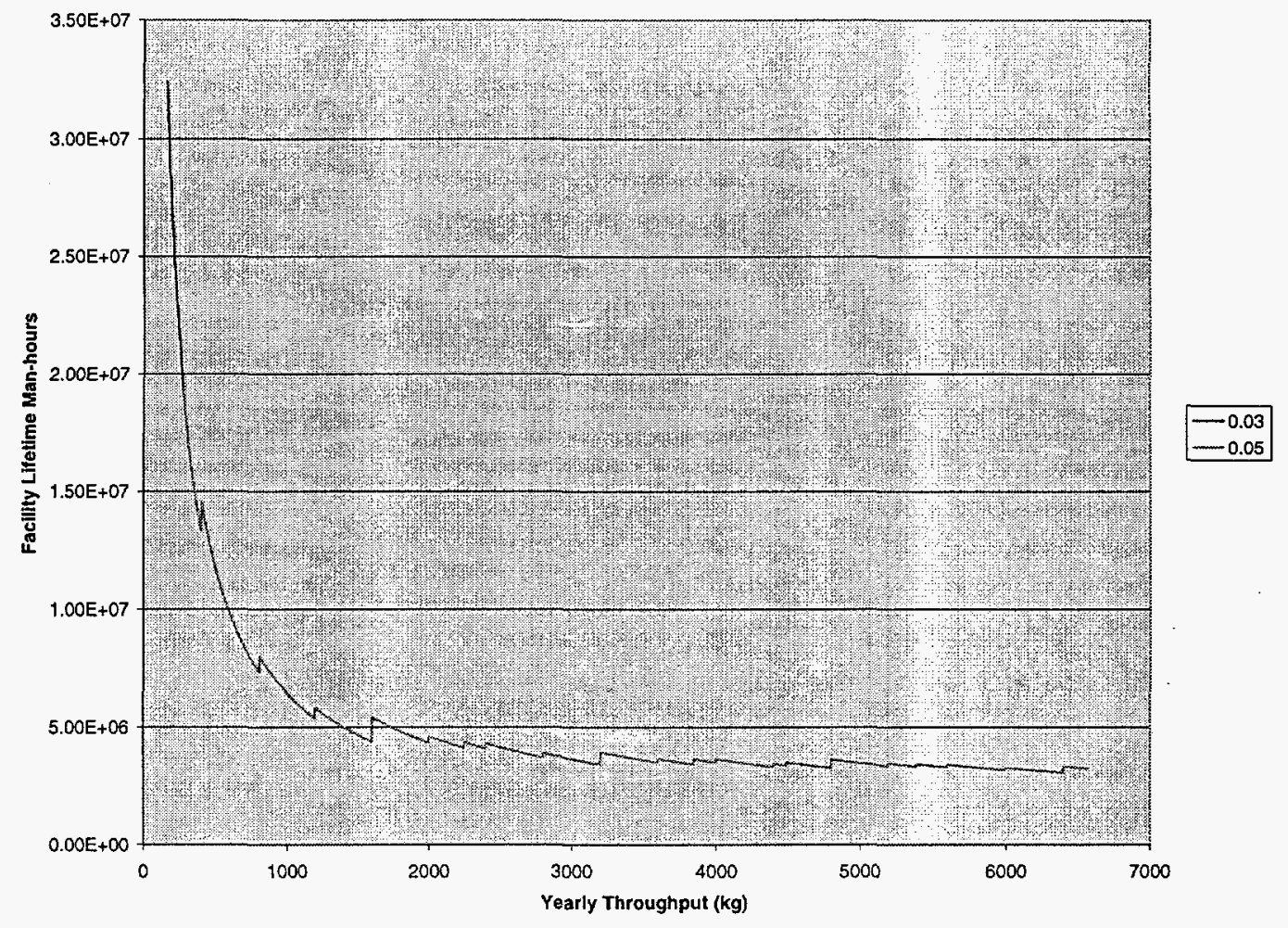

Figure 6: Number of Man-Hours Required over the Lifetime of the ARIES Facility versus the Yearly Throughput of the Facility to Produce MOX Fuel for a PWR at 3\% and 5\% Pu Concentration

The next step was to narrow the field of focus of the data for better analysis. This was done by focusing on the goals of the disposition project and this study. The primary goal of DOE for these facilities is to get rid of approximately $35 \mathrm{MT}$ over a relatively short period of time. At the low throughput end of the disposition quantities, the amount of time required for completion increases dramatically. It is also seen on Figures 4 and 5 that below 2,000 kg per year, the number of lifetime man-hours and squarefoot hours exponentially increases as the throughput approaches zero. Therefore, the yearly throughput less than $2,000 \mathrm{~kg}$ of plutonium throughput per year can be eliminated. In addition, having a large facility that processes large amounts of plutonium in a short period of time would have many extra costs. Among these costs are increased decontamination and decommissioning costs. Therefore, throughputs greater than $5,000 \mathrm{~kg}$ of plutonium per year was selected to be eliminated since the time it would take to construct, and later decommission the facilities, would amount to the time to convert $35 \mathrm{MT}$ of plutonium. This leaves a window of $3,000 \mathrm{~kg}$ per year. Figure 7 shows the results from Figure 4 for this range.

It is seen on Figure 7 that local minimums occur at 2778, 2913, 3023, 3493, $3838,4663,4728,4583$, and $5023 \mathrm{~kg}$ per year for the MOX facility. These minimums occur because the throughput has fully utilized one or more of the modules potential throughput. When the yearly throughput is increased by another kilogram of plutonium, an additional module is required to put out that amount. 


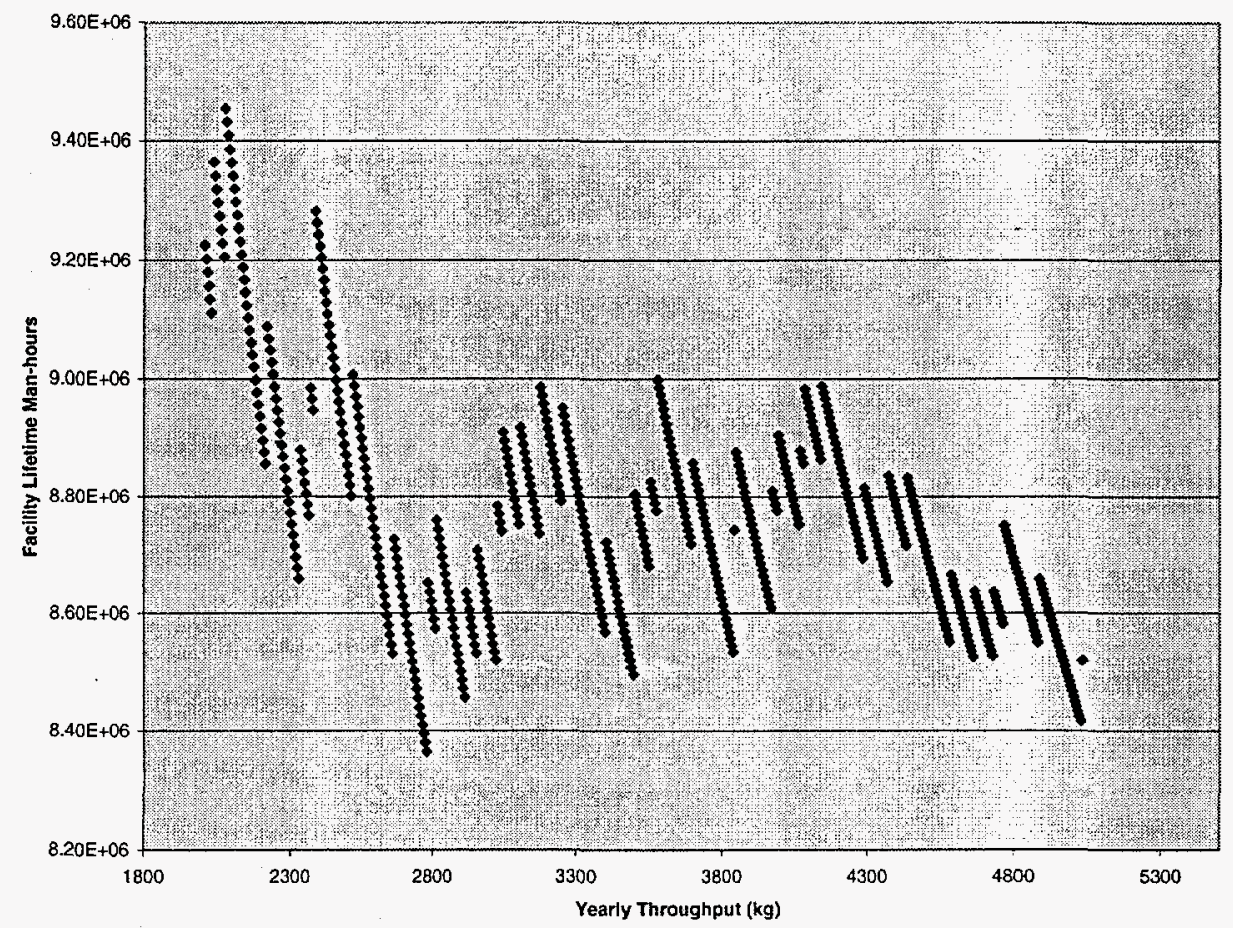

Figure 7: Number of Man-Hours over the Lifetime of the MOX FFF Facility versus the Yearly Throughput of the Facility to Produce MOX Fuel for a PWR at a 7\% Pu Concentration for Throughputs between 1800 and $5300 \mathrm{~kg}$ Pu Per Year

By analyzing the graph for workers at the ARIES facility, we can find the minimums and compare them.

The graph for the ARIES facility shows local minimums at 2793, 3193, 3593, $3838,3993,4393,4488,4793$, and $5028 \mathrm{~kg}$ plutonium per year. In order to evaluate the optimal facility size for both facilities, the two graphs are plotted together. By combining the worker-hours for the MOX and ARIES facilities, local minimums occur at 2779 , $3024,3177,3497,3840,4368,4728$, and $5023 \mathrm{~kg}$ of plutonium per year. The next stage is to analyze the area of the facility using the same technique.

The graph of the combined land areas for both facilities gives matching results for the minimums as the combined worker totals. This is as it should be considering both the number of workers and the area are dependent on the quantity of each module used in both facilities. By comparing the minimum values obtained from each graph for the separate facilities and comparing them to the combined total graph, it can be determined what the optimal values for a facility should be. Table 6 matches the results for easier comparison. All values for the MOX facility are given, while only values that are in close proximity to those numbers are shown for ARIES for simplification. The combined column of Table 6 will be the values that will be focused on when drawing conclusions. 


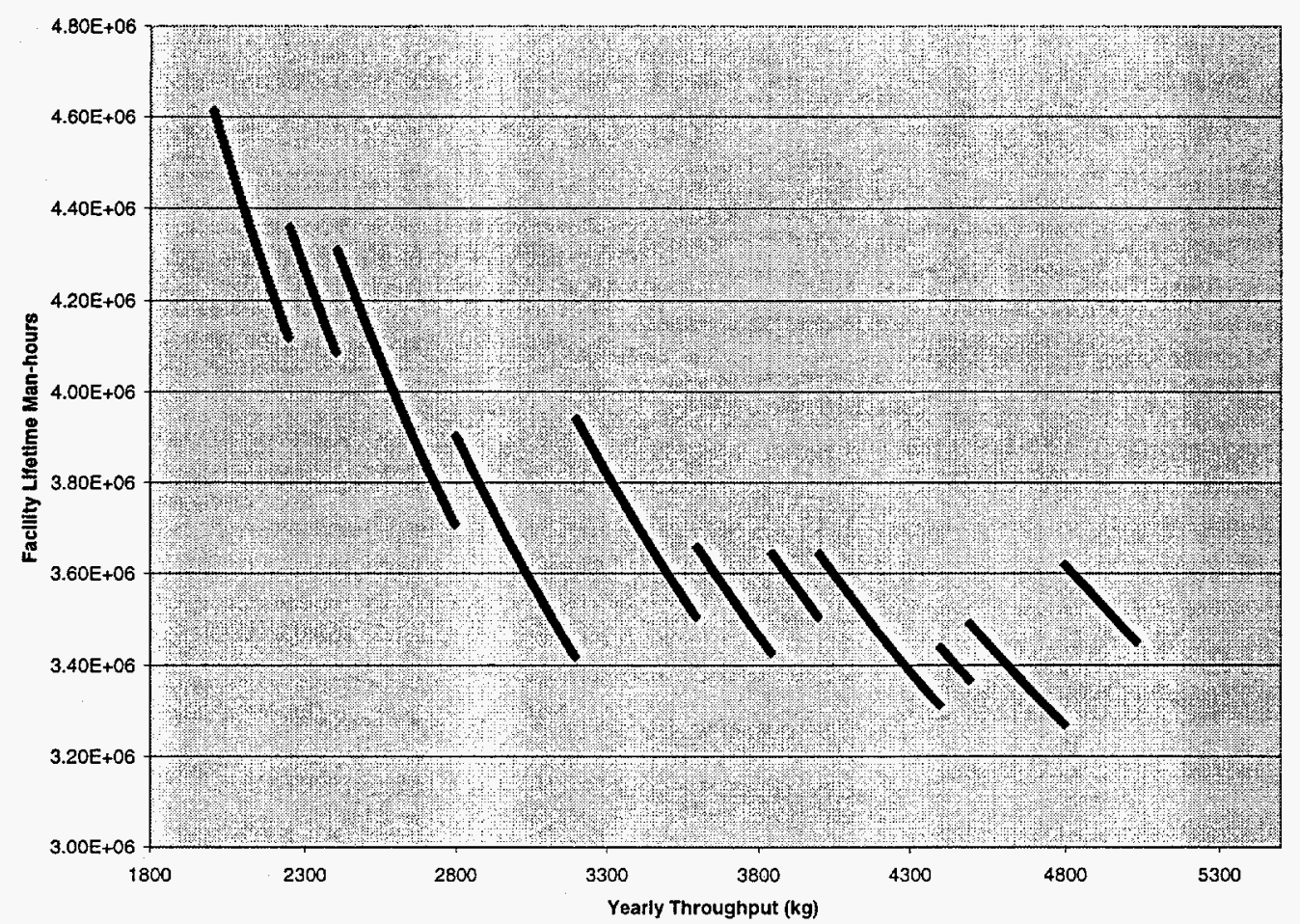

Figure 8: Number of Man-Hours over the Lifetime of the ARIES Facility versus the Yearly Throughput of the Facility to Produce $\mathrm{PuO}_{2}$ for $\mathrm{MOX}$ Fuel Production for a PWR at a $7 \% \mathrm{Pu}$ Concentration for Throughputs between 1800 and $5300 \mathrm{~kg} \mathrm{Pu}$ Per Year 


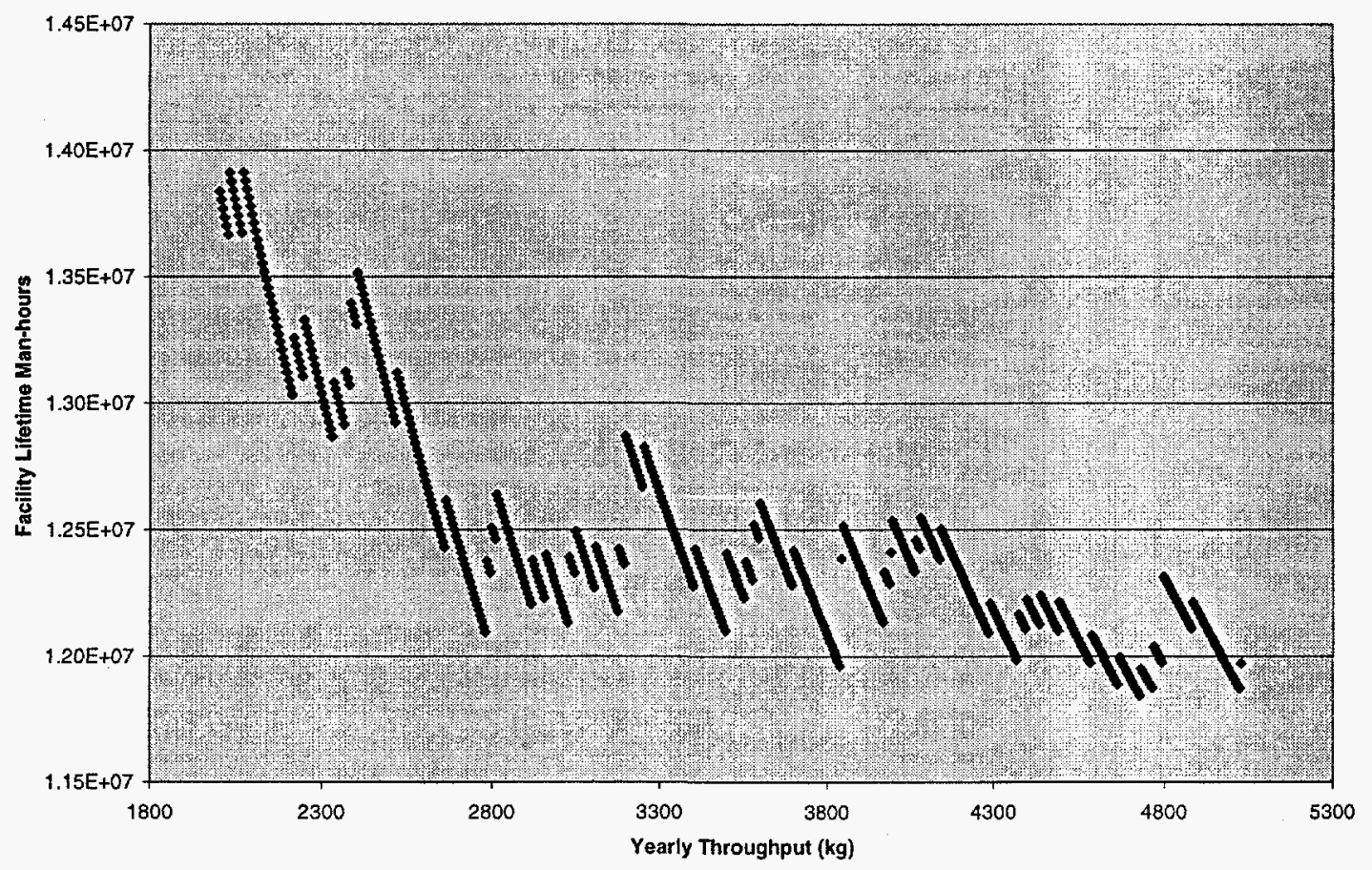

Figure 9: Number of Man-Hours Over the Lifetime of the Combined MOX FFF and the ARIES Facility versus the Yearly Throughput of the Facility to Produce MOX Fuel for a PWR at a 7\% Pu Concentration for Throughputs between 1800 and $5300 \mathrm{~kg} \mathrm{Pu}$ Per Year 


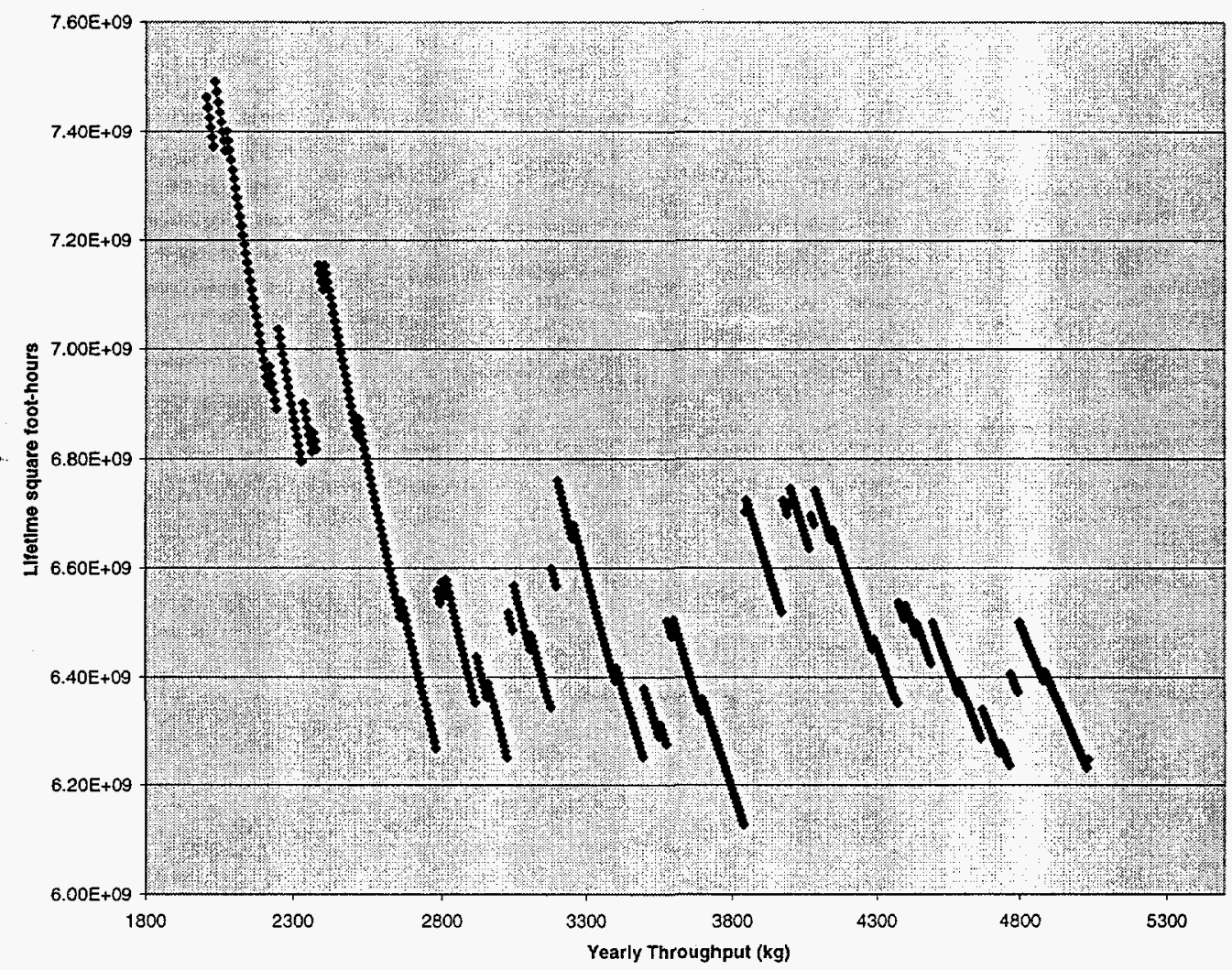

Figure 10: Number of Square-Feet of the Facility Multiplied by the Number of Hours of Operation Required Over the Lifetime of the Combined MOX FFF and ARIES Facility Versus the Yearly Throughput of the Facility to Produce MOX Fuel for a PWR at a 7\% Pu Concentration Plotted Between 1800 and $5300 \mathrm{Kg} \mathrm{Pu}$ Per Year

Table 6: Comparison of Minimum Values Calculated for each Facility and the Combined Total

\begin{tabular}{|l|l|l|}
\hline $\begin{array}{l}\text { MOX (optimal kg } \\
\text { Pu/year) }\end{array}$ & $\begin{array}{l}\text { ARIES (optimal kg } \\
\text { Pu/year) }\end{array}$ & $\begin{array}{l}\text { Combined (optimal kg } \\
\text { Pu/year) }\end{array}$ \\
\hline 2778 & 2793 & 2779 \\
\hline 2913 & & \\
\hline 3023 & & 3024 \\
\hline & 3193 & 3177 \\
\hline 3493 & 3593 & 3497 \\
\hline 3838 & 3838 & 3840 \\
\hline 4663 & & \\
\hline 4728 & 4793 & 4728 \\
\hline 4583 & & \\
\hline 5023 & 5028 & 5023 \\
\hline
\end{tabular}




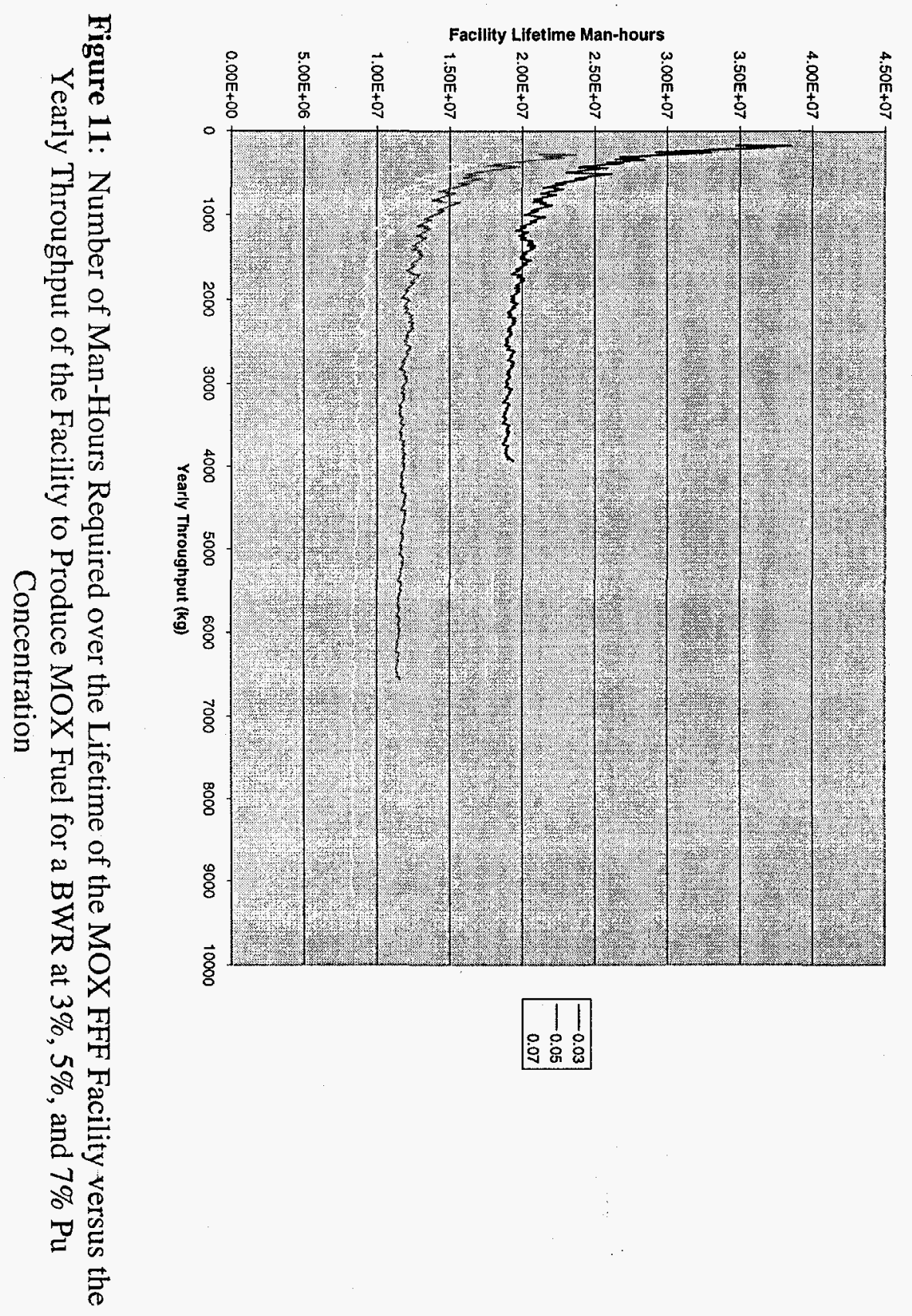




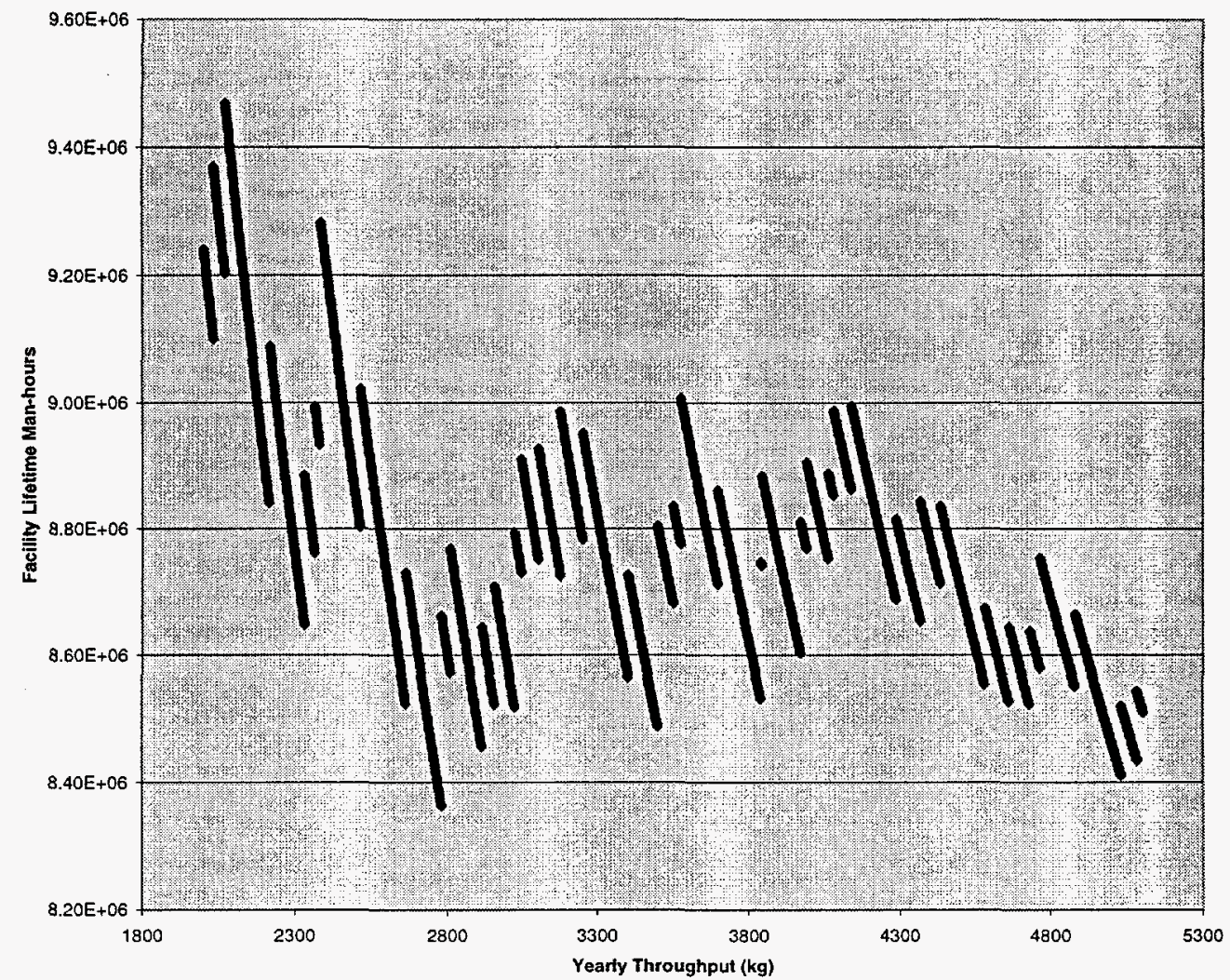

Figure 12: Number of Man-Hours over the Lifetime of the MOX FFF Facility versus the Yearly Throughput of the Facility to Produce MOX Fuel for a BWR at a 7\% Pu Concentration for Throughputs between 1800 and $5300 \mathrm{~kg}$ Pu Per Year 


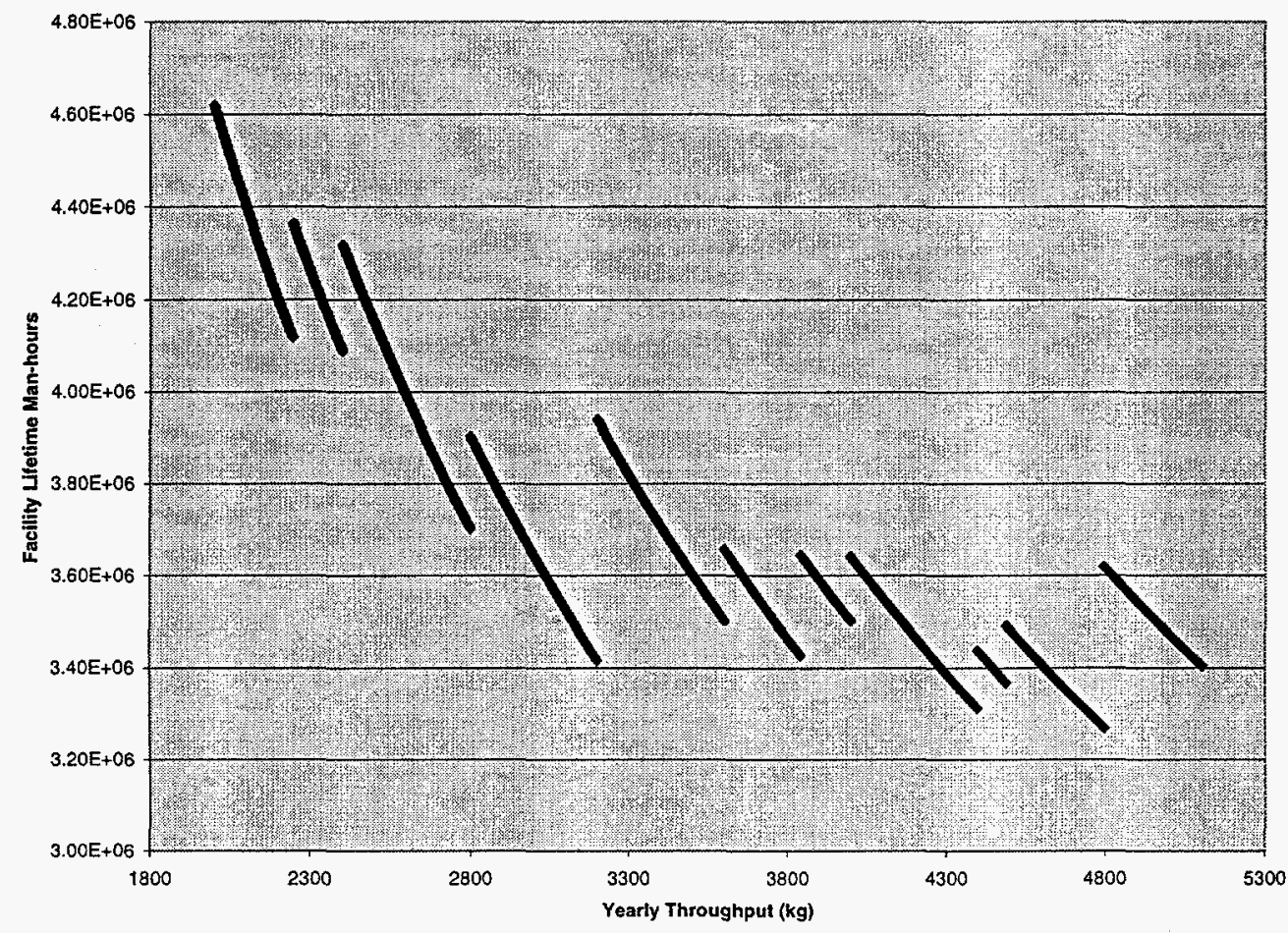

Figure 13: Number of Man-Hours over the Lifetime of the ARIES Facility versus the Yearly Throughput of the Facility to Produce $\mathrm{PuO}_{2}$ for $\mathrm{MOX}$ Fuel for a BWR at a $7 \% \mathrm{Pu}$ Concentration for Throughputs between 1800 and $5300 \mathrm{~kg}$ Pu Per Year 


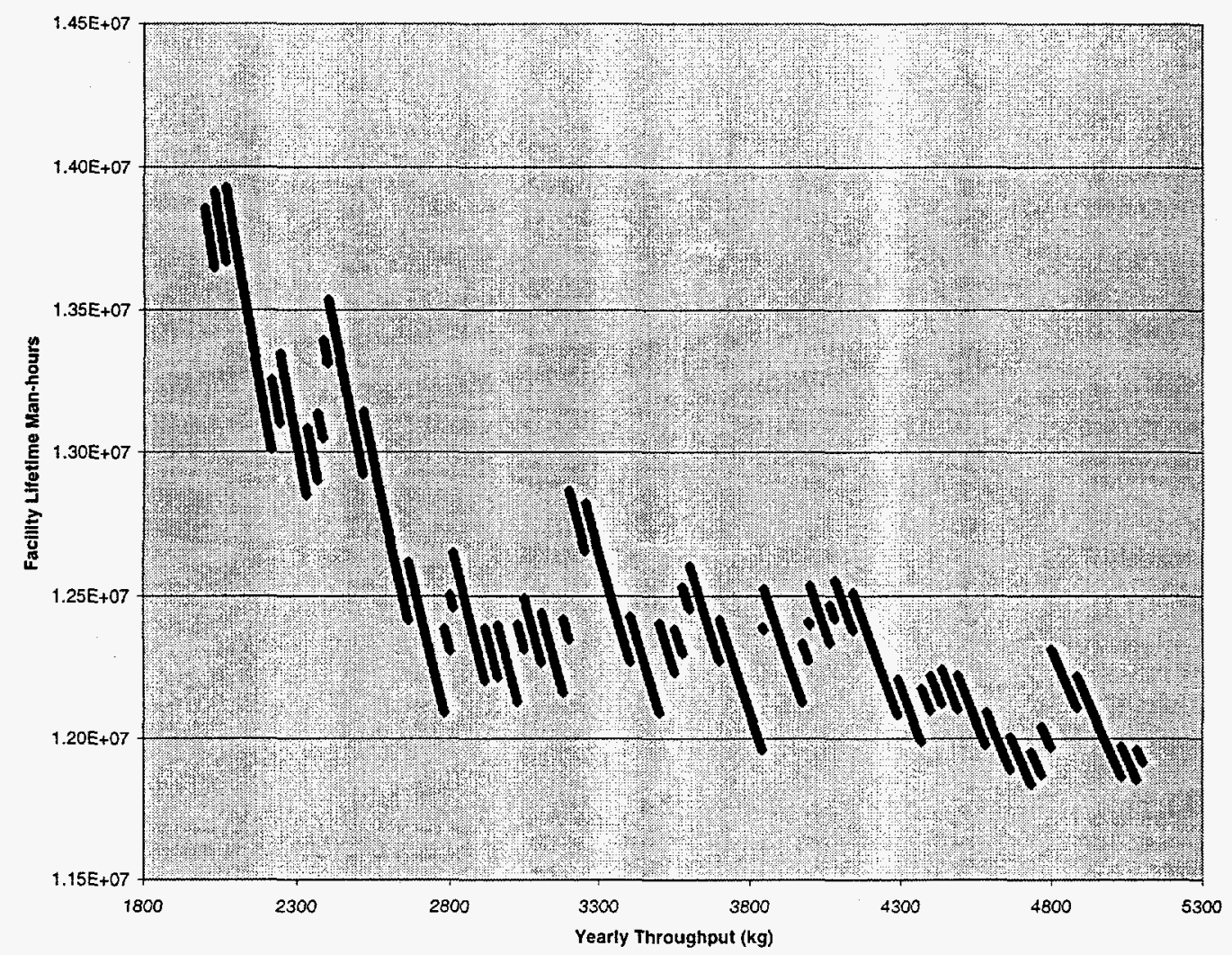

Figure 14: Number of Man-Hours over the Lifetime of the Combined MOX FFF and ARIES Facility versus the Yearly Throughput of the Facility to Produce MOX Fuel for a BWR at a 7\% Pu Concentration for Throughputs between 1800 and $5300 \mathrm{~kg} \mathrm{Pu}$ Per Year

Table 7: Comparison of Minimum Values Calculated for each Facility and the Combined Total for BWR Fuel

\begin{tabular}{|l|l|l|}
\hline MOX & ARIES & Total \\
\hline 2779 & 2798 & 2779 \\
\hline 2914 & & \\
\hline 3024 & 3197 & 3024 \\
\hline 3497 & 3597 & 3497 \\
\hline 3840 & 3840 & 3840 \\
\hline 3971 & 3997 & 3971 \\
\hline 4731 & 4796 & 4731 \\
\hline 5027 & & 5027 \\
\hline
\end{tabular}

\subsection{BOILING WATER REACTORS}

The next type of reactor under consideration is the BWR. This reactor is based on the GE-11 BWR design described earlier. There are 54 fuel rods per bundle. The results are graphed and tabulated in the same way as those for a PWR. The results are shown in the following graphs, first with a comparison of the different plutonium concentrations, and then with a focus on the worker-hour minimums for the MOX, ARIES and combined facilities. 
Table 8: Optimal Values of Combined Pu throughput for the MOX FFF and ARIES Facility for both Reactor Types

\begin{tabular}{|l|l|l|}
\hline PWR & BWR & Optimal values \\
\hline 2779 & 2779 & 2779 \\
\hline 3024 & 3024 & 3024 \\
\hline 3177 & 3177 & 3177 \\
\hline 3497 & 3497 & 3497 \\
\hline 3840 & 3840 & 3840 \\
\hline 4368 & 4368 & 4368 \\
\hline 4728 & 4731 & 4728 \\
\hline 5023 & 5027 & 5023 \\
\hline
\end{tabular}

\subsection{RESULT COMPARISON}

In order to find the optimal size of both facilities, the results for the PWR and the BWR must be compared. If the facilities are to be used to construct fuel for a single type of reactor, only optimization specific to that type need consideration. However, since both types of reactors are being considered, and possibly concurrently, an optimization compatible for both fuel types is performed. By comparing the two results, the comparison shows that there is no difference in the throughputs at which the minimum man-hours occur, only in the values of the minimum number of man-hours required for produce BWR fuel versus PWR fuel. These values do not take into account the individual capacity of each facility for each throughput. Taking those into account, 3177 and $4368 \mathrm{~kg}$ per year throughputs can be eliminated because there is not an optimal MOX plant size near those throughputs. It can be noted that in some of the cases, the ARIES plant has a higher optimal throughput than the combined minimums. This is acceptable since it acts as the input to the MOX plant, and will act as a buffer for the flow of feed material. It is also accepted since the ARIES facility may be occasionally used to process non-MOX suitable plutonium for other purposes.

Of the six minimums remaining, the choices can be further narrowed by examining the number of workers and area required for those values. As the values for a PWR and BWR differ only by an order of magnitude, only one set need be looked at. Table 9 shows a breakdown of the computed values of workers and land area for the ARIES and MOX FFF to produce MOX fuel for a PWR, as well as the number of year required to process $35 \mathrm{MT}$ of Pu metal. Analyzing the data on Table 9, it is seen that there are no significant discrepancies for the various throughputs. However, as previously

Table 9: Number of Workers and Land Area at Minimums for PWR Fuel

\begin{tabular}{|l|l|l|l|l|r|}
\hline $\begin{array}{l}\text { Pu throughput } \\
\text { (kg/year) }\end{array}$ & $\begin{array}{l}\text { MOX } \\
\text { Workers }\end{array}$ & MOX Area & $\begin{array}{l}\text { ARIES } \\
\text { Workers }\end{array}$ & ARIES Area & $\begin{array}{l}\text { Years for } \\
\text { completion }\end{array}$ \\
\hline 2779 & 83 & 44,300 & 37 & 17,900 & 12.6 \\
\hline 3024 & 92 & 49,100 & 39 & 18,400 & 11.6 \\
\hline 3497 & 106 & 57,300 & 45 & 20,700 & 10.0 \\
\hline 3840 & 117 & 62,800 & 47 & 21,200 & 9.1 \\
\hline 4728 & 144 & 78,200 & 56 & 27,500 & 7.4 \\
\hline 5023 & 151 & 82,000 & 62 & 29,800 & 7.0 \\
\hline
\end{tabular}


described, a larger facility increases operating and future costs. Therefore, throughputs of 4,728 and $5,023 \mathrm{~kg}$ plutonium per year facilities were eliminated. By examining the graphs, it is observed that the number of manhours for a throughput of $3,024 \mathrm{~kg}$ of plutonium is greater than those for the three remaining throughputs. It will therefore be eliminated. This leaves $2,779,3,497$, and $3,840 \mathrm{~kg}$ of plutonium per year as the optimal facility throughputs.

The final step of analysis is to input the three throughputs and back-calculate the values of the burnup, the number of reactors, and the corefraction that would make these values required values. Figures 15, 16, and 17 show the plots of the corefraction vs. burnup for various number of reactors. Because of the constraints on the number of reactors ( 2 to 6 ), the burnup (20,000 to 40,000 $\mathrm{MWd} / \mathrm{MTHM}$ ), and the corefraction (10$40 \%$ ), some calculated values fell outside of these ranges and are omitted from the graphs.

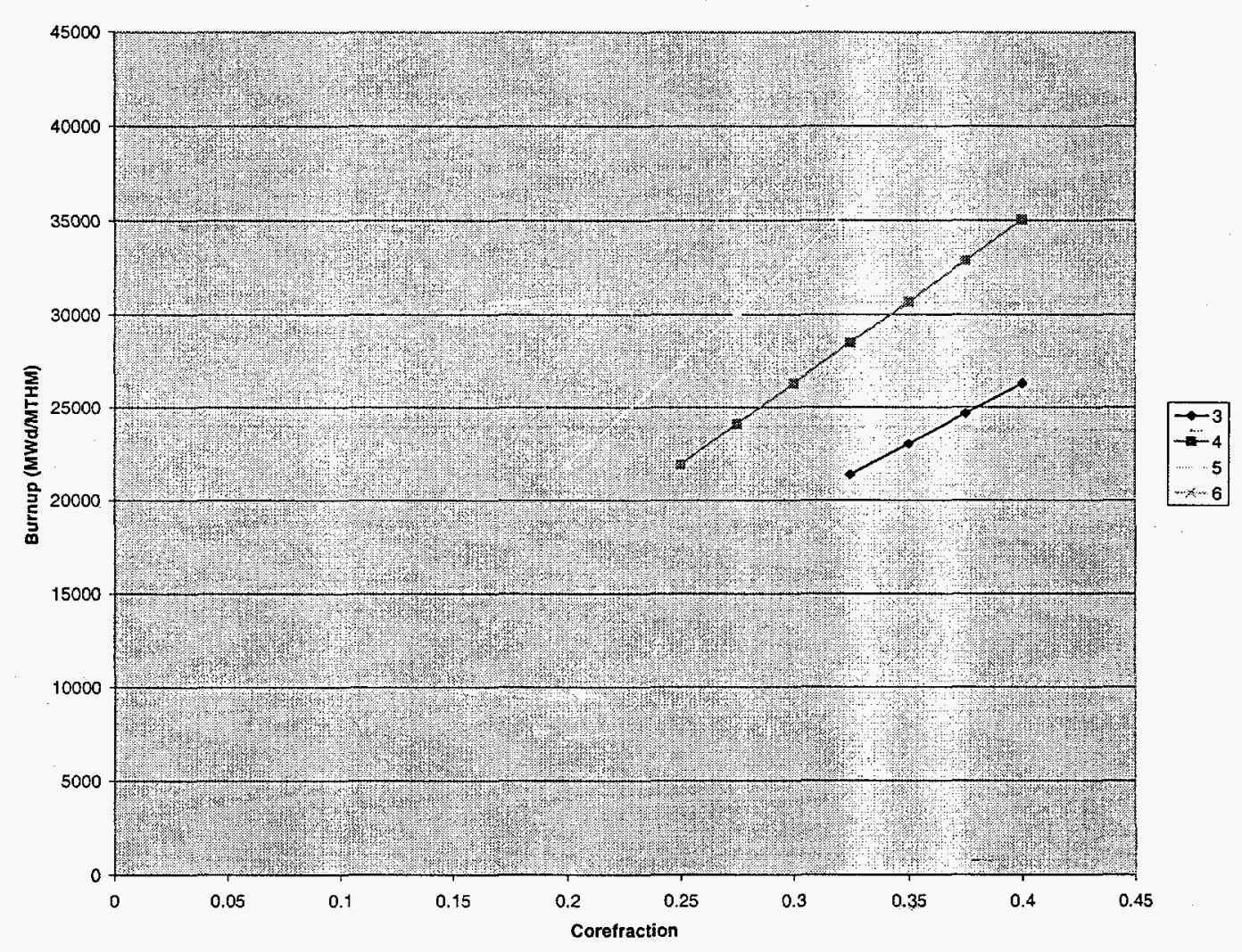

Figure 15: Burnup of the MOX Fuel When Used for Power Production vs. the Corefraction of the Reactor that is MOX Fuel for Various Number of Reactors (3-6) Used to Produce Power from the MOX Fuel 


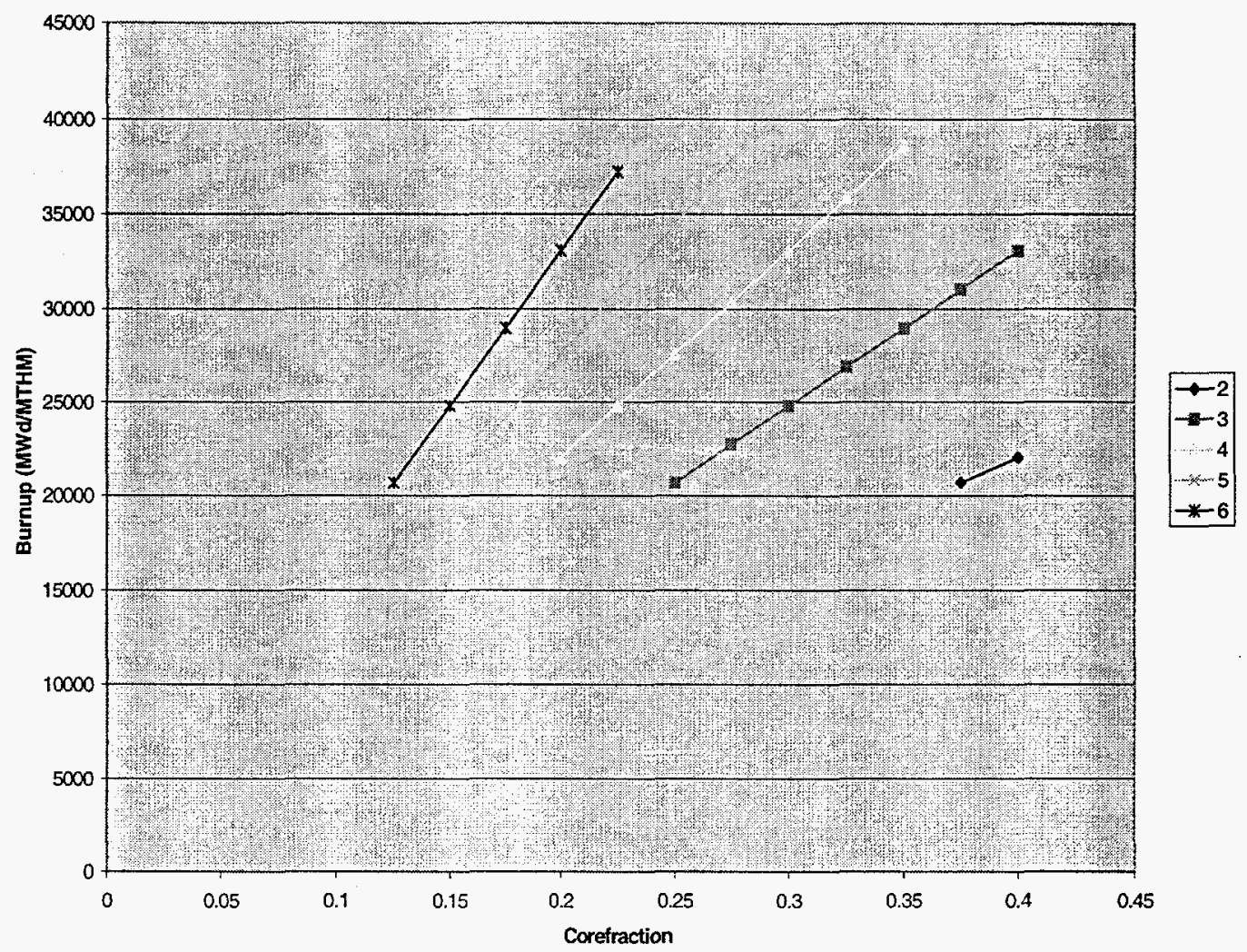

Figure 16: Burnup of the MOX Fuel When Used for Power Production vs. the Corefraction of the Reactor that is MOX Fuel for Various Number of Reactors (2-6) Used to Produce Power from the MOX Fuel for a Throughput of $2779 \mathrm{~kg}$ Pu Per Year 


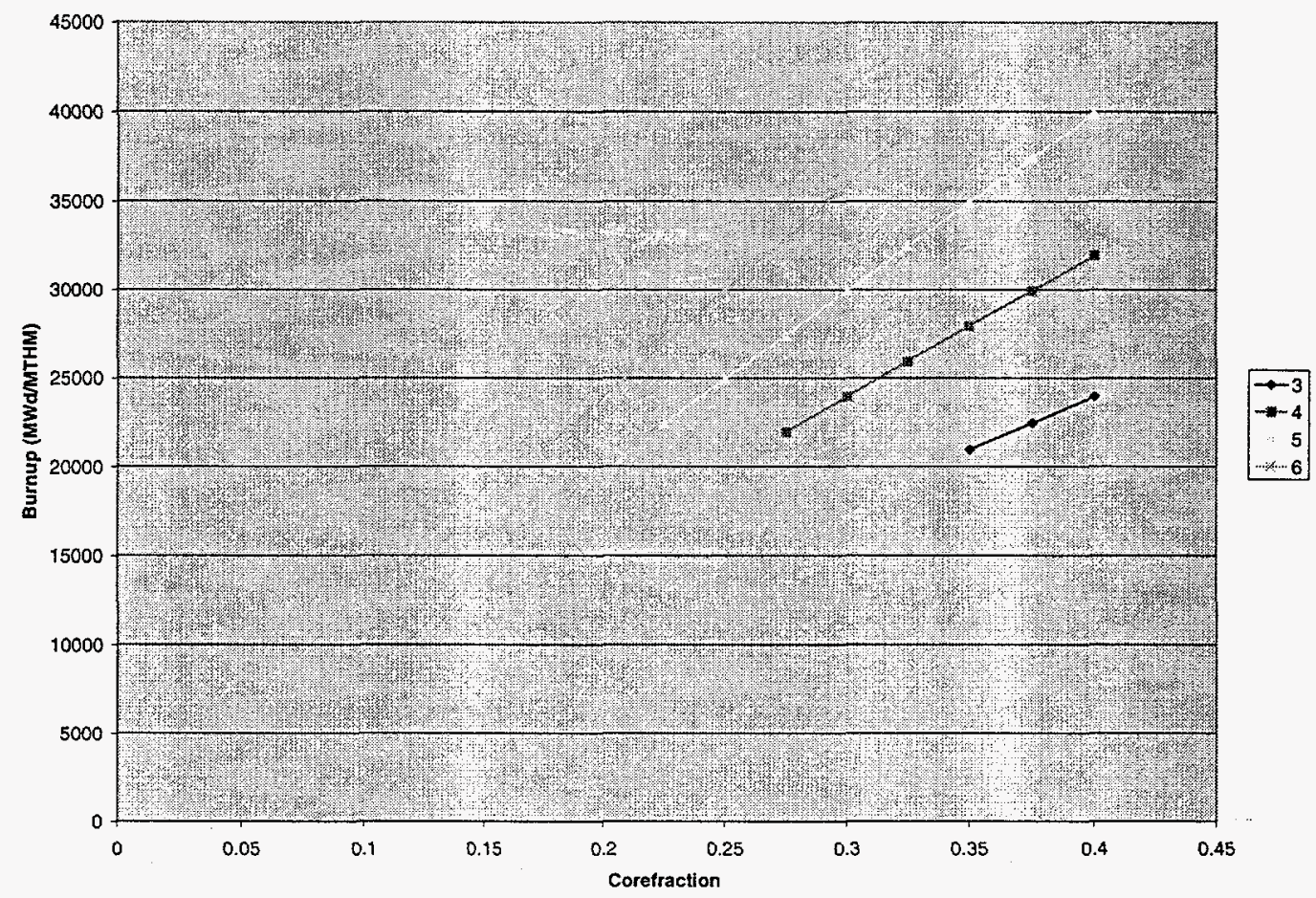

Figure 17: Burnup of the MOX Fuel When Used for Power Production vs. the Corefraction of the Reactor that is MOX Fuel for Various Number of Reactors (3-6) Used to Produce Power from the MOX Fuel for a Throughput of $3840 \mathrm{~kg}$ Pu Per Year 



\section{CONCLUSION}

The optimization of the $\mathrm{Pu}$ throughput of the pit disassembly and conversion facility, and the mixed-oxide fuel fabrication plant was started by identifying the processing steps between the Pu metal arriving at the ARIES facility to the MOX fuel leaving the MOX FFF. These steps were broken down into modules, and the number of workers and space required for each was estimated from preliminary plant designs. The throughput of each module was calculated and the boundary conditions for required outputs were defined. From this, a FORTRAN program was written to back-calculate the number of man-hours for the lifetime of the plant and area needed for each facility for varying plutonium concentrations. It was determined that the optimal configuration for the defined boundary conditions was at $7 \%$ plutonium, the upper bound of the Pu concentration. It was assumed that a throughput of less than $2,000 \mathrm{~kg}$ and greater than $5,000 \mathrm{~kg} \mathrm{Pu}$ was undesirable. From the localized graphs, regional minimums were recognized and defined. These were narrowed down by incompatibility with the optimal throughputs of either the ARIES or the MOX facility. The remaining optimal throughput values, in order of increasing man-hours, were 3,497, 2,779, and $3,840 \mathrm{~kg} \mathrm{Pu}$. These translated into facility lifetimes of $9.1,10.0$, and 12.6 years, respectively. If this is compared with DOE's plan of 3.5 MT/year for 10 years, then it matches the third result.

The results show that 2 reactors would be able to handle the power production from the facility at $7 \% \mathrm{Pu}$ concentration. However, this would require a very low burnup of the fuel, which would result in a low power output from the amount of fuel present. This would be very inefficient.

The minimum costs observed overall are at 7,538 MT/year. However, this facility would be too large to be an efficient conversion process. The time needed to construct, and later decontaminate and decommission, the facility would be greater than the process life of the facility. The quantity of workers and land space required would also be too large to be cost-effective. There is no minimum time required for complete disposition, as the facility could be made large enough to convert the entire quantity of plutonium metal in less than a year. However, the limitations for this facility would be the same as previously described.

Based on the results, it is recommended that the facilities be built for throughputs of $2,779 \mathrm{~kg}$ of plutonium per year. Because it is the smallest optimal throughput, the facility sizes will be smaller, requiring less maintenance and decontamination. It will also require fewer workers to be hired. Due to the larger lifetime, the workers that will be hired will be employed for a longer duration, which will benefit the regions in which the plants are built due to a sustained input of money into the local economies. Smaller facilities would also decrease the draw on the regional utilities, such as water and electricity. 



\section{REFERENCES}

1. DeMuth, S.F., "Preconceptual Design for Separation of Plutonium and Gallium by Ion Exchange," Los Alamos National Laboratory, LA-UR-97-3769, September 30, 1997.

2. DeMuth, S.F., "Ion Exchange Separation of Plutonium from Gallium (1) Resource and Inventory Requirements, (2) Waste, Emissions, and Effluent, and (3) Facility Size, Rev. 1," Los Alamos National Laboratory, LA-UR-97-3902, September 1997.

3. DOE/EIS-0229, "Storage and Disposition of Weapons-Usable Fissile Materials Final Programmatic Environmental Impact Statement," Department of Energy, Office of Fissile Materials Disposition, December 1996.

4. Hower, L.D. Jr., "Mixed-Oxide Fuel Pellet Fabrication and Fuel Rod Assembly for Dresden 1, Batch 7 Reload," Gulf United Nuclear Fuels Corporation, GU5308, January 1974.

5. LA-UR-97-2208, "Exposure Minimization/Layout Optimization Scope," Los Alamos National Laboratory, July 1997.

6. LA-UR-97-2067, "Initial Response to the Surplus Plutonium Disposition Environmental Impact Statement Data Call for a Mixed Oxide Fuel Fabrication Facility," Los Alamos National Laboratory, June 6, 1997.

7. LA-UR-97-2909, "Pit Disassembly and Conversion Facility Environmental
Impact Statement Data Response - Pantex Plant," Los Alamos National Laboratory, July 29, 1997.

8. NUREG-0002, "Final Generic Environmental, Statement on the Use of Recycle Plutonium in Mixed Oxide Fuel in Light Water Cooled Reactors," Office of Nuclear Material Safety and Safeguards, U.S. Nuclear Regulatory Commission, August 1976.

9. Olsen R.E., Goodman, J., "Review of Waste Management for a Large-Scale Mixed Oxide Fuel Fabrication Facility," Westinghouse Electric Corporation, WCAP-9144, September 1977.

10. Sinkule, Barbara, "Waste Estimate Calculations: Wastes of Various Types," Los Alamos National Laboratory, LAUR-97-1933, 1997.

11. "Study of Plutonium Disposition Using Existing GE Boiling Water Reactors," General Electric Nuclear Energy report NEDO-32351, DOE contract DE-AC0393SF19681, April 1994.

12. Taube, Mieczyslaw, "Plutonium," Institute of Nuclear Research, Warszawa, Macmillan Company, New York, 1964.

13. Trellue, H.R., Baros, T., "Nuclear Fuels Technologies Fiscal Year 1997 Research and Development Test Results," Los Alamos National Laboratory, LA-UR-974423, November 1997.

14. Westinghouse Electrical Corporation, "Environmental Report - Westinghouse Recycle Fuels Plant," July 1973. 



\section{APPENDIX A \\ Example of a FORTRAN Program Written to Calculate Data for Fuel \\ Construction for Use in a PWR}

This program calculates the values of workers and area for the MOX and ARIES facility, and the number of years for completion, as the throughput increases, for $\mathrm{Pu}$ concentrations varying from $3 \%$ to $7 \%$. An excerpt from the beginning of the output file follows showing data for the $3 \%$ and the beginning of the $3.5 \%$ output.

FORTRAN Program:

\begin{tabular}{|c|c|c|}
\hline \multicolumn{2}{|c|}{ *** KEN SCHWARTZ } & $* * *$ \\
\hline \multicolumn{3}{|c|}{$* * * *$} \\
\hline$* * *$ & THIS PROGRAM WILL CALCULATE THE NUMBER & \\
\hline$* * *$ & OF WORKERS AND AREA OF A PIT DISSASSEMBLY & \\
\hline$* * *$ & AND CONVERSION FACILITY, MOX FUEL & \\
\hline$* * *$ & FABRICATION FACILITY, AND THE NUMBER OF & \\
\hline *** & YEARS REQUIRED TO CONVERT 35 METRIC TONS & \\
\hline \multirow{2}{*}{\multicolumn{3}{|c|}{$\begin{array}{l}* * * * * * * * * * * * * * * * * * * * * * * * * * * * * * * * * * * * * * * * * * * * * * * * * * * * * * * * * \\
* * * \\
* \mathrm{VARTARIFS}\end{array}$}} \\
\hline & & \\
\hline$* * *$ & WORKM = TOTAL WORKERS OF MOX FACILITY & \\
\hline$* * *$ & AREATOTM = TOTAL AREA OF MOX FACILITY & \\
\hline$* * *$ & WORKA = TOTAL WORKERS OF ARIES FACILITY & \\
\hline$* * *$ & AREATOTA = TOTAL AREA OF ARIES FACILITY & \\
\hline$* * *$ & MASSPU = MASS $(\mathrm{KG})$ PLUTONIUM THROUGHPUT & $* * *$ \\
\hline$* * *$ & REACTORS TYPE PWR= PINS=264 & $* * *$ \\
\hline *** & $\mathrm{BWR}=\mathrm{PINS}=54$ & \\
\hline
\end{tabular}

PROGRAM THESIS 1

REAL MASSPU, REQKG, PUMIN, PUMAX, PUCONC

REAL KGPIN, KGBUN, KGPEL, REQBUN, REQPIN, TEMP

REAL PRODBUN, REQPEL, REC2, WASTE2, REJ2, REC3

REAL WASTE3, REJ3, REC4, WASTE4, REJ4, REC5, WASTE5, REJ5

REAL REC6, WASTE6, REJ6, RECA6, WASTEA6

REAL RESULT(7,12000), HOURS, PINS, PELLETS

INTEGER AREATOTM, AREATOTA, WORKA, WORKM, TRIAL, X, Y

INTEGER MOD, I

OPEN (UNIT=8, FLE='FORTTH6', STATUS='NEW')

TRIAL $=0$

PINS $=264$.

PELLETS $=360$.

HOURS $=8000$. 


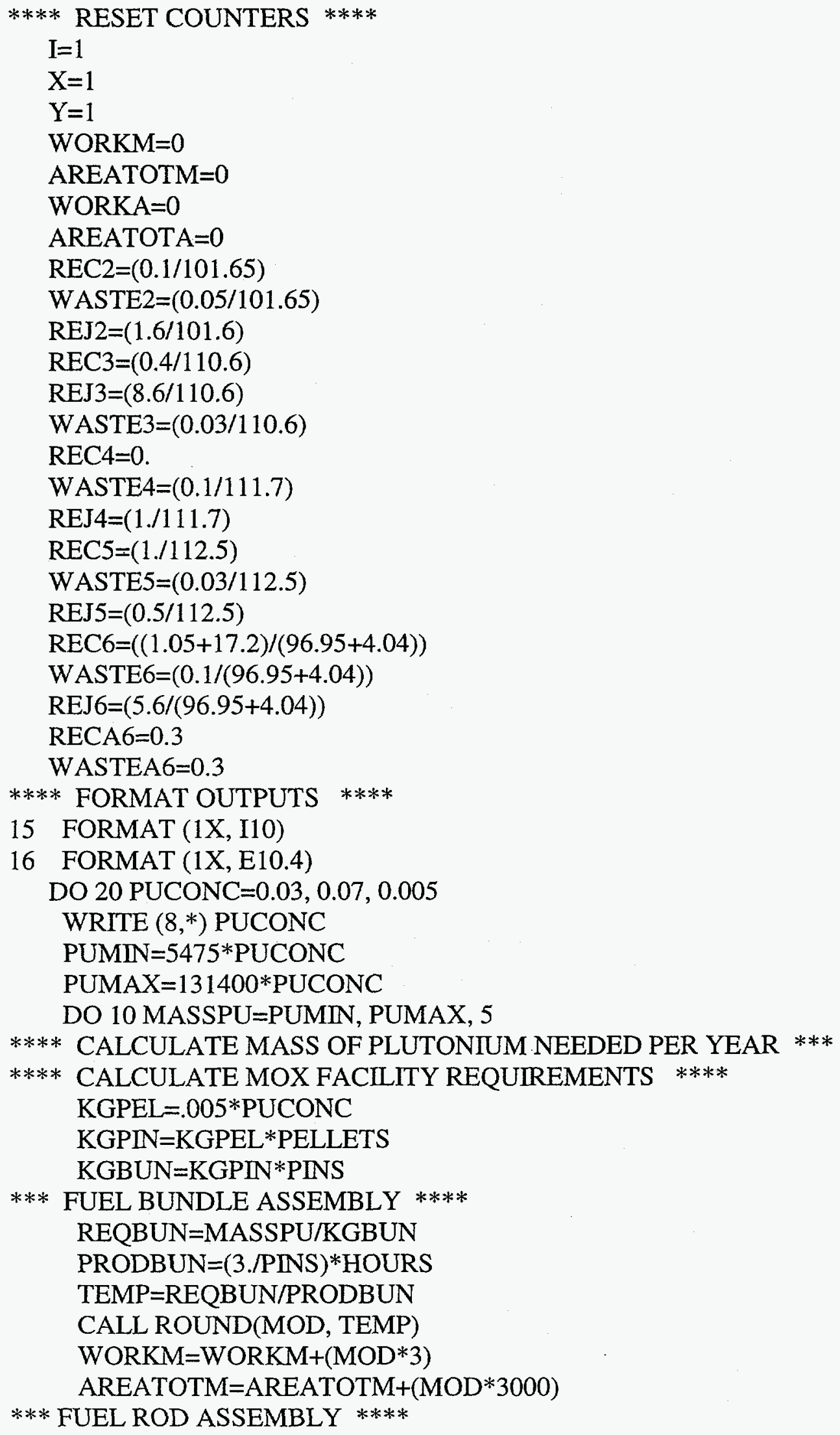




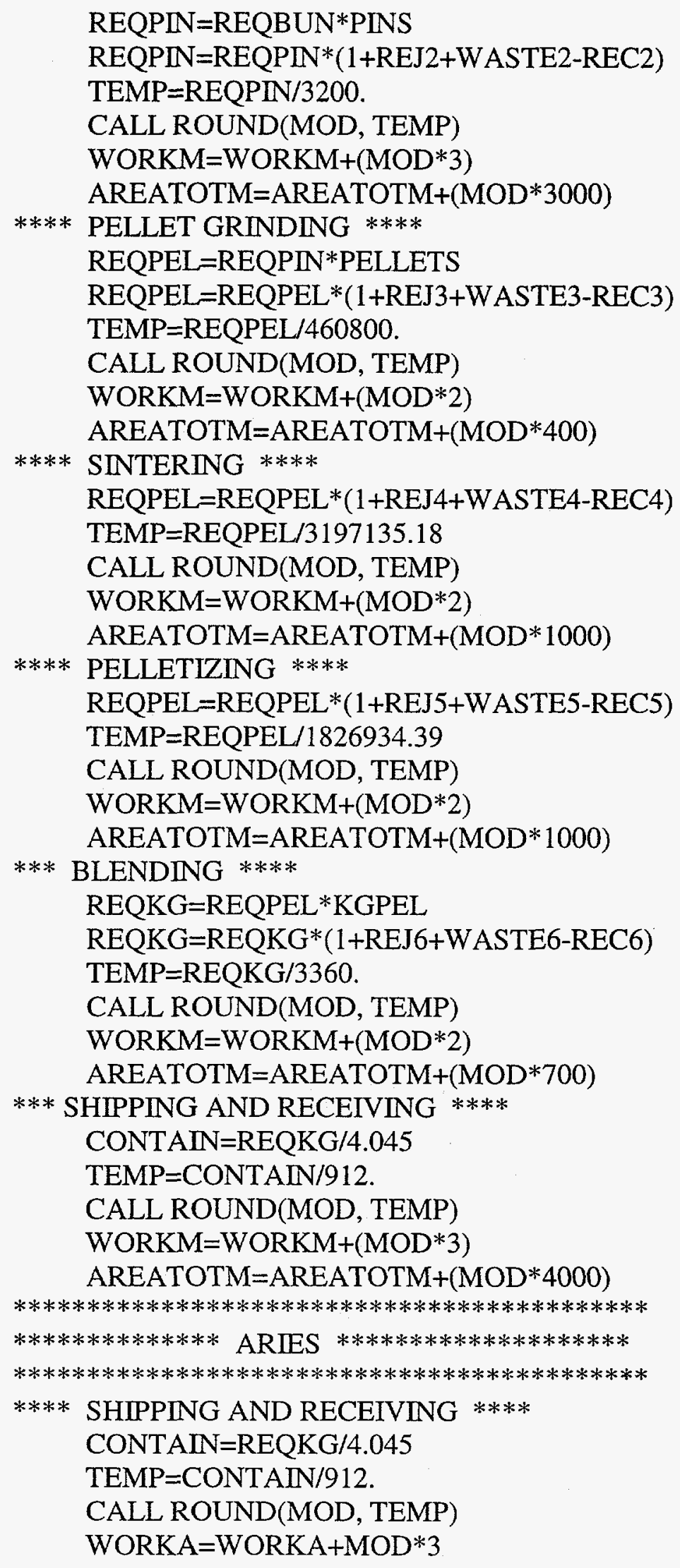


AREATOTA $=$ AREATOTA + MOD $* 4000$

**** SECONDARY CANNING $* * * *$

TEMP=CONTAIN/1920.

CALL ROUND(MOD, TEMP)

WORKA=WORKA+MOD*2

AREATOTA=AREATOTA+MOD* 1000

$* * * *$ ELECTRODECONTAMINATION $* * * *$

TEMP $=$ CONTAIN $/ 1280$.

CALL ROUND(MOD, TEMP)

WORKA=WORKA+MOD*2

AREATOTA $=$ AREATOTA + MOD $* 600$

**** PRIMARY CANNING $* * * *$

TEMP=CONTAIN/1920.

CALL ROUND(MOD, TEMP)

WORKA=WORKA+MOD $* 2$

AREATOTA=AREATOTA+MOD $* 600$

*** GALLIUM REMOVAL ****

TEMP=REQKG/1536.

CALL ROUND(MOD, TEMP)

WORKA $=$ WORKA+MOD $* 2$

AREATOTA=AREATOTA+MOD $* 500$

**** HYDOX ****

REQKG=REQKG*(1+WASTEA6-RECA6)

TEMP=REQKG/384.

CALL ROUND(MOD, TEMP)

WORKA $=$ WORKA+MOD $* 2$

AREATOTA $=$ AREATOTA + MOD $* 500$

**** BISECTION ****

TEMP=REQKG/(384.*4.)

CALL ROUND(MOD, TEMP)

WORKA $=$ WORKA+MOD*2

AREATOTA=AREATOTA+MOD*1300

$* * * * \mathrm{NDA} * * * *$

TEMP=REQKG/(539.*4.)

CALL ROUND(MOD, TEMP)

WORKA=WORKA+MOD*2

AREATOTA=AREATOTA+MOD*1300

**** PIT RECEIVING ****

$M O D=1$

WORKA $=$ WORKA + MOD $* 2$

AREATOTA $=$ AREATOTA + MOD $* 2000$

$* * * * *$ WRITE DATA TO FORTTH.XLS $* * * * * *$

$\operatorname{RESULT}(1, \mathrm{I})=\mathrm{I}$

$\operatorname{RESULT}(2, \mathrm{I})=\mathrm{MASSPU}$

$\operatorname{RESULT}(3, \mathrm{I})=$ WORKM

$\operatorname{RESULT}(4, \mathrm{I})=$ AREATOTM 


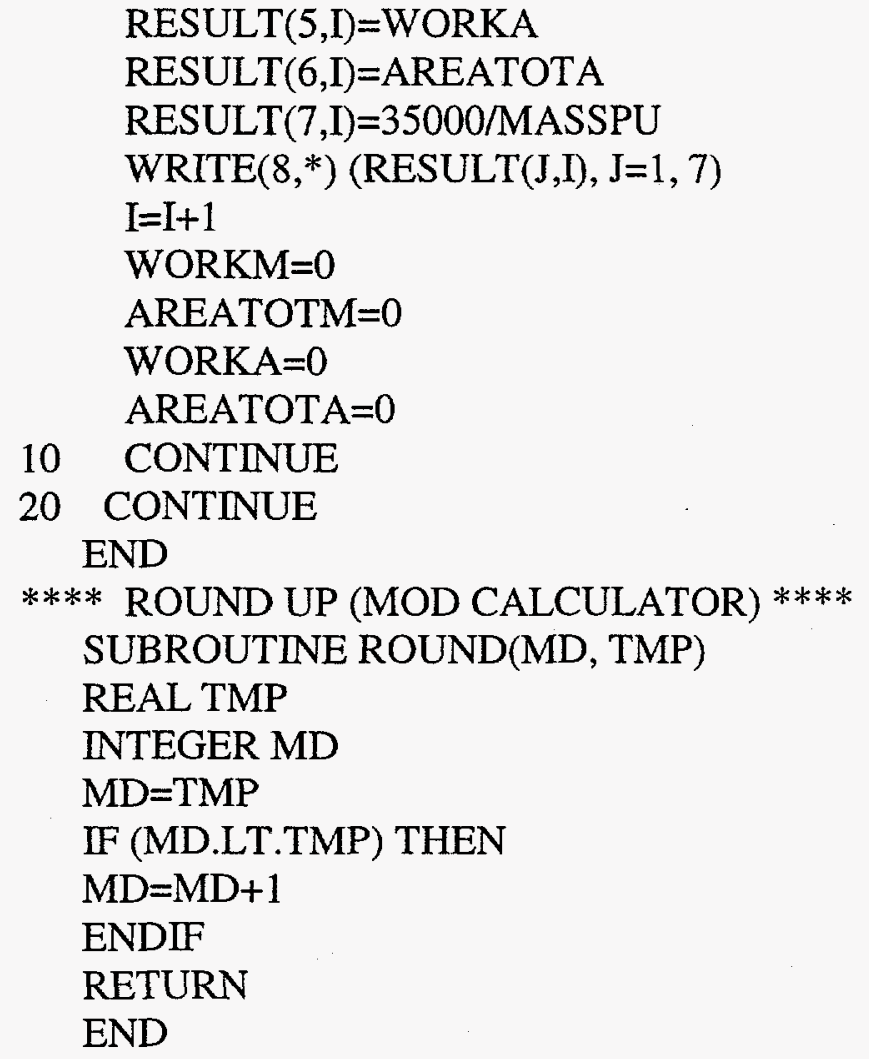

Output File:

\begin{tabular}{rrrrrrr}
\multicolumn{2}{c}{ throughput } & MOXW & MOXA & ARIESW ARIESA & years \\
0.03 & & & & & & \\
1 & 164.25 & 21 & 13900 & 19 & 11800 & 213.0898 \\
2 & 169.25 & 21 & 13900 & 19 & 11800 & 206.7947 \\
3 & 174.25 & 24 & 16900 & 19 & 11800 & 200.8608 \\
4 & 179.25 & 24 & 16900 & 19 & 11800 & 195.258 \\
5 & 184.25 & 24 & 16900 & 19 & 11800 & 189.9593 \\
6 & 189.25 & 24 & 16900 & 19 & 11800 & 184.9406 \\
7 & 194.25 & 26 & 17300 & 19 & 11800 & 180.1802 \\
8 & 199.25 & 26 & 17300 & 19 & 11800 & 175.6587 \\
9 & 204.25 & 26 & 17300 & 19 & 11800 & 171.3586 \\
10 & 209.25 & 26 & 17300 & 19 & 11800 & 167.264 \\
11 & 214.25 & 26 & 17300 & 19 & 11800 & 163.3606 \\
12 & 219.25 & 26 & 17300 & 19 & 11800 & 159.6351 \\
13 & 224.25 & 26 & 17300 & 19 & 11800 & 156.0758 \\
14 & 229.25 & 26 & 17300 & 19 & 11800 & 152.6718 \\
15 & 234.25 & 26 & 17300 & 19 & 11800 & 149.413 \\
16 & 239.25 & 26 & 17300 & 19 & 11800 & 146.2905 \\
17 & 244.25 & 26 & 17300 & 19 & 11800 & 143.2958 \\
18 & 249.25 & 26 & 17300 & 19 & 11800 & 140.4213
\end{tabular}




\begin{tabular}{|c|c|c|c|c|c|}
\hline 19 & 254.25 & 30 & 18700 & 19 & 11800137.6598 \\
\hline 20 & 259.25 & 30 & 18700 & 19 & 11800135.0048 \\
\hline 21 & 264.25 & 30 & 18700 & 19 & 11800132.4503 \\
\hline 22 & 269.25 & 30 & 18700 & 19 & 11800129.9907 \\
\hline 23 & 274.25 & 30 & 18700 & 19 & 11800127.6208 \\
\hline 24 & 279.25 & 30 & 18700 & 19 & $11800 \quad 125.3357$ \\
\hline 25 & 284.25 & 30 & 18700 & 19 & $11800 \quad 123.1311$ \\
\hline 26 & 289.25 & 30 & 18700 & 19 & 11800121.0026 \\
\hline 27 & 294.25 & 30 & 18700 & 19 & 11800118.9465 \\
\hline 28 & 299.25 & 30 & 18700 & 19 & $11800 \quad 116.9591$ \\
\hline 29 & 304.25 & 30 & 18700 & 19 & $11800 \quad 115.037$ \\
\hline 30 & 309.25 & 30 & 18700 & 19 & $11800 \quad 113.177$ \\
\hline 31 & 314.25 & 30 & 18700 & 19 & 11800111.3763 \\
\hline 32 & 319.25 & 32 & 19100 & 19 & $11800 \quad 109.632$ \\
\hline 33 & 324.25 & 32 & 19100 & 19 & 11800107.9414 \\
\hline 34 & 329.25 & 32 & 19100 & 19 & $11800 \quad 106.3022$ \\
\hline 35 & 334.25 & 32 & 19100 & 19 & $11800 \quad 104.712$ \\
\hline 36 & 339.25 & 32 & 19100 & 19 & 11800103.1688 \\
\hline 37 & 344.25 & 35 & 22100 & 19 & 11800101.6703 \\
\hline 38 & 349.25 & 35 & 22100 & 19 & 11800100.2147 \\
\hline 39 & 354.25 & 35 & 22100 & 19 & 1180098.80029 \\
\hline 40 & 359.25 & 35 & 22100 & 19 & 1180097.42519 \\
\hline 41 & 364.25 & 35 & 22100 & 19 & 1180096.08785 \\
\hline 42 & 369.25 & 35 & 22100 & 19 & 1180094.78673 \\
\hline 43 & 374.25 & 35 & 22100 & 19 & 1180093.52037 \\
\hline 44 & 379.25 & 35 & 22100 & 19 & 1180092.28741 \\
\hline 45 & 384.25 & 37 & 22500 & 19 & 1180091.08653 \\
\hline 46 & 389.25 & 37 & 22500 & 19 & $11800 \quad 89.9165$ \\
\hline 47 & 394.25 & 37 & 22500 & 19 & 1180088.77615 \\
\hline 48 & 399.25 & 37 & 22500 & 19 & 1180087.66437 \\
\hline 49 & 404.25 & 37 & 22500 & 21 & 1230086.58009 \\
\hline 50 & 409.25 & 37 & 22500 & 21 & 1230085.52229 \\
\hline 51 & 414.25 & 37 & 22500 & 21 & 1230084.49004 \\
\hline 52 & 419.25 & 37 & 22500 & 21 & 1230083.48241 \\
\hline 53 & 424.25 & 37 & 22500 & 21 & 1230082.49853 \\
\hline 54 & 429.25 & 37 & 22500 & 21 & 1230081.53757 \\
\hline 55 & 434.25 & 37 & 22500 & 21 & 1230080.59873 \\
\hline 56 & 439.25 & 39 & 23500 & 21 & 1230079.68127 \\
\hline 57 & 444.25 & 41 & 23900 & 21 & 1230078.78447 \\
\hline 58 & 449.25 & 41 & 23900 & 21 & 1230077.90762 \\
\hline 59 & 454.25 & 41 & 23900 & 21 & 1230077.05008 \\
\hline 60 & 459.25 & 41 & 23900 & 21 & 1230076.21121 \\
\hline 61 & 464.25 & 41 & 23900 & 21 & 1230075.39041 \\
\hline 62 & 469.25 & 41 & 23900 & 21 & $12300 \quad 74.5871$ \\
\hline 63 & 474.25 & 41 & 23900 & 21 & 1230073.80074 \\
\hline 64 & 479.25 & 41 & 23900 & 21 & 1230073.03078 \\
\hline
\end{tabular}




\begin{tabular}{|c|c|c|c|c|c|}
\hline 65 & 484.25 & 41 & 23900 & 21 & 1230072.27672 \\
\hline 66 & 489.25 & 41 & 23900 & 21 & 1230071.53807 \\
\hline 67 & 494.25 & 41 & 23900 & 21 & 1230070.81436 \\
\hline 68 & 499.25 & 41 & 23900 & 21 & 1230070.10516 \\
\hline 69 & 504.25 & 43 & 24900 & 21 & 1230069.41001 \\
\hline 70 & 509.25 & 45 & 25300 & 21 & 1230068.72852 \\
\hline 71 & 514.25 & 48 & 28300 & 21 & 1230068.06028 \\
\hline 72 & 519.25 & 48 & 28300 & 21 & 1230067.40491 \\
\hline 73 & 524.25 & 48 & 28300 & 21 & 1230066.76204 \\
\hline 74 & 529.25 & 48 & 28300 & 21 & 1230066.13132 \\
\hline 75 & 534.25 & 48 & 28300 & 21 & $12300 \quad 65.5124$ \\
\hline 76 & 539.25 & 48 & 28300 & 21 & 1230064.90496 \\
\hline 77 & 544.25 & 48 & 28300 & 21 & 1230064.30869 \\
\hline 78 & 549.25 & 48 & 28300 & 21 & 1230063.72326 \\
\hline 79 & 554.25 & 48 & 28300 & 21 & $12300 \quad 63.1484$ \\
\hline 80 & 559.25 & 48 & 28300 & 21 & 1230062.58382 \\
\hline 81 & 564.25 & 48 & 28300 & 21 & $12300 \quad 62.02924$ \\
\hline 82 & 569.25 & 48 & 28300 & 21 & 1230061.48441 \\
\hline 83 & 574.25 & 50 & 28700 & 21 & 1230060.94906 \\
\hline 84 & 579.25 & 50 & 28700 & 21 & 1230060.42296 \\
\hline 85 & 584.25 & 50 & 28700 & 21 & 1230059.90586 \\
\hline 86 & 589.25 & 50 & 28700 & 21 & 1230059.39754 \\
\hline 87 & 594.25 & 50 & 28700 & 21 & 1230058.89777 \\
\hline 88 & 599.25 & 50 & 28700 & 21 & 1230058.40634 \\
\hline 89 & 604.25 & 50 & 28700 & 21 & 1230057.92305 \\
\hline 90 & 609.25 & 50 & 28700 & 21 & 1230057.44768 \\
\hline 91 & 614.25 & 50 & 28700 & 21 & 1230056.98006 \\
\hline 92 & 619.25 & 50 & 28700 & 21 & 1230056.51999 \\
\hline 93 & 624.25 & 50 & 28700 & 21 & 1230056.06728 \\
\hline 94 & 629.25 & 50 & 28700 & 21 & 1230055.62177 \\
\hline 95 & 634.25 & 52 & 29100 & 21 & 1230055.18329 \\
\hline 96 & 639.25 & 52 & 29100 & 21 & 1230054.75166 \\
\hline 97 & 644.25 & 52 & 29100 & 21 & 1230054.32674 \\
\hline 98 & 649.25 & 52 & 29100 & 21 & 1230053.90836 \\
\hline 99 & 654.25 & 52 & 29100 & 21 & 1230053.49637 \\
\hline 100 & 659.25 & 52 & 29100 & 21 & 1230053.09063 \\
\hline 101 & 664.25 & 52 & 29100 & 21 & 1230052.69101 \\
\hline 102 & 669.25 & 52 & 29100 & 21 & 1230052.29735 \\
\hline 103 & 674.25 & 52 & 29100 & 21 & 1230051.90953 \\
\hline 104 & 679.25 & 52 & 29100 & 21 & 1230051.52742 \\
\hline 105 & 684.25 & 55 & 32100 & 21 & 1230051.15089 \\
\hline 106 & 689.25 & 55 & 32100 & 21 & 1230050.77983 \\
\hline 107 & 694.25 & 55 & 32100 & 21 & 1230050.41412 \\
\hline 108 & 699.25 & 57 & 32500 & 21 & 1230050.05363 \\
\hline 109 & 704.25 & 57 & 32500 & 21 & 1230049.69826 \\
\hline 110 & 709.25 & 57 & 32500 & 21 & $12300 \quad 49.3479$ \\
\hline
\end{tabular}




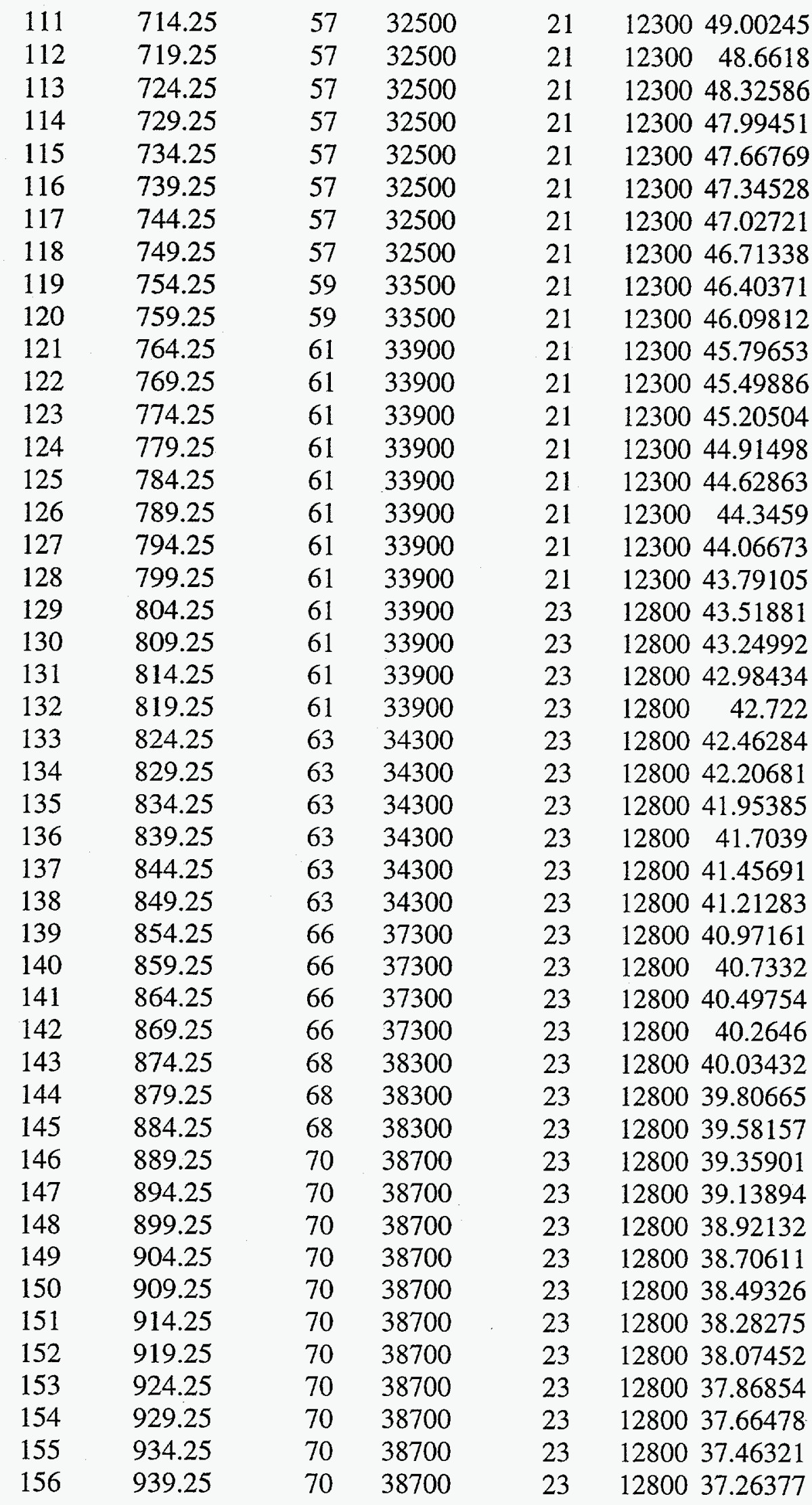




\begin{tabular}{|c|c|c|c|c|c|}
\hline 157 & 944.25 & 70 & 38700 & 23 & 1280037.06646 \\
\hline 158 & 949.25 & 70 & 38700 & 23 & 1280036.87122 \\
\hline 159 & 954.25 & 72 & 39100 & 23 & 1280036.67802 \\
\hline 160 & 959.25 & 72 & 39100 & 23 & 1280036.48684 \\
\hline 161 & 964.25 & 72 & 39100 & 23 & 1280036.29764 \\
\hline 162 & 969.25 & 72 & 39100 & 23 & 1280036.11039 \\
\hline 163 & 974.25 & 72 & 39100 & 23 & 1280035.92507 \\
\hline 164 & 979.25 & 72 & 39100 & 23 & 1280035.74164 \\
\hline 165 & 984.25 & 72 & 39100 & 23 & 1280035.56007 \\
\hline 166 & 989.25 & 72 & 39100 & 23 & 1280035.38034 \\
\hline 167 & 994.25 & 72 & 39100 & 23 & 1280035.20242 \\
\hline 168 & 999.25 & 72 & 39100 & 23 & 1280035.02627 \\
\hline 169 & 1004.25 & 74 & 40100 & 23 & 1280034.85188 \\
\hline 170 & 1009.25 & 74 & 40100 & 23 & 1280034.67922 \\
\hline 171 & 1014.25 & 76 & 40500 & 23 & 1280034.50826 \\
\hline 172 & 1019.25 & 76 & 40500 & 23 & 1280034.33897 \\
\hline 173 & 1024.25 & 79 & 43500 & 23 & 1280034.17134 \\
\hline 174 & 1029.25 & 79 & 43500 & 23 & 1280034.00534 \\
\hline 175 & 1034.25 & 79 & 43500 & 23 & 1280033.84095 \\
\hline 176 & 1039.25 & 79 & 43500 & 23 & 1280033.67813 \\
\hline 177 & 1044.25 & 79 & 43500 & 23 & 1280033.51688 \\
\hline 178 & 1049.25 & 79 & 43500 & 23 & 1280033.35716 \\
\hline 179 & 1054.25 & 79 & 43500 & 23 & 1280033.19896 \\
\hline 180 & 1059.25 & 79 & 43500 & 23 & 1280033.04225 \\
\hline 181 & 1064.25 & 79 & 43500 & 23 & 1280032.88701 \\
\hline 182 & 1069.25 & 79 & 43500 & 23 & 1280032.73322 \\
\hline 183 & 1074.25 & 79 & 43500 & 23 & 1280032.58087 \\
\hline 184 & 1079.25 & 81 & 43900 & 23 & 1280032.42993 \\
\hline 185 & 1084.25 & 81 & 43900 & 23 & 1280032.28038 \\
\hline 186 & 1089.25 & 81 & 43900 & 23 & $12800 \quad 32.1322$ \\
\hline 187 & 1094.25 & 81 & 43900 & 23 & 1280031.98538 \\
\hline 188 & 1099.25 & 81 & 43900 & 23 & 1280031.83989 \\
\hline 189 & 1104.25 & 81 & 43900 & 23 & 1280031.69572 \\
\hline 190 & 1109.25 & 81 & 43900 & 23 & 1280031.55285 \\
\hline 191 & 1114.25 & 81 & 43900 & 23 & 1280031.41126 \\
\hline 192 & 1119.25 & 81 & 43900 & 23 & 1280031.27094 \\
\hline 193 & 1124.25 & 81 & 43900 & 23 & 1280031.13187 \\
\hline 194 & 1129.25 & 81 & 43900 & 23 & 1280030.99402 \\
\hline 195 & 1134.25 & 81 & 43900 & 23 & $12800 \quad 30.8574$ \\
\hline 196 & 1139.25 & 81 & 43900 & 23 & $12800 \quad 30.72197$ \\
\hline 197 & 1144.25 & 83 & 44300 & 23 & 1280030.58772 \\
\hline 198 & 1149.25 & 83 & 44300 & 23 & 1280030.45465 \\
\hline 199 & 1154.25 & 83 & 44300 & 23 & $12800 \quad 30.32272$ \\
\hline 200 & 1159.25 & 83 & 44300 & 23 & 1280030.19193 \\
\hline 201 & 1164.25 & 83 & 44300 & 23 & $12800 \cdot 30.06227$ \\
\hline 202 & 1169.25 & 83 & 44300 & 23 & 1280029.93372 \\
\hline
\end{tabular}




\begin{tabular}{|c|c|c|c|c|c|}
\hline 203 & 1174.25 & 83 & 44300 & 23 & 1280029.80626 \\
\hline 204 & 1179.25 & 83 & 44300 & 23 & 1280029.67988 \\
\hline 205 & 1184.25 & 83 & 44300 & 23 & 1280029.55457 \\
\hline 206 & 1189.25 & 83 & 44300 & 23 & 1280029.43031 \\
\hline 207 & 1194.25 & 86 & 47300 & 23 & $12800 \quad 29.3071$ \\
\hline 208 & 1199.25 & 86 & 47300 & 25 & 1330029.18491 \\
\hline 209 & 1204.25 & 88 & 47700 & 25 & 1330029.06373 \\
\hline 210 & 1209.25 & 88 & 47700 & 25 & 1330028.94356 \\
\hline 211 & 1214.25 & 88 & 47700 & 25 & 1330028.82438 \\
\hline 212 & 1219.25 & 88 & 47700 & 25 & 1330028.70617 \\
\hline 213 & 1224.25 & 88 & 47700 & 25 & 1330028.58893 \\
\hline 214 & 1229.25 & 88 & 47700 & 25 & 1330028.47265 \\
\hline 215 & 1234.25 & 88 & 47700 & 25 & $13300 \quad 28.3573$ \\
\hline 216 & 1239.25 & 88 & 47700 & 25 & 1330028.24289 \\
\hline 217 & 1244.25 & 88 & 47700 & 25 & 1330028.12939 \\
\hline 218 & 1249.25 & 90 & 48700 & 25 & 1330028.01681 \\
\hline 219 & 1254.25 & 90 & 48700 & 25 & 1330027.90512 \\
\hline 220 & 1259.25 & 90 & 48700 & 25 & 1330027.79432 \\
\hline 221 & 1264.25 & 90 & 48700 & 25 & $13300 \quad 27.6844$ \\
\hline 222 & 1269.25 & 92 & 49100 & 25 & 1330027.57534 \\
\hline 223 & 1274.25 & 92 & 49100 & 25 & 1330027.46714 \\
\hline 224 & 1279.25 & 92 & 49100 & 25 & 1330027.35978 \\
\hline 225 & 1284.25 & 92 & 49100 & 25 & 1330027.25326 \\
\hline 226 & 1289.25 & 92 & 49100 & 25 & 1330027.14757 \\
\hline 227 & 1294.25 & 92 & 49100 & 25 & 1330027.04269 \\
\hline 228 & 1299.25 & 95 & 52100 & 25 & 1330026.93862 \\
\hline 229 & 1304.25 & 95 & 52100 & 25 & 1330026.83535 \\
\hline 230 & 1309.25 & 97 & 53100 & 25 & 1330026.73286 \\
\hline 231 & 1314.25 & 97 & 53100 & 25 & 1330026.63116 \\
\hline 232 & 1319.25 & 97 & 53100 & 25 & 1330026.53023 \\
\hline 233 & 1324.25 & 97 & 53100 & 25 & 1330026.43006 \\
\hline 234 & 1329.25 & 97 & 53100 & 25 & 1330026.33064 \\
\hline 235 & 1334.25 & 99 & 53500 & 25 & 1330026.23197 \\
\hline 236 & 1339.25 & 99 & 53500 & 25 & 1330026.13403 \\
\hline 237 & 1344.25 & 99 & 53500 & 25 & 1330026.03682 \\
\hline 238 & 1349.25 & 99 & 53500 & 25 & 1330025.94034 \\
\hline 239 & 1354.25 & 99 & 53500 & 25 & 1330025.84456 \\
\hline 240 & 1359.25 & 99 & 53500 & 25 & 1330025.74949 \\
\hline 241 & 1364.25 & 102 & 56500 & 25 & 1330025.65512 \\
\hline 242 & 1369.25 & 102 & 56500 & 25 & $13300 \quad 25.56144$ \\
\hline 243 & 1374.25 & 102 & 56500 & 25 & $13300 \quad 25.46844$ \\
\hline 244 & 1379.25 & 102 & 56500 & 25 & 1330025.37611 \\
\hline 245 & 1384.25 & 102 & 56500 & 25 & 1330025.28445 \\
\hline 246 & 1389.25 & 102 & 56500 & 25 & 1330025.19345 \\
\hline 247 & 1394.25 & 104 & 56900 & 25 & $13300 \quad 25.1031$ \\
\hline 248 & 1399.25 & 104 & 56900 & 25 & 25.0134 \\
\hline
\end{tabular}




\begin{tabular}{|c|c|c|c|c|c|}
\hline 249 & 1404.25 & 104 & 56900 & 25 & 1330024.92434 \\
\hline 250 & 1409.25 & 104 & 56900 & 25 & 1330024.83591 \\
\hline 251 & 1414.25 & 104 & 56900 & 25 & $13300 \quad 24.7481$ \\
\hline 252 & 1419.25 & 104 & 56900 & 25 & 1330024.66091 \\
\hline 253 & 1424.25 & 104 & 56900 & 25 & 1330024.57434 \\
\hline 254 & 1429.25 & 104 & 56900 & 25 & 1330024.48837 \\
\hline 255 & 1434.25 & 104 & 56900 & 25 & $13300 \quad 24.403$ \\
\hline 256 & 1439.25 & 104 & 56900 & 25 & 1330024.31822 \\
\hline 257 & 1444.25 & 104 & 56900 & 25 & 1330024.23403 \\
\hline 258 & 1449.25 & 104 & 56900 & 25 & 1330024.15042 \\
\hline 259 & 1454.25 & 104 & 56900 & 25 & 1330024.06739 \\
\hline 260 & 1459.25 & 106 & 57300 & 25 & 1330023.98492 \\
\hline 261 & 1464.25 & 106 & 57300 & 25 & 1330023.90302 \\
\hline 262 & 1469.25 & 106 & 57300 & 25 & 1330023.82168 \\
\hline 263 & 1474.25 & 106 & 57300 & 25 & 1330023.74088 \\
\hline 264 & 1479.25 & 106 & 57300 & 25 & 1330023.66064 \\
\hline 265 & 1484.25 & 106 & 57300 & 25 & 1330023.58093 \\
\hline 266 & 1489.25 & 106 & 57300 & 25 & 1330023.50176 \\
\hline 267 & 1494.25 & 106 & 57300 & 25 & 1330023.42312 \\
\hline 268 & 1499.25 & 108 & 58300 & 25 & 1330023.34501 \\
\hline 269 & 1504.25 & 108 & 58300 & 25 & 1330023.26741 \\
\hline 270 & 1509.25 & 108 & 58300 & 25 & 1330023.19033 \\
\hline 271 & 1514.25 & 108 & 58300 & 25 & 1330023.11375 \\
\hline 272 & 1519.25 & 108 & 58300 & 25 & 1330023.03768 \\
\hline 273 & 1524.25 & 110 & 58700 & 25 & 1330022.96211 \\
\hline 274 & 1529.25 & 110 & 58700 & 25 & 1330022.88704 \\
\hline 275 & 1534.25 & 113 & 61700 & 25 & 1330022.81245 \\
\hline 276 & 1539.25 & 113 & 61700 & 25 & 1330022.73835 \\
\hline 277 & 1544.25 & 113 & 61700 & 25 & 1330022.66472 \\
\hline 278 & 1549.25 & 113 & 61700 & 25 & 1330022.59158 \\
\hline 279 & 1554.25 & 113 & 61700 & 25 & $13300 \quad 22.5189$ \\
\hline 280 & 1559.25 & 113 & 61700 & 25 & 1330022.44669 \\
\hline 281 & 1564.25 & 113 & 61700 & 25 & 1330022.37494 \\
\hline 282 & 1569.25 & 113 & 61700 & 25 & 1330022.30365 \\
\hline 283 & 1574.25 & 113 & 61700 & 25 & 1330022.23281 \\
\hline 284 & 1579.25 & 113 & 61700 & 25 & 1330022.16242 \\
\hline 285 & 1584.25 & 115 & 62100 & 25 & 1330022.09247 \\
\hline 286 & 1589.25 & 115 & 62100 & 25 & 1330022.02297 \\
\hline 287 & 1594.25 & 115 & 62100 & 25 & $13300 \quad 21.9539$ \\
\hline 288 & 1599.25 & 115 & 62100 & 31 & 1560021.88526 \\
\hline 289 & 1604.25 & 115 & 62100 & 31 & 1560021.81705 \\
\hline 290 & 1609.25 & 115 & 62100 & 31 & 1560021.74926 \\
\hline 291 & 1614.25 & 115 & 62100 & 31 & $15600 \quad 21.6819$ \\
\hline 292 & 1619.25 & 115 & 62100 & 31 & 1560021.61494 \\
\hline 293 & 1624.25 & 115 & 62100 & 31 & 1560021.54841 \\
\hline 294 & 1629.25 & 115 & 62100 & 31 & 1560021.48228 \\
\hline
\end{tabular}




\begin{tabular}{|c|c|c|c|c|c|}
\hline 295 & 1634.25 & 115 & 62100 & 31 & 1560021.41655 \\
\hline 296 & 1639.25 & 115 & 62100 & 31 & 1560021.35123 \\
\hline 297 & 1644.25 & 115 & 62100 & 31 & $15600 \quad 21.2863$ \\
\hline 298 & 1649.25 & 117 & 62500 & 31 & 1560021.22177 \\
\hline 299 & 1654.25 & 117 & 62500 & 31 & 1560021.15763 \\
\hline 300 & 1659.25 & 117 & 62500 & 31 & 1560021.09387 \\
\hline 301 & 1664.25 & 117 & 62500 & 31 & 1560021.03049 \\
\hline 302 & 1669.25 & 117 & 62500 & 31 & $15600 \quad 20.9675$ \\
\hline 303 & 1674.25 & 117 & 62500 & 31 & 1560020.90488 \\
\hline 304 & 1679.25 & 117 & 62500 & 31 & 1560020.84264 \\
\hline 305 & 1684.25 & 117 & 62500 & 31 & 1560020.78076 \\
\hline 306 & 1689.25 & 117 & 62500 & 31 & 1560020.71925 \\
\hline 307 & 1694.25 & 117 & 62500 & 31 & 1560020.65811 \\
\hline 308 & 1699.25 & 117 & 62500 & 31 & 1560020.59732 \\
\hline 309 & 1704.25 & 120 & 65500 & 31 & 1560020.53689 \\
\hline 310 & 1709.25 & 120 & 65500 & 31 & 1560020.47682 \\
\hline 311 & 1714.25 & 122 & 65900 & 31 & 1560020.41709 \\
\hline 312 & 1719.25 & 122 & 65900 & 31 & 1560020.35771 \\
\hline 313 & 1724.25 & 122 & 65900 & 31 & 1560020.29868 \\
\hline 314 & 1729.25 & 122 & 65900 & 31 & 1560020.23999 \\
\hline 315 & 1734.25 & 122 & 65900 & 31 & 1560020.18163 \\
\hline 316 & 1739.25 & 122 & 65900 & 31 & 1560020.12362 \\
\hline 317 & 1744.25 & 124 & 66900 & 31 & 1560020.06593 \\
\hline 318 & 1749.25 & 126 & 67900 & 31 & 1560020.00858 \\
\hline 319 & 1754.25 & 126 & 67900 & 31 & 1560019.95155 \\
\hline 320 & 1759.25 & 126 & 67900 & 31 & 1560019.89484 \\
\hline 321 & 1764.25 & 126 & 67900 & 31 & 1560019.83846 \\
\hline 322 & 1769.25 & 126 & 67900 & 31 & 1560019.78239 \\
\hline 323 & 1774.25 & 126 & 67900 & 31 & 1560019.72664 \\
\hline 324 & 1779.25 & 128 & 68300 & 31 & $15600 \quad 19.67121$ \\
\hline 325 & 1784.25 & 128 & 68300 & 31 & $15600 \quad 19.61609$ \\
\hline 326 & 1789.25 & 128 & 68300 & 31 & $15600 \quad 19.56127$ \\
\hline 327 & 1794.25 & 128 & 68300 & 31 & 1560019.50676 \\
\hline 328 & 1799.25 & 128 & 68300 & 31 & 1560019.45255 \\
\hline 329 & 1804.25 & 128 & 68300 & 31 & 1560019.39864 \\
\hline 330 & 1809.25 & 128 & 68300 & 31 & 1560019.34503 \\
\hline 331 & 1814.25 & 128 & 68300 & 31 & $15600 \quad 19.29172$ \\
\hline 332 & 1819.25 & 128 & 68300 & 31 & $15600 \quad 19.2387$ \\
\hline 333 & 1824.25 & 128 & 68300 & 31 & 1560019.18597 \\
\hline 334 & 1829.25 & 128 & 68300 & 31 & $15600 \quad 19.13352$ \\
\hline 335 & 1834.25 & 128 & 68300 & 31 & 1560019.08137 \\
\hline 336 & 1839.25 & 130 & 68700 & 31 & $15600 \quad 19.0295$ \\
\hline 337 & 1844.25 & 130 & 68700 & 31 & $15600 \quad 18.9779$ \\
\hline 338 & 1849.25 & 130 & 68700 & 31 & 1560018.92659 \\
\hline 339 & 1854.25 & 130 & 68700 & 31 & 1560018.87556 \\
\hline 340 & 1859.25 & 130 & 68700 & 31 & 1560018.82479 \\
\hline
\end{tabular}




\begin{tabular}{|c|c|c|c|c|c|}
\hline 341 & 1864.25 & 130 & 68700 & 31 & $15600 \quad 18.77431$ \\
\hline 342 & 1869.25 & 130 & 68700 & 31 & 1560018.72409 \\
\hline 343 & 1874.25 & 133 & 71700 & 31 & 1560018.67414 \\
\hline 344 & 1879.25 & 133 & 71700 & 31 & 1560018.62445 \\
\hline 345 & 1884.25 & 133 & 71700 & 31 & 1560018.57503 \\
\hline 346 & 1889.25 & 133 & 71700 & 31 & 1560018.52587 \\
\hline 347 & 1894.25 & 133 & 71700 & 31 & 1560018.47697 \\
\hline 348 & 1899.25 & 133 & 71700 & 31 & 1560018.42833 \\
\hline 349 & 1904.25 & 135 & 72100 & 31 & 1560018.37994 \\
\hline 350 & 1909.25 & 135 & 72100 & 31 & $15600 \quad 18.33181$ \\
\hline 351 & 1914.25 & 135 & 72100 & 31 & 1560018.28392 \\
\hline 352 & 1919.25 & 135 & 72100 & 31 & 1560018.23629 \\
\hline 353 & 1924.25 & 135 & 72100 & 31 & $15600 \quad 18.18891$ \\
\hline 354 & 1929.25 & 135 & 72100 & 31 & 1560018.14177 \\
\hline 355 & 1934.25 & 135 & 72100 & 31 & 1560018.09487 \\
\hline 356 & 1939.25 & 135 & 72100 & 31 & $15600 \quad 18.04821$ \\
\hline 357 & 1944.25 & 135 & 72100 & 31 & $15600 \quad 18.0018$ \\
\hline 358 & 1949.25 & 135 & 72100 & 31 & 1560017.95562 \\
\hline 359 & 1954.25 & 135 & 72100 & 31 & 1560017.90968 \\
\hline 360 & 1959.25 & 135 & 72100 & 31 & 1560017.86398 \\
\hline 361 & 1964.25 & 135 & 72100 & 31 & $15600 \quad 17.81851$ \\
\hline 362 & 1969.25 & 137 & 72500 & 31 & $15600 \quad 17.77326$ \\
\hline 363 & 1974.25 & 137 & 72500 & 31 & $15600 \quad 17.72825$ \\
\hline 364 & 1979.25 & 137 & 72500 & 31 & 15600.17 .68347 \\
\hline 365 & 1984.25 & 137 & 72500 & 31 & 1560017.63891 \\
\hline 366 & 1989.25 & 137 & 72500 & 31 & 1560017.59457 \\
\hline 367 & 1994.25 & 137 & 72500 & 31 & 1560017.55046 \\
\hline 368 & 1999.25 & 139 & 73500 & 33 & 1610017.50657 \\
\hline 369 & 2004.25 & 139 & 73500 & 33 & 1610017.46289 \\
\hline 370 & 2009.25 & 139 & 73500 & 33 & $16100 \quad 17.41944$ \\
\hline 371 & 2014.25 & 139 & 73500 & 33 & 1610017.37619 \\
\hline 372 & 2019.25 & 139 & 73500 & 33 & $\begin{array}{lll}16100 & 17.33317\end{array}$ \\
\hline 373 & 2024.25 & 139 & 73500 & 33 & 1610017.29035 \\
\hline 374 & 2029.25 & 141 & 73900 & 33 & $16100 \quad 17.24775$ \\
\hline 375 & 2034.25 & 141 & 73900 & 33 & 1610017.20536 \\
\hline 376 & 2039.25 & 141 & 73900 & 33 & 1610017.16317 \\
\hline 377 & 2044.25 & 144 & 76900 & 33 & 1610017.12119 \\
\hline 378 & 2049.25 & 144 & 76900 & 33 & $16100 \quad 17.07942$ \\
\hline 379 & 2054.25 & 144 & 76900 & 33 & 1610017.03785 \\
\hline 380 & 2059.25 & 144 & 76900 & 33 & 1610016.99648 \\
\hline 381 & 2064.25 & 144 & 76900 & 33 & 1610016.95531 \\
\hline 382 & 2069.25 & 144 & 76900 & 33 & 1610016.91434 \\
\hline 383 & 2074.25 & 144 & 76900 & 33 & 1610016.87357 \\
\hline 384 & 2079.25 & 144 & 76900 & 33 & 1610016.83299 \\
\hline 385 & 2084.25 & 144 & 76900 & 33 & 1610016.79261 \\
\hline 386 & 2089.25 & 144 & 76900 & 33 & 1610016.75242 \\
\hline
\end{tabular}




\begin{tabular}{|c|c|c|c|c|c|}
\hline 387 & 2094.25 & 146 & 77300 & 33 & 1610016.71243 \\
\hline 388 & 2099.25 & 146 & 77300 & 33 & 1610016.67262 \\
\hline 389 & 2104.25 & 146 & 77300 & 33 & 1610016.63301 \\
\hline 390 & 2109.25 & 146 & 77300 & 33 & 1610016.59358 \\
\hline 391 & 2114.25 & 146 & 77300 & 33 & 1610016.55433 \\
\hline 392 & 2119.25 & 146 & 77300 & 33 & 1610016.51528 \\
\hline 393 & 2124.25 & 146 & 77300 & 33 & $16100 \quad 16.4764$ \\
\hline 394 & 2129.25 & 146 & 77300 & 33 & 1610016.43771 \\
\hline 395 & 2134.25 & 146 & 77300 & 33 & $16100 \quad 16.3992$ \\
\hline 396 & 2139.25 & 146 & 77300 & 33 & 1610016.36087 \\
\hline 397 & 2144.25 & 146 & 77300 & 33 & $16100 \quad 16.32272$ \\
\hline 398 & 2149.25 & 146 & 77300 & 33 & 1610016.28475 \\
\hline 399 & 2154.25 & 146 & 77300 & 33 & $16100 \quad 16.24695$ \\
\hline 400 & 2159.25 & 148 & 77700 & 33 & $16100 \quad 16.20933$ \\
\hline 401 & 2164.25 & 148 & 77700 & 33 & 1610016.17188 \\
\hline 402 & 2169.25 & 148 & 77700 & 33 & 1610016.13461 \\
\hline 403 & 2174.25 & 148 & 77700 & 33 & 1610016.09751 \\
\hline 404 & 2179.25 & 150 & 78700 & 33 & 1610016.06057 \\
\hline 405 & 2184.25 & 150 & 78700 & 33 & 1610016.02381 \\
\hline 406 & 2189.25 & 150 & 78700 & 33 & 1610015.98721 \\
\hline 407 & 2194.25 & 150 & 78700 & 33 & 1610015.95078 \\
\hline 408 & 2199.25 & 150 & 78700 & 33 & 1610015.91452 \\
\hline 409 & 2204.25 & 150 & 78700 & 33 & $16100 \quad 15.87842$ \\
\hline 410 & 2209.25 & 150 & 78700 & 33 & 1610015.84248 \\
\hline 411 & 2214.25 & 153 & 81700 & 33 & 1610015.80671 \\
\hline 412 & 2219.25 & 155 & 82100 & 33 & 1610015.77109 \\
\hline 413 & 2224.25 & 155 & 82100 & 33 & 1610015.73564 \\
\hline 414 & 2229.25 & 155 & 82100 & 33 & 1610015.70035 \\
\hline 415 & 2234.25 & 155 & 82100 & 33 & 1610015.66521 \\
\hline 416 & 2239.25 & 155 & 82100 & 33 & 1610015.63023 \\
\hline 417 & 2244.25 & 155 & 82100 & 33 & 1610015.59541 \\
\hline 418 & 2249.25 & 157 & 83100 & 35 & $17400 \quad 15.56074$ \\
\hline 419 & 2254.25 & 157 & 83100 & 35 & 1740015.52623 \\
\hline 420 & 2259.25 & 157 & 83100 & 35 & 1740015.49187 \\
\hline 421 & 2264.25 & 157 & 83100 & 35 & 1740015.45766 \\
\hline 422 & 2269.25 & 157 & 83100 & 35 & $17400 \quad 15.4236$ \\
\hline 423 & 2274.25 & 157 & 83100 & 35 & 1740015.38969 \\
\hline 424 & 2279.25 & 157 & 83100 & 35 & 1740015.35593 \\
\hline 425 & 2284.25 & 159 & 83500 & 35 & $17400 \quad 15.32232$ \\
\hline 426 & 2289.25 & 159 & 83500 & 35 & $17400 \quad 15.28885$ \\
\hline 427 & 2294.25 & 159 & 83500 & 35 & $17400 \quad 15.25553$ \\
\hline 428 & 2299.25 & 159 & 83500 & 35 & 1740015.22235 \\
\hline 429 & 2304.25 & 159 & 83500 & 35 & 1740015.18932 \\
\hline 430 & 2309.25 & 159 & 83500 & 35 & 1740015.15644 \\
\hline 431 & 2314.25 & 159 & 83500 & 35 & 1740015.12369 \\
\hline 432 & 2319.25 & 159 & 83500 & 35 & 1740015.0910 \\
\hline
\end{tabular}




\begin{tabular}{|c|c|c|c|c|c|c|}
\hline 433 & 2324.25 & 159 & 83500 & 35 & 17400 & 15.05862 \\
\hline 434 & 2329.25 & 159 & 83500 & 35 & 17400 & 15.0263 \\
\hline 435 & 2334.25 & 159 & 83500 & 35 & 17400 & 14.99411 \\
\hline 436 & 2339.25 & 159 & 83500 & 35 & 17400 & 14.96206 \\
\hline 437 & 2344.25 & 159 & 83500 & 35 & 17400 & 14.93015 \\
\hline 438 & 2349.25 & 161 & 83900 & 35 & 17400 & 14.89837 \\
\hline 439 & 2354.25 & 161 & 83900 & 35 & 17400 & 14.86673 \\
\hline 440 & 2359.25 & 161 & 83900 & 35 & 17400 & 14.83522 \\
\hline 441 & 2364.25 & 161 & 83900 & 35 & 17400 & 14.80385 \\
\hline 442 & 2369.25 & 161 & 83900 & 35 & 17400 & 14.77261 \\
\hline 443 & 2374.25 & 161 & 83900 & 35 & 17400 & 14.7415 \\
\hline 444 & 2379.25 & 161 & 83900 & 35 & 17400 & 14.71052 \\
\hline 445 & 2384.25 & 164 & 86900 & 35 & 17400 & 14.67967 \\
\hline 446 & 2389.25 & 164 & 86900 & 35 & 17400 & 14.64895 \\
\hline 447 & 2394.25 & 164 & 86900 & 35 & 17400 & 14.61836 \\
\hline 448 & 2399.25 & 164 & 86900 & 37 & 17900 & 14.58789 \\
\hline 449 & 2404.25 & 164 & 86900 & 37 & 17900 & 14.55755 \\
\hline 450 & 2409.25 & 166 & 87300 & 37 & 17900 & 14.52734 \\
\hline 451 & 2414.25 & 166 & 87300 & 37 & 17900 & 14.49726 \\
\hline 452 & 2419.25 & 166 & 87300 & 37 & 17900 & 14.46729 \\
\hline 453 & 2424.25 & 166 & 87300 & 37 & 17900 & 14.43746 \\
\hline 454 & 2429.25 & 166 & 87300 & 37 & 17900 & 14.40774 \\
\hline 455 & 2434.25 & 166 & 87300 & 37 & 17900 & 14.37815 \\
\hline 456 & 2439.25 & 166 & 87300 & 37 & 17900 & 14.34867 \\
\hline 457 & 2444.25 & 166 & 87300 & 37 & 17900 & 14.31932 \\
\hline 458 & 2449.25 & 166 & 87300 & 37 & 17900 & 14.29009 \\
\hline 459 & 2454.25 & 166 & 87300 & 37 & 17900 & 14.26098 \\
\hline 460 & 2459.25 & 166 & 87300 & 37 & 17900 & 14.23198 \\
\hline 461 & 2464.25 & 166 & 87300 & 37 & 17900 & 14.2031 \\
\hline 462 & 2469.25 & 166 & 87300 & 37 & 17900 & 14.17434 \\
\hline 463 & 2474.25 & 168 & 87700 & 37 & 17900 & 14.1457 \\
\hline 464 & 2479.25 & 168 & 87700 & 37 & 17900 & 14.11717 \\
\hline 465 & 2484.25 & 168 & 87700 & 37 & 17900 & 14.08876 \\
\hline 466 & 2489.25 & 168 & 87700 & 37 & 17900 & 14.06046 \\
\hline 467 & 2494.25 & 168 & 87700 & 37 & 17900 & 14.03227 \\
\hline 468 & 2499.25 & 170 & 88700 & 37 & 17900 & 14.0042 \\
\hline 469 & 2504.25 & 170 & 88700 & 37 & 17900 & 13.97624 \\
\hline 470 & 2509.25 & 170 & 88700 & 37 & 17900 & 13.94839 \\
\hline 471 & 2514.25 & 170 & 88700 & 37 & 17900 & 13.92065 \\
\hline 472 & 2519.25 & 170 & 88700 & 37 & 17900 & 13.89302 \\
\hline 473 & 2524.25 & 170 & 88700 & 37 & 17900 & 13.8655 \\
\hline 474 & 2529.25 & 170 & 88700 & 37 & 17900 & 13.83809 \\
\hline 475 & 2534.25 & 170 & 88700 & 37 & 17900 & 13.81079 \\
\hline 476 & 2539.25 & 172 & 89100 & 37 & 17900 & 13.7836 \\
\hline 477 & 2544.25 & 172 & 89100 & 37 & 17900 & 13.75651 \\
\hline 478 & 2549.25 & 172 & 89100 & 37 & 17900 & 13.72953 \\
\hline
\end{tabular}




\begin{tabular}{|c|c|c|c|c|c|}
\hline 479 & 2554.25 & 175 & 92100 & 37 & 1790013.70265 \\
\hline 480 & 2559.25 & 175 & 92100 & 37 & 1790013.67588 \\
\hline 481 & 2564.25 & 175 & 92100 & 37 & 1790013.64921 \\
\hline 482 & 2569.25 & 175 & 92100 & 37 & 1790013.62265 \\
\hline 483 & 2574.25 & 175 & 92100 & 37 & 1790013.59619 \\
\hline 484 & 2579.25 & 175 & 92100 & 37 & 1790013.56984 \\
\hline 485 & 2584.25 & 175 & 92100 & 37 & 1790013.54358 \\
\hline 486 & 2589.25 & 175 & 92100 & 37 & 1790013.51743 \\
\hline 487 & 2594.25 & 178 & 95100 & 37 & $17900 \quad 13.49138$ \\
\hline 488 & 2599.25 & 180 & 95500 & 37 & 1790013.46542 \\
\hline 489 & 2604.25 & 180 & 95500 & 37 & $17900 \quad 13.43957$ \\
\hline 490 & 2609.25 & 180 & 95500 & 37 & $17900 \quad 13.41382$ \\
\hline 491 & 2614.25 & 182 & 96500 & 37 & 1790013.38816 \\
\hline 492 & 2619.25 & 182 & 96500 & 37 & $17900 \quad 13.3626$ \\
\hline 493 & 2624.25 & 182 & 96500 & 37 & 1790013.33714 \\
\hline 494 & 2629.25 & 182 & 96500 & 37 & 1790013.31178 \\
\hline 495 & 2634.25 & 182 & 96500 & 37 & $17900 \quad 13.28651$ \\
\hline 496 & 2639.25 & 182 & 96500 & 37 & 1790013.26134 \\
\hline 497 & 2644.25 & 182 & 96500 & 37 & $17900 \quad 13.23627$ \\
\hline 498 & 2649.25 & 182 & 96500 & 37 & 1790013.21129 \\
\hline 499 & 2654.25 & 182 & 96500 & 37 & $17900 \quad 13.1864$ \\
\hline 500 & 2659.25 & 182 & 96500 & 37 & 1790013.16161 \\
\hline 501 & 2664.25 & 184 & 96900 & 37 & $17900 \quad 13.13691$ \\
\hline 502 & 2669.25 & 184 & 96900 & 37 & $17900 \quad 13.1123$ \\
\hline 503 & 2674.25 & 184 & 96900 & 37 & $17900 \quad 13.08778$ \\
\hline 504 & 2679.25 & 184 & 96900 & 37 & 1790013.06336 \\
\hline 505 & 2684.25 & 184 & 96900 & 37 & 1790013.03902 \\
\hline 506 & 2689.25 & 184 & 96900 & 37 & $17900 \quad 13.01478$ \\
\hline 507 & 2694.25 & 184 & 96900 & 37 & 1790012.99063 \\
\hline 508 & 2699.25 & 184 & 96900 & 37 & $17900 \quad 12.96657$ \\
\hline 509 & 2704.25 & 184 & 96900 & 37 & 1790012.94259 \\
\hline 510 & 2709.25 & 184 & 96900 & 37 & $17900 \quad 12.9187$ \\
\hline 511 & 2714.25 & 184 & 96900 & 37 & 1790012.89491 \\
\hline 512 & 2719.25 & 184 & 96900 & 37 & $17900 \quad 12.8712$ \\
\hline 513 & 2724.25 & 187 & 99900 & 37 & $17900 \quad 12.84757$ \\
\hline 514 & 2729.25 & 189 & 100300 & 37 & $17900 \quad 12.82404$ \\
\hline 515 & 2734.25 & 189 & 100300 & 37 & 1790012.80058 \\
\hline 516 & 2739.25 & 189 & 100300 & 37 & $17900 \quad 12.77722$ \\
\hline 517 & 2744.25 & 189 & 100300 & 37 & 1790012.75394 \\
\hline 518 & 2749.25 & 191 & 101300 & 37 & $17900 \quad 12.73074$ \\
\hline 519 & 2754.25 & 191 & 101300 & 37 & 1790012.70763 \\
\hline 520 & 2759.25 & 191 & 101300 & 37 & 1790012.68461 \\
\hline 521 & 2764.25 & 191 & 101300 & 37 & 1790012.66166 \\
\hline 522 & 2769.25 & 191 & 101300 & 37 & $17900 \quad 12.6388$ \\
\hline 523 & 2774.25 & 191 & 101300 & 37 & 1790012.61602 \\
\hline 524 & 2779.25 & 191 & 101300 & 37 & $17900 \quad 12.59333$ \\
\hline
\end{tabular}




\begin{tabular}{|c|c|c|c|c|c|}
\hline 525 & 2784.25 & 191 & 101300 & 37 & $17900 \quad 12.57071$ \\
\hline 526 & 2789.25 & 193 & 101700 & 37 & $\begin{array}{lll}17900 & 12.54818\end{array}$ \\
\hline 527 & 2794.25 & 193 & 101700 & 37 & $17900 \quad 12.52572$ \\
\hline 528 & 2799.25 & 193 & 101700 & 39 & $18400 \quad 12.50335$ \\
\hline 529 & 2804.25 & 193 & 101700 & 39 & 1840012.48106 \\
\hline 530 & 2809.25 & 193 & 101700 & 39 & 1840012.45884 \\
\hline 531 & 2814.25 & 193 & 101700 & 39 & 1840012.43671 \\
\hline 532 & 2819.25 & 193 & 101700 & 39 & 1840012.41465 \\
\hline 533 & 2824.25 & 193 & 101700 & 39 & 1840012.39267 \\
\hline 534 & 2829.25 & 193 & 101700 & 39 & 1840012.37077 \\
\hline 535 & 2834.25 & 193 & 101700 & 39 & $18400 \quad 12.34895$ \\
\hline 536 & 2839.25 & 193 & 101700 & 39 & $18400 \quad 12.3272$ \\
\hline 537 & 2844.25 & 193 & 101700 & 39 & 1840012.30553 \\
\hline 538 & 2849.25 & 193 & 101700 & 39 & $18400 \quad 12.28393$ \\
\hline 539 & 2854.25 & 195 & 102100 & 39 & $18400 \quad 12.26242$ \\
\hline 540 & 2859.25 & 195 & 102100 & 39 & $18400 \quad 12.24097$ \\
\hline 541 & 2864.25 & 195 & 102100 & 39 & $18400 \quad 12.2196$ \\
\hline 542 & 2869.25 & 195 & 102100 & 39 & 1840012.19831 \\
\hline 543 & 2874.25 & 195 & 102100 & 39 & 1840012.17709 \\
\hline 544 & 2879.25 & 195 & 102100 & 39 & 1840012.15594 \\
\hline 545 & 2884.25 & 195 & 102100 & 39 & 1840012.13487 \\
\hline 546 & 2889.25 & 195 & 102100 & 39 & $18400 \quad 12.11387$ \\
\hline 547 & 2894.25 & 198 & 105100 & 39 & 1840012.09294 \\
\hline 548 & 2899.25 & 198 & 105100 & 39 & 1840012.07209 \\
\hline 549 & 2904.25 & 198 & 105100 & 39 & $18400 \quad 12.0513$ \\
\hline 550 & 2909.25 & 198 & 105100 & 39 & 1840012.03059 \\
\hline 551 & 2914.25 & 198 & 105100 & 39 & 1840012.00995 \\
\hline 552 & 2919.25 & 200 & 105500 & 39 & 1840011.98938 \\
\hline 553 & 2924.25 & 200 & 105500 & 39 & 1840011.96888 \\
\hline 554 & 2929.25 & 200 & 105500 & 39 & 1840011.94845 \\
\hline 555 & 2934.25 & 200 & 105500 & 39 & 1840011.92809 \\
\hline 556 & 2939.25 & 200 & 105500 & 39 & $18400 \quad 11.9078$ \\
\hline 557 & 2944.25 & 200 & 105500 & 39 & 1840011.88758 \\
\hline 558 & 2949.25 & 200 & 105500 & 39 & 1840011.86742 \\
\hline 559 & 2954.25 & 200 & 105500 & 39 & 1840011.84734 \\
\hline 560 & 2959.25 & 200 & 105500 & 39 & 1840011.82732 \\
\hline 561 & 2964.25 & 200 & 105500 & 39 & 1840011.80737 \\
\hline 562 & 2969.25 & 200 & 105500 & 39 & 1840011.78749 \\
\hline 563 & 2974.25 & 200 & 105500 & 39 & 1840011.76767 \\
\hline 564 & 2979.25 & 202 & 105900 & 39 & 1840011.74792 \\
\hline 565 & 2984.25 & 202 & 105900 & 39 & 1840011.72824 \\
\hline 566 & 2989.25 & 202 & 105900 & 39 & 1840011.70862 \\
\hline 567 & 2994.25 & 202 & 105900 & 39 & 1840011.68907 \\
\hline 568 & 2999.25 & 204 & 106900 & 39 & 1840011.66958 \\
\hline 569 & 3004.25 & 204 & 106900 & 39 & 1840011.65016 \\
\hline 570 & 3009.25 & 204 & 106900 & 39 & 1840011.63081 \\
\hline
\end{tabular}




\begin{tabular}{|c|c|c|c|c|c|}
\hline 571 & 3014.25 & 204 & 106900 & 39 & 1840011.61151 \\
\hline 572 & 3019.25 & 204 & 106900 & 39 & 1840011.59228 \\
\hline 573 & 3024.25 & 204 & 106900 & 39 & 1840011.57312 \\
\hline 574 & 3029.25 & 204 & 106900 & 39 & 1840011.55402 \\
\hline 575 & 3034.25 & 204 & 106900 & 39 & 1840011.53498 \\
\hline 576 & 3039.25 & 204 & 106900 & 39 & $18400 \quad 11.516$ \\
\hline 577 & 3044.25 & 206 & 107300 & 39 & 1840011.49708 \\
\hline 578 & 3049.25 & 208 & 108300 & 39 & 1840011.47823 \\
\hline 579 & 3054.25 & 208 & 108300 & 39 & 1840011.45944 \\
\hline 580 & 3059.25 & 208 & 108300 & 39 & 1840011.44071 \\
\hline 581 & 3064.25 & 211 & 111300 & 39 & 1840011.42204 \\
\hline 582 & 3069.25 & 211 & 111300 & 39 & 1840011.40344 \\
\hline 583 & 3074.25 & 211 & 111300 & 39 & 1840011.38489 \\
\hline 584 & 3079.25 & 211 & 111300 & 39 & $18400 \quad 11.3664$ \\
\hline 585 & 3084.25 & 211 & 111300 & 39 & 1840011.34798 \\
\hline 586 & 3089.25 & 211 & 111300 & 39 & 1840011.32961 \\
\hline 587 & 3094.25 & 211 & 111300 & 39 & $18400 \quad 11.3113$ \\
\hline 588 & 3099.25 & 211 & 111300 & 39 & 1840011.29305 \\
\hline 589 & 3104.25 & 211 & 111300 & 39 & 1840011.27487 \\
\hline 590 & 3109.25 & 213 & 111700 & 39 & 1840011.25673 \\
\hline 591 & 3114.25 & 213 & 111700 & 39 & 1840011.23866 \\
\hline 592 & 3119.25 & 213 & 111700 & 39 & 1840011.22065 \\
\hline 593 & 3124.25 & 213 & 111700 & 39 & 1840011.20269 \\
\hline 594 & 3129.25 & 213 & 111700 & 39 & $18400 \quad 11.18479$ \\
\hline 595 & 3134.25 & 213 & 111700 & 39 & 1840011.16695 \\
\hline 596 & 3139.25 & 213 & 111700 & 39 & 1840011.14916 \\
\hline 597 & 3144.25 & 213 & 111700 & 39 & $18400 \quad 11.13143$ \\
\hline 598 & 3149.25 & 213 & 111700 & 39 & 1840011.11376 \\
\hline 599 & 3154.25 & 213 & 111700 & 39 & 1840011.09614 \\
\hline 600 & 3159.25 & 213 & 111700 & 39 & 1840011.07858 \\
\hline 601 & 3164.25 & 213 & 111700 & 39 & 1840011.06107 \\
\hline 602 & 3169.25 & 215 & 112100 & 39 & 1840011.04362 \\
\hline 603 & 3174.25 & 215 & 112100 & 39 & 1840011.02623 \\
\hline 604 & 3179.25 & 215 & 112100 & 39 & 1840011.00889 \\
\hline 605 & 3184.25 & 215 & 112100 & 39 & $18400 \quad 10.9916$ \\
\hline 606 & 3189.25 & 215 & 112100 & 39 & $18400 \quad 10.97437$ \\
\hline 607 & 3194.25 & 215 & 112100 & 39 & 1840010.95719 \\
\hline 608 & 3199.25 & 215 & 112100 & 45 & 2070010.94006 \\
\hline 609 & 3204.25 & 215 & 112100 & 45 & 2070010.92299 \\
\hline 610 & 3209.25 & 215 & 112100 & 45 & $20700 \quad 10.90598$ \\
\hline 611 & 3214.25 & 215 & 112100 & 45 & $20700 \quad 10.88901$ \\
\hline 612 & 3219.25 & 215 & 112100 & 45 & $20700 \quad 10.8721$ \\
\hline 613 & 3224.25 & 215 & 112100 & 45 & $20700 \quad 10.85524$ \\
\hline 614 & 3229.25 & 215 & 112100 & 45 & 2070010.83843 \\
\hline 615 & 3234.25 & 220 & 115500 & 45 & 2070010.82167 \\
\hline 616 & 3239.25 & 220 & 115500 & 45 & 2070010.80497 \\
\hline
\end{tabular}




\begin{tabular}{|c|c|c|c|c|c|c|}
\hline 617 & 3244.25 & 220 & 115500 & 45 & 20700 & 10.78832 \\
\hline 618 & 3249.25 & 222 & 116500 & 45 & 20700 & 10.77172 \\
\hline 619 & 3254.25 & 222 & 116500 & 45 & 20700 & 10.75517 \\
\hline 620 & 3259.25 & 222 & 116500 & 45 & 20700 & 10.73867 \\
\hline 621 & 3264.25 & 222 & 116500 & 45 & 20700 & 10.72222 \\
\hline 622 & 3269.25 & 222 & 116500 & 45 & 20700 & 10.70582 \\
\hline 623 & 3274.25 & 222 & 116500 & 45 & 20700 & 10.68947 \\
\hline 624 & 3279.25 & 222 & 116500 & 45 & 20700 & 10.67317 \\
\hline 625 & 3284.25 & 222 & 116500 & 45 & 20700 & 10.65692 \\
\hline 626 & 3289.25 & 222 & 116500 & 45 & 20700 & 10.64072 \\
\hline 627 & 3294.25 & 222 & 116500 & 45 & 20700 & 10.62457 \\
\hline 628 & 3299.25 & 224 & 116900 & 45 & 20700 & 10.60847 \\
\hline 629 & 3304.25 & 224 & 116900 & 45 & 20700 & 10.59242 \\
\hline 630 & 3309.25 & 224 & 116900 & 45 & 20700 & 10.57642 \\
\hline 631 & 3314.25 & 224 & 116900 & 45 & 20700 & 10.56046 \\
\hline 632 & 3319.25 & 224 & 116900 & 45 & 20700 & 10.54455 \\
\hline 633 & 3324.25 & 224 & 116900 & 45 & 20700 & 10.52869 \\
\hline 634 & 3329.25 & 224 & 116900 & 45 & 20700 & 10.51288 \\
\hline 635 & 3334.25 & 224 & 116900 & 45 & 20700 & 10.49711 \\
\hline 636 & 3339.25 & 224 & 116900 & 45 & 20700 & 10.4814 \\
\hline 637 & 3344.25 & 224 & 116900 & 45 & 20700 & 10.46572 \\
\hline 638 & 3349.25 & 224 & 116900 & 45 & 20700 & 10.4501 \\
\hline 639 & 3354.25 & 224 & 116900 & 45 & 20700 & 10.43452 \\
\hline 640 & 3359.25 & 226 & 117300 & 45 & 20700 & 10.41899 \\
\hline 641 & 3364.25 & 226 & 117300 & 45 & 20700 & 10.40351 \\
\hline 642 & 3369.25 & 226 & 117300 & 45 & 20700 & 10.38807 \\
\hline 643 & 3374.25 & 226 & 117300 & 45 & 20700 & 10.37267 \\
\hline 644 & 3379.25 & 226 & 117300 & 45 & 20700 & 10.35733 \\
\hline 645 & 3384.25 & 226 & 117300 & 45 & 20700 & 10.34203 \\
\hline 646 & 3389.25 & 226 & 117300 & 45 & 20700 & 10.32677 \\
\hline 647 & 3394.25 & 226 & 117300 & 45 & 20700 & 10.31156 \\
\hline 648 & 3399.25 & 226 & 117300 & 45 & 20700 & 10.29639 \\
\hline 649 & 3404.25 & 229 & 120300 & 45 & 20700 & 10.28127 \\
\hline 650 & 3409.25 & 229 & 120300 & 45 & 20700 & 10.26619 \\
\hline 651 & 3414.25 & 229 & 120300 & 45 & 20700 & 10.25115 \\
\hline 652 & 3419.25 & 229 & 120300 & 45 & 20700 & 10.23616 \\
\hline 653 & 3424.25 & 231 & 120700 & 45 & 20700 & 10.22122 \\
\hline 654 & 3429.25 & 231 & 120700 & 45 & 20700 & 10.20631 \\
\hline 655 & 3434.25 & 231 & 120700 & 45 & 20700 & 10.19145 \\
\hline 656 & 3439.25 & 231 & 120700 & 45 & 20700 & 10.17664 \\
\hline 657 & 3444.25 & 231 & 120700 & 45 & 20700 & 10.16186 \\
\hline 658 & 3449.25 & 231 & 120700 & 45 & 20700 & 10.14713 \\
\hline 659 & 3454.25 & 231 & 120700 & 45 & 20700 & 10.13245 \\
\hline 660 & 3459.25 & 231 & 120700 & 45 & 20700 & 10.1178 \\
\hline 661 & 3464.25 & 231 & 120700 & 45 & 20700 & 10.1032 \\
\hline 662 & 3469.25 & 231 & 120700 & 45 & 20700 & 10.08864 \\
\hline
\end{tabular}




\begin{tabular}{|c|c|c|c|c|c|}
\hline 663 & 3474.25 & 231 & 120700 & 45 & $20700 \quad 10.07412$ \\
\hline 664 & 3479.25 & 231 & 120700 & 45 & 2070010.05964 \\
\hline 665 & 3484.25 & 233 & 121700 & 45 & $20700 \quad 10.0452$ \\
\hline 666 & 3489.25 & 235 & 122100 & 45 & 2070010.03081 \\
\hline 667 & 3494.25 & 235 & 122100 & 45 & 2070010.01646 \\
\hline 668 & 3499.25 & 239 & 123800 & 45 & $20700 \quad 10.00214$ \\
\hline 669 & 3504.25 & 239 & 123800 & 45 & 207009.987872 \\
\hline 670 & 3509.25 & 239 & 123800 & 45 & 207009.973641 \\
\hline 671 & 3514.25 & 239 & 123800 & 45 & 207009.959451 \\
\hline 672 & 3519.25 & 239 & 123800 & 45 & 207009.945301 \\
\hline 673 & 3524.25 & 239 & 123800 & 45 & 207009.931191 \\
\hline 674 & 3529.25 & 239 & 123800 & 45 & 207009.917121 \\
\hline 675 & 3534.25 & 239 & 123800 & 45 & 207009.903091 \\
\hline 676 & 3539.25 & 239 & 123800 & 45 & 207009.889101 \\
\hline 677 & 3544.25 & 239 & 123800 & 45 & $20700 \quad 9.87515$ \\
\hline 678 & 3549.25 & 241 & 124200 & 45 & 207009.861239 \\
\hline 679 & 3554.25 & 241 & 124200 & 45 & 207009.847365 \\
\hline 680 & 3559.25 & 241 & 124200 & 45 & 207009.833532 \\
\hline 681 & 3564.25 & 241 & 124200 & 45 & 207009.819737 \\
\hline 682 & 3569.25 & 241 & 124200 & 45 & 207009.805982 \\
\hline 683 & 3574.25 & 241 & 124200 & 45 & 207009.792264 \\
\hline 684 & 3579.25 & 244 & 127200 & 45 & 207009.778585 \\
\hline 685 & 3584.25 & 244 & 127200 & 45 & $20700 \quad 9.764944$ \\
\hline 686 & 3589.25 & 244 & 127200 & 45 & 207009.751341 \\
\hline 687 & 3594.25 & 244 & 127200 & 45 & 207009.737776 \\
\hline 688 & 3599.25 & 244 & 127200 & 47 & 212009.724248 \\
\hline 689 & 3604.25 & 244 & 127200 & 47 & 212009.710758 \\
\hline 690 & 3609.25 & 244 & 127200 & 47 & 212009.697306 \\
\hline 691 & 3614.25 & 246 & 127600 & 47 & $21200 \quad 9.68389$ \\
\hline 692 & 3619.25 & 246 & 127600 & 47 & 212009.670512 \\
\hline 693 & 3624.25 & 246 & 127600 & 47 & $21200 \quad 9.65717$ \\
\hline 694 & 3629.25 & 246 & 127600 & 47 & 212009.643866 \\
\hline 695 & 3634.25 & 246 & 127600 & 47 & 212009.630598 \\
\hline 696 & 3639.25 & 246 & 127600 & 47 & 212009.617366 \\
\hline 697 & 3644.25 & 246 & 127600 & 47 & 212009.604171 \\
\hline 698 & 3649.25 & 246 & 127600 & 47 & 212009.591012 \\
\hline 699 & 3654.25 & 246 & 127600 & 47 & 212009.577889 \\
\hline 700 & 3659.25 & 246 & 127600 & 47 & 212009.564801 \\
\hline 701 & 3664.25 & 246 & 127600 & 47 & $21200 \quad 9.55175$ \\
\hline 702 & 3669.25 & 246 & 127600 & 47 & 212009.538734 \\
\hline 703 & 3674.25 & 246 & 127600 & 47 & 212009.525754 \\
\hline 704 & 3679.25 & 248 & 128000 & 47 & 212009.512808 \\
\hline 705 & 3684.25 & 248 & 128000 & 47 & 212009.499898 \\
\hline 706 & 3689.25 & 248 & 128000 & 47 & 212009.487023 \\
\hline 707 & 3694.25 & 248 & 128000 & 47 & 212009.474183 \\
\hline 708 & 3699.25 & 248 & 128000 & 47 & 212009.461377 \\
\hline
\end{tabular}




\begin{tabular}{|c|c|c|c|c|c|c|}
\hline 709 & 3704.25 & 248 & 128000 & 47 & 21200 & 9.448607 \\
\hline 710 & 3709.25 & 248 & 128000 & 47 & 21200 & 9.43587 \\
\hline 711 & 3714.25 & 248 & 128000 & 47 & 21200 & 9.423167 \\
\hline 712 & 3719.25 & 248 & 128000 & 47 & 21200 & 9.4105 \\
\hline 713 & 3724.25 & 248 & 128000 & 47 & 21200 & 9.397865 \\
\hline 714 & 3729.25 & 248 & 128000 & 47 & 21200 & 9.385265 \\
\hline 715 & 3734.25 & 248 & 128000 & 47 & 21200 & 9.372699 \\
\hline 716 & 3739.25 & 250 & 128400 & 47 & 21200 & 9.360166 \\
\hline 717 & 3744.25 & 250 & 128400 & 47 & 21200 & 9.347667 \\
\hline 718 & 3749.25 & 255 & 132400 & 47 & 21200 & 9.3352 \\
\hline 719 & 3754.25 & 255 & 132400 & 47 & 21200 & 9.322767 \\
\hline 720 & 3759.25 & 255 & 132400 & 47 & 21200 & 9.310368 \\
\hline 721 & 3764.25 & 255 & 132400 & 47 & 21200 & 9.298001 \\
\hline 722 & 3769.25 & 255 & 132400 & 47 & 21200 & 9.285667 \\
\hline 723 & 3774.25 & 255 & 132400 & 47 & 21200 & 9.273366 \\
\hline 724 & 3779.25 & 255 & 132400 & 47 & 21200 & 9.261097 \\
\hline 725 & 3784.25 & 255 & 132400 & 47 & 21200 & 9.24886 \\
\hline 726 & 3789.25 & 255 & 132400 & 47 & 21200 & 9.236656 \\
\hline 727 & 3794.25 & 255 & 132400 & 47 & 21200 & 9.224484 \\
\hline 728 & 3799.25 & 255 & 132400 & 47 & 21200 & 9.212344 \\
\hline 729 & 3804.25 & 257 & 132800 & 47 & 21200 & 9.200236 \\
\hline 730 & 3809.25 & 257 & 132800 & 47 & 21200 & 9.18816 \\
\hline 731 & 3814.25 & 257 & 132800 & 47 & 21200 & 9.176116 \\
\hline 732 & 3819.25 & 257 & 132800 & 47 & 21200 & 9.164103 \\
\hline 733 & 3824.25 & 257 & 132800 & 47 & 21200 & 9.152122 \\
\hline 734 & 3829.25 & 257 & 132800 & 47 & 21200 & 9.140171 \\
\hline 735 & 3834.25 & 257 & 132800 & 47 & 21200 & 9.128252 \\
\hline 736 & 3839.25 & 257 & 132800 & 47 & 21200 & 9.116364 \\
\hline 737 & 3844.25 & 260 & 136800 & 50 & 25200 & 9.104507 \\
\hline 738 & 3849.25 & 260 & 136800 & 50 & 25200 & 9.09268 \\
\hline 739 & 3854.25 & 260 & 136800 & 50 & 25200 & 9.080885 \\
\hline 740 & 3859.25 & 260 & 136800 & 50 & 25200 & 9.06912 \\
\hline 741 & 3864.25 & 260 & 136800 & 50 & 25200 & 9.057385 \\
\hline 742 & 3869.25 & 262 & 137200 & 50 & 25200 & 9.045681 \\
\hline 743 & 3874.25 & 262 & 137200 & 50 & 25200 & 9.034006 \\
\hline 744 & 3879.25 & 262 & 137200 & 50 & 25200 & 9.022363 \\
\hline 745 & 3884.25 & 262 & 137200 & 50 & 25200 & 9.010749 \\
\hline 746 & 3889.25 & 265 & 140200 & 50 & 25200 & 8.999165 \\
\hline 747 & 3894.25 & 265 & 140200 & 50 & 25200 & 8.98761 \\
\hline 748 & 3899.25 & 265 & 140200 & 50 & 25200 & 8.976085 \\
\hline 749 & 3904.25 & 265 & 140200 & 50 & 25200 & 8.96459 \\
\hline 750 & 3909.25 & 265 & 140200 & 50 & 25200 & 8.953124 \\
\hline 751 & 3914.25 & 265 & 140200 & 50 & 25200 & 8.941688 \\
\hline 752 & 3919.25 & 270 & 144200 & 50 & 25200 & 8.93028 \\
\hline 753 & 3924.25 & 270 & 144200 & 50 & 25200 & 8.918901 \\
\hline 754 & 3929.25 & 272 & 144600 & 50 & 25200 & 8.907553 \\
\hline
\end{tabular}




$\begin{array}{rrrrrrr}755 & 3934.25 & 272 & 144600 & 50 & 25200 & 8.896232 \\ 756 & 3939.25 & 272 & 144600 & 50 & 25200 & 8.88494 \\ 0.035 & & & & & & \\ 757 & 191.625 & 21 & 13900 & 19 & 11800 & 182.6484 \\ 758 & 196.625 & 21 & 13900 & 19 & 11800 & 178.0038 \\ 759 & 201.625 & 24 & 16900 & 19 & 11800 & 173.5896\end{array}$




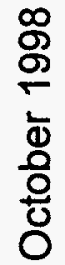

$\frac{2}{4}$

음 Z

틀

웅

U

롤

응

55

무

능

0 인

zz

브으

응당

얼

क $\frac{\alpha}{m}$

u这

$0 \times$

똥온

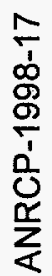

